\title{
Natural Expectations, Macroeconomic Dynamics, and Asset Pricing
}

\section{Citation}

Fuster, Andreas, Benjamin Hebert, and David Laibson. 2011. Natural expectations, macroeconomic dynamics, and asset pricing. NBER Macroeconomics Annual 26(1): 1-48.

\section{Published Version}

doi:10.1086/663989

\section{Permanent link}

http://nrs.harvard.edu/urn-3:HUL.InstRepos:10140029

\section{Terms of Use}

This article was downloaded from Harvard University's DASH repository, and is made available under the terms and conditions applicable to Open Access Policy Articles, as set forth at http:// nrs.harvard.edu/urn-3:HUL.InstRepos:dash.current.terms-of-use\#OAP

\section{Share Your Story}

The Harvard community has made this article openly available.

Please share how this access benefits you. Submit a story.

Accessibility 
NBER WORKING PAPER SERIES

NATURAL EXPECTATIONS, MACROECONOMIC DYNAMICS, AND ASSET
PRICING

Andreas Fuster

Benjamin Hebert

David Laibson

Working Paper 17301

http://www.nber.org/papers/w17301

NATIONAL BUREAU OF ECONOMIC RESEARCH

1050 Massachusetts Avenue

Cambridge, MA 02138

August 2011

We are grateful to Daron Acemoglu, Nicholas Barberis, John Beshears, Markus Brunnermeier, John Campbell, James Choi, Larry Christiano, John Driscoll, Emmanuel Farhi, Kenneth French, Xavier Gabaix, Stefano Giglio, Lars Peter Hansen, Blake LeBaron, Greg Mankiw, Joshua Schwartzstein, Andrei Shleifer, Jeremy Stein, Jim Stock, Michael Woodford, our discussants Marty Eichenbaum and George Evans, and seminar/conference participants for helpful comments and discussions. WeWLH indebted to Brendan Price and Fernando Yu for excellent research assistance. David Laibson acknowledges support from the NIA (P01AG005842). The views expressed herein are those of the authors and do[QRW necessarily reflect the views of the National Bureau of Economic Research.

(C) 2011 by Andreas Fuster, Benjamin Hebert, and David Laibson. All rights reserved. Short sections of text, not to exceed two paragraphs, may be quoted without explicit permission provided that full credit, including $\odot$ notice, is given to the source. 
Natural Expectations, Macroeconomic Dynamics, and Asset Pricing

Andreas Fuster, Benjamin Hebert, and David Laibson

NBER Working Paper No. 17301

August 2011

JEL No. D84,E32,G12

\begin{abstract}
$\underline{\text { ABSTRACT }}$
How does an economy behave if (1) fundamentals are truly hump-shaped, exhibiting momentum in the short run and partial mean reversion in the long run, and (2) agents do not know that fundamentals are hump-shaped and base their beliefs on parsimonious models that they fit to the available data? A class of parsimonious models leads to qualitatively similar biases and generates empirically observed patterns in asset prices and macroeconomic dynamics. First, parsimonious models will robustly pick up the short-term momentum in fundamentals but will generally fail to fully capture the long-run mean reversion. Beliefs will therefore be characterized by endogenous extrapolation bias and pro-cyclical excess optimism. Second, asset prices will be highly volatile and exhibit partial mean reversion-i.e., overreaction. Excess returns will be negatively predicted by lagged excess returns, P/E ratios, and consumption growth. Third, real economic activity will have amplified cycles. For example, consumption growth will be negatively auto-correlated in the medium run. Fourth, the equity premium will be large. Agents will perceive that equities are very risky when in fact long-run equity returns will co-vary only weakly with long-run consumption growth. If agents had rational expectations, the equity premium would be close to zero. Fifth, sophisticated agents-i.e., those who are assumed to know the true model—will hold far more equity than investors who use parsimonious models. Moreover, sophisticated agents will follow a counter-cyclical asset allocation policy. These predicted effects are qualitatively confirmed in U.S. data.
\end{abstract}

\author{
Andreas Fuster \\ Department of Economics \\ Harvard University \\ Littauer Center \\ 1805 Cambridge St. \\ Cambridge, MA 02138 \\ afuster@fas.harvard.edu \\ Benjamin Hebert \\ Department of Economics \\ Harvard University \\ Littauer Center \\ 1805 Cambridge St. \\ Cambridge, MA 02138 \\ benmhebert@gmail.com
}

\author{
David Laibson \\ Department of Economics \\ Littauer M-12 \\ Harvard University \\ Cambridge, MA 02138 \\ and NBER \\ dlaibson@harvard.edu
}




\section{Introduction}

Most macroeconomic models assume that people know the true model of the economy - i.e., rational expectations. In this paper, we follow a different tradition and assume that agents use simple prediction models that are estimated using historical data. ${ }^{1}$ In other words, agents adopt a parsimonious model that fits the available data. In general, this parsimonious model will not nest the true model (though the true model may nest the parsimonious model). Following Fuster, Laibson, and Mendel (2010), we call the resulting beliefs natural expectations. ${ }^{2}$ We assume that agents use simplified models because economists and non-economists-statisticians, professional forecasters, and firms - regularly make such simplifications.

People use simple models for a wide range of good reasons. Simple models are easier to understand, easier to explain, and easier to employ. Simplicity also reduces the risks of overfitting, which is the reasoning that underlies many formal model selection criteria. Whatever the mix of reasons-pragmatic, psychological/suboptimal, and statistical-economic agents usually do use simple models to understand economic dynamics.

We study a class of parsimonious models that generates empirically observed patterns in asset prices and macroeconomic dynamics. To illustrate this claim, we study an economy in which fundamentals are hump-shaped, exhibiting momentum in the short run and partial mean reversion in the long run. Hump-shaped dynamics are controversial in the sense that economists continue to debate whether such cyclical dynamics are present in aggregate fluctuations. ${ }^{3}$ This debate is consistent with our claims, since we only want to argue that hump-shaped dynamics are plausible. Hump-shaped dynamics match the point estimates from ARIMA models of various economic time series, though standard errors are large enough that the data do not rule out alternative dynamics. $^{4}$

We will ask, "How would an economy behave if (1) fundamentals were truly hump-shaped, and (2) agents adopted a parsimonious model of the fundamental process, fit to the available

\footnotetext{
${ }^{1}$ For example, Barberis, Shleifer, and Vishny (1998), Hong, Stein, and Yu (2007), and Branch and Evans (2010) study settings in which agents estimate a misspecified model and optimize against that model.

${ }^{2}$ The current paper is more parsimonious since it zeros out a weighting parameter that is used in Fuster, Laibson, and Mendel (2010).

${ }^{3}$ See Campbell and Mankiw (1987), Cochrane (1988), Morley, Nelson, and Zivot (2003), and Perron and Wada (2009) for a range of opinions.

${ }^{4}$ Fuster, Laibson, and Mendel (2010) provide some empirical evidence for hump-shaped dynamics in different economic time series.
} 
data?"5 We embed these two assumptions-hump-shaped fundamentals and natural expectationsin a consumption/asset-pricing model. ${ }^{6}$ We use a habit model to generate slow adjustment in consumption; however, as we combine habit formation with CARA preferences (Alessie and Lusardi, 1997), these habits do not produce counter-cyclical variation in risk premia. ${ }^{7}$

The following five sets of results emerge from our analysis. Some of these results are comparative: how does equilibrium behavior in an economy with natural expectations compare to equilibrium behavior that would have arisen if agents knew the true model-i.e., if agents had rational expectations?

First, simple models robustly pick up the short-term momentum in fundamentals but often fail to capture the full extent of long-run mean reversion. Under natural expectations, beliefs will often be characterized by endogenous extrapolation bias in levels. Forecasts about fundamentals will be too persistent, such that beliefs will be too optimistic in good times and too pessimistic in bad times, relative to the rational expectations benchmark.

Second, under natural expectations, asset prices will be highly volatile (LeRoy and Porter, 1981; Shiller, 1981) and exhibit partial mean reversion-i.e., overreaction. Excess returns will be negatively predicted by lagged excess returns (Fama and French, 1988a; Poterba and Summers, 1988), price/earnings ratios (Campbell and Shiller, 1988a, 2005), and consumption growth. Excess returns will be positively predicted by lagged 'cay', a measure of transitory deviations of consumption from wealth (Lettau and Ludvigson, 2001). ${ }^{8}$

Third, real economic activity will have amplified cycles. For example, consumption growth will be positively auto-correlated in the short run and negatively auto-correlated in the medium run. Consumption growth will be weakly negatively predicted by lagged excess returns and P/E ratios.

Fourth, the equity premium will be large. Agents will perceive that equities are very risky

\footnotetext{
${ }^{5}$ The agents in our model behave as if they thought their model represented the truth; i.e., their decisions do not take into account the possibility of misspecification or display a concern for "robustness" (cf. Hansen, 2007; Hansen and Sargent, 2007, 2010). We hope to explore the differences between models with natural expectations and models of robustness in future work.

${ }^{6}$ To keep the analysis in our paper maximally tractable, we abstract away from learning and give agents a fixed simple model that is estimated from data available in 2011. Adding learning would complicate the analysis, but not change the qualitative results.

${ }^{7}$ In contrast, Campbell and Cochrane (1999) use a habit model that generates counter-cyclical risk premia, thereby explaining numerous asset pricing regularities.

${ }^{8}$ When 'cay' is low, wealth is transitorily high. In our economy, this predicts low future excess returns.
} 
when in fact long-run equity returns will co-vary only weakly with long-run consumption growth. The covariance of consumption growth and asset returns will be close to zero over short-run horizons (because of slow adjustment in consumption), it will be higher over medium-run horizons (as consumption catches up with asset prices), and it will fall again over long-run horizons (as asset prices and consumption both mean revert). If agents had rational expectations, the equity premium in our economy would be close to zero.

Fifth, sophisticated agents-i.e., those who are assumed to know the true model—will hold far more equity than investors with natural expectations. Moreover, sophisticated agents will be "value" investors, following a counter-cyclical investment policy.

These five sets of predicted effects are qualitatively confirmed in U.S. data. An economy in which agents estimate simple models-e.g., an $\mathrm{AR}(10)$ in earnings growth, when the datagenerating process is assumed to be $\mathrm{AR}(40)$ - generates simulated behavior that quantitatively matches the point estimates observed in U.S. data. However, the moments that we study have large standard errors because of the limited span of available data. It is therefore not possible to reject classical models in which excess returns are unpredictable and consumption is consistent with rational expectations.

The body of the paper is divided into six sections; appendices are used for derivations. Section 2 discusses the econometric and psychological motivations for natural expectations, as well as the related literature. Section 3 solves and calibrates a consumption-based asset pricing model, which generalizes the model in Fuster, Laibson, and Mendel (2010). Section 4 reports model simulations and compares these simulations to the empirical evidence from U.S. We focus on eight moments that summarize the key properties of the model. We show that a parsimonious version of the model matches these moments. Section 5 discusses the behavior of sophisticated agents. Section 6 concludes and identifies directions for future work.

\section{The Appeal of Simple Models}

The premise of our approach to understanding macroeconomic and financial dynamics is that economic agents tend to make forecasts based on statistical or mental models that are reasonable given the data available to them, but "too simple" to fully capture the long-term dynamics of 
many economic time series.

In this section, we motivate our assumptions both on statistical and psychological grounds, though we believe that the psychological motivations are more important. ${ }^{9}$ We will also discuss how simple models lead agents to overestimate the persistence of shocks when the true process is hump-shaped. Finally, we summarize evidence from different settings that are related to our approach.

\subsection{Statistical Perspective}

Choosing the right model to forecast an economic time series is by no means a trivial task, and there is no single generally accepted way of doing so. When choosing how many parameters to include, a modeler faces a trade-off between improving the fit of the model in-sample and the risk of overfitting the available data, which may result in poor out-of-sample forecasts. A number of formal statistical criteria have been proposed to formalize the trade-off between fit and parsimony. The best-known and most popular ones are the Akaike Information Criterion (AIC) and the Schwarz or Bayesian Information Criterion (BIC). ${ }^{10}$ These criteria are both asymptotically optimal, but in different ways. If the set of candidate models is not presumed to contain the true model (perhaps because the true model is of infinite dimension), the AIC is efficient in that it will select the candidate model with minimum mean squared error distribution with probability 1 as the sample size grows to infinity. If instead the true model is among the set of candidate models, the BIC will select it with probability 1 asymptotically (the BIC is consistent), while the AIC will tend to result in an overparametrized model (Hannan, 1980).

When the likelihood function is Gaussian, the two criteria can be written as follows:

$$
\begin{aligned}
& \mathrm{AIC}=\ln \left(\hat{\sigma}^{2}\right)+\frac{2 k}{T} \\
& \mathrm{BIC}=\ln \left(\hat{\sigma}^{2}\right)+\frac{\ln (T) \cdot k}{T}
\end{aligned}
$$

where $\hat{\sigma}^{2}$ is the error variance estimated by maximum likelihood, $k$ the number of parameters

\footnotetext{
${ }^{9}$ Brav and Heaton (2002) emphasize that when explaining "financial anomalies," behavioral theories and rational theories with structural uncertainty are often very similar mathematically and also in terms of predictions. We remain relatively agnostic as to whether the reliance on models that fail to capture long-term dynamics is "behavioral" or "rational" in our setting, and focus on the implications.

${ }^{10}$ McQuarrie and Tsai (1998) provide an overview of these and other selection criteria.
} 
(including the constant), and $T$ the number of observations. One is supposed to pick the model with the smallest value of the preferred criterion. Both criteria trade off fit and parsimony: as $k$ increases, $\hat{\sigma}^{2}$ decreases, but the second ("penalty") term increases. Generally, the BIC imposes a larger penalty for increasing the number of parameters, and thus will tend to select models with fewer parameters than the AIC. A relatively recent literature based on extensive simulation studies has argued that a version of the AIC corrected for small sample sizes, the AICc, tends to perform well (in various senses) and, relative to the AIC, reduces the likelihood of overfitting. ${ }^{11}$

It is not clear which criterion should be preferred. If one believes that the true model is among the candidate models, and as $T \rightarrow \infty$, there seems to be a clear case for the BIC. Yet, in practice, these conditions are rarely met, and it appears that which criterion is preferred is to some extent a matter of taste. ${ }^{12}$ While strictly speaking, each criteria picks one model, a reasonable pragmatic strategy would be to choose a model that is close to the best model according to different criteria, or perhaps to make forecasts based on averaging the predictions of different models.

For the purpose of our work, what matters is whether a modeler who is presented with a time series of length equal to the typical macroeconomic time series (e.g., 250 quarters) and who relies on (one of) these information criteria will generally pick a model that correctly captures the properties of the data-generating process. In particular, we are interested in time series that feature hump-shaped dynamics, in the sense that they are characterized by momentum (positive autocorrelation in growth rates) in the short run but (partially) revert back to the mean in the long run. To our knowledge, this is not a question that has been formally analyzed in the existing literature, so we now present some suggestive evidence from Monte Carlo simulations to shed light on this question.

Assume that the true data-generating process is an $\operatorname{ARIMA}(0,1,16)$, and for simplicity assume that the modeler considers univariate models of the $\operatorname{ARIMA}(p, 1,0)$ and $\operatorname{ARIMA}(0,1, q)$ classes. The process we study has a hump-shaped impulse response function with a long-term persistence

\footnotetext{
${ }^{11}$ The AICc can be written as $\ln \left(\hat{\sigma}^{2}\right)+\frac{T+k-1}{T-k-1}$.

${ }^{12}$ McQuarrie and Tsai (1998) indicate that "AIC is probably the most commonly used model selection criterion for time series data" (p. 2). On the other hand, Neath and Cavanaugh (1997) note that BIC "is often preferred over AIC by practitioners who find appeal in either its Bayesian justification or its tendency to choose more parsimonious models than AIC" (p. 559) For an interesting discussion on this topic from an online forum for "statisticians, data analysts, data miners and data visualization experts," see http://stats.stackexchange.com/questions/577/ is-there-any-reason-to-prefer-the-aic-or-bic-over-the-other.
} 
of $0.5 .{ }^{13}$ We draw 100 samples of length 255 (which is the number of observations we will use in the estimation of the aggregate earnings process) and estimate $\operatorname{AR}(p, 1,0)$ models for $p=1, \ldots, 25$ and $\operatorname{MA}(0,1, q)$ models for $q=4,8,12,16,20,24 .^{14}$

In our 100 simulations, the $\mathrm{AIC}$ selects an $\mathrm{AR}(1), \mathrm{AR}(2)$, or $\mathrm{AR}(3)$ in 60 cases; the $\mathrm{BIC}$ does so in all cases. The average estimated long-term persistence of a shock implied by the AICc-selected model equals 1.02 , and is below 0.8 only in $25 \%$ of cases. For the BIC-selected model, it is never below 1 . Thus, in the vast majority of cases, a modeler who considers this set of candidate models and selects based on AICc or BIC would grossly overestimate the persistence of shocks to the process. Note that while it appears difficult to capture the mean-reversion in a sample of this length, it is not impossible: for instance, the implied persistence from an estimated MA(16) (the true model order) averages 0.56 and is below 0.8 in $88 \%$ of cases. ${ }^{15}$ Yet the improvement that the MA(16) brings in terms of fit relative to, for example, an $\mathrm{AR}(2)$ rarely justifies the large increase in the number of parameters (an $\operatorname{MA}(q)$ with $q \geq 16$ is selected nine times by the AICc).

In large part, the difficulty that these models have in detecting mean reversion seems due to the relatively short sample length. If we repeat the same exercise but with 1255 observations instead of 255, the AICc selects the MA(16) in 75\% of cases, and the mean long-term persistence of a shock estimated by the preferred model decreases to 0.53 , i.e. very close to the actual persistence of the data-generating process.

We have conducted similar simulations with other data-generating processes. With somewhat less complicated hump-shape patterns, the AICc often does well in terms of selecting a model that gets the long-term persistence approximately right, while the BIC tends to select low-order models (with 5 coefficients or less) in the vast majority of cases. Overall, our simulations suggest

\footnotetext{
${ }^{13}$ The MA coefficients are: $+0.15,+0.1,-0.02,-0.05,-0.05,-0.05,-0.05,-0.05,-0.06,-0.06,-0.06,-0.06,-0.06,-0.06,-0.06$, -0.06. The long-term persistence of an $\operatorname{ARIMA}(p, 1, q)$ process is given by (1+sum of MA coefficients)/(1-sum of AR coefficients).

${ }^{14}$ Estimating MA models with a large number of terms is computationally demanding, which is why we only estimate a subset of the possible models one might consider. In our simulations the maximum likelihood estimation of MA models sometimes failed to converge, or the maximum likelihood estimator of the root (i.e., the negative of the sum of the lagged MA coefficients) "piled up" at a value of 1, which means that the predicted long-term persistence of a shock equaled 0 . This pileup occurs because the sample likelihood function is locally flat at an MA root of 1 , so that it is a local maximum of the likelihood function and may be the global maximum in finite samples, even if the true MA root is less than unity (see Campbell and Mankiw, 1987 or Stock, 1994 for discussions). It seems likely that a modeler would be highly skeptical of such a result. Also, our modeler does not consider $\operatorname{ARIMA}(p, 1, q)$ models with both $p$ and $q>0$. While such models are often estimated in practice, based on our results and some additional smaller-scale simulations, it seems very unlikely that estimating more models would change our qualitative conclusions.

${ }^{15}$ For these calculations, we drop simulations in which the sum of MA coefficients equalled exactly -1 (cf. previous footnote).
} 
that even a sophisticated modeler who goes through the trouble of estimating and comparing a wide range of candidate models may well end up with a model that vastly overestimates the longterm persistence of shocks. ${ }^{16}$ To be clear, we are not claiming that it is impossible to find a model that gets the long-term dynamics right. One could use more sophisticated methods than ARIMAs (e.g., multivariate models), add more ex-ante imposed structure to the model, or attempt to form unbiased estimates of long-term persistence at the expense of one-period-ahead forecast accuracy. We argue that these practices are neither straightforward nor widespread.

So far, we have discussed the model selection problem under the assumption that the stochastic process of interest is stable over time and that economic agents should use all the historical data that is available to them in estimating a model, and weigh all observations equally. However, it is possible that the properties of the data-generating process change over time, and so it may well be optimal for an agent to down-weight or discard old data. ${ }^{17}$ While we will not attempt a normative analysis of optimal model selection under the possibility that parameters of the data-generating process (such as the mean growth rate of earnings) change over time, it seems intuitive that in such a world, agents would tend to use shorter effective samples to estimate their models, and this would increase the likelihood of picking a low-order model.

\subsection{Psychological Perspective}

Psychological factors also lead agents to adopt simple models. In fact, we believe that psychological considerations are far more important in driving preferences for simplicity than the statistical considerations reviewed above. Even if non-parsimonious, complicated models were statistically optimal, real people would probably not adopt such models.

Constraints on memory and cognition make it difficult for agents to work with complicated models, leading decision-makers to adopt simplifications and heuristics (e.g., Tversky and Kahneman, 1974; Gigerenzer and Goldstein, 1996; Gabaix et al., 2006; Gabaix, 2011). Simple models are relatively easy to comprehend, use, revise, and explain. Complicated "black-box" models are viewed with a degree of suspicion; programmers themselves are boundedly rational so high-

\footnotetext{
${ }^{16}$ The spectral formulas derived by ? for understanding the consequences of misspecification in regression provide a useful way of thinking about our agents' problem. This point is developed in a note by Lawrence Christiano, available at http://faculty.wcas.northwestern.edu/ lchrist/finc520/note_on_fhl.pdf .

${ }^{17} \mathrm{~A}$ large literature in statistics and economics studies methods to detect regime switching or structural breaks.
} 
dimensional computational models often have subtle programming errors and other unintended or poorly understood features that make such models unreliable. Even when people do use complicated models, the conclusions are rarely taken at face value and usually tempered with "common sense" about how the world works.

The 'psychological' motives for simplicity can also be interpreted through a rational lens. If complicated models tend to induce confusion or mistakes, then simple models may be the lesser of two evils. Complicated models also engender high costs for agents with costly cognition ${ }^{18}$, providing another rational explanation for choosing simple models.

There are also specific psychological biases that reinforce our approach. The heuristic of representativeness (Kahneman and Tversky, 1973; Tversky and Kahneman, 1974) leads people to believe that small samples are representative of the world at large. Representativeness has two implications for our analysis. First, recent observations are viewed as representative of the future. Thus representativeness leads agents to underestimate the degree of mean reversion (Kahneman and Tversky, 1973).

Second, representativeness leads agents to mistakenly believe that the properties of population samples will be reliably observed in small samples (e.g., Rabin, 2002; Rabin and Vayanos, 2010). This is sometimes referred to as the (psychological) 'law of small numbers.' Agents mistakenly believe that the ergodic properties of a time series can be inferred by studying a short sub-sample (e.g., 20 years of data). In addition, a willingness to rely on short sub-samples implicitly reinforces the tendency to rely on models without long lag effects.

The availability heuristic (Tversky and Kahneman, 1973) also reinforces our modeling approach. Availability leads people to overweight information that is easily accessible and salient. Hence, availability bias also implies that people will excessively overweight recent data and underweight data from the distant past.

Some observers have argued that related biases play an important role in driving aggregate dynamics. For instance, Reinhart and Rogoff (2009) document how investors time and time again fall prey to the belief that "this time is different" and that this belief causes recurrent financial crises. Relatedly, Shiller (2005) points out the lure of "new era" stories and how they are associated with episodes of bubbles in asset markets. Barberis (2010) notes that over-extrapolation of past

\footnotetext{
${ }^{18}$ For example, see Sims (1998, 2003); Gabaix et al. (2006); Woodford (2009).
} 
price changes may have been an important psychological driving force during the run-up to the Great Recession. We now turn to a large body of related economic research.

\subsection{Additional Related Literature}

There is a small but growing body of evidence on deviations from rational expectations. For instance, lab experiments in which subjects forecast financial or other time series find that extrapolative expectations or "trend following" provide a good description of observed beliefs (De Bondt, 1993; Hey, 1994) and may be a driving force behind the bubbles that are observed in asset-market experiments (Haruvy, Lahav, and Noussair, 2007, Hommes et al., 2008). On the other hand, Dwyer et al. (1993) finds that subjects' forecasts of a random walk (in which growth has no persistence) do not deviate systematically from the rational expectations forecast. This is consistent with our model, where extrapolation is not "baked in" but depends on the predictions generated by estimating simple models on the available data.

In field data, a number of papers have argued that asset allocation choices are affected by extrapolation of recent price appreciation (Chevalier and Ellison, 1997; Sirri and Tufano, 1998; Benartzi, 2001; Choi et al., 2004, 2009; Benartzi and Thaler, 2007; Chalmers and Reuter, 2009; Previtero, 2010; Malmendier and Nagel, 2011). One could argue that biases in expectations have little or no effect on asset prices because investors with biased beliefs are relatively poor, while wealthier market participants may be more rational. However, Vissing-Jorgensen (2003) documents that at the peak of the market in 2000-01, even wealthy investors expected continuously high stock returns. Bacchetta, Mertens, and van Wincoop (2009) conduct a similar exercise and find that, in several asset markets, (institutional or wealthy individual) investors' expectational errors about future returns are predicted by the same variables that predict excess returns.

One might alternatively think that the expectations held (and made public) by financial analysts, which may have a strong influence on asset prices, are not biased. However, De Bondt and Thaler (1990) argue that security analysts overreact and make earnings-per-share forecasts that are too extreme. ${ }^{19}$ Most of the studies on analyst forecasts look at relatively short-run forecasts, while our model mostly has implications for long-run forecasts. Bulkley and Harris (1997) study

\footnotetext{
${ }^{19}$ Other studies instead find that analysts underreact. Easterwood and Nutt (1999) argue that analysts overreact to positive information but underreact to negative information. Lim (2001) argues that considering analysts' objective function can "rationalize" their biases.
} 
five-years earnings forecasts for about 500 U.S. companies and report results which are consistent with our model: i) analysts appear to extrapolate past growth in earnings when forecasting future growth, even though there is pronounced negative serial correlation in earnings growth over five-year periods, and ii) analysts' forecasts and excess returns over the subsequent five years are significantly negatively correlated. ${ }^{20}$ Chan, Karceski, and Lakonishok (2003) provide further evidence that there is little predictability of long-term earnings growth rates, but that investors and analysts behave as if recent growth rates were positive predictors of future growth.

A significant literature in behavioral finance has accumulated evidence on cross-sectional stock return patterns that are consistent with such biases in expectations having strong effects on prices: De Bondt and Thaler $(1985,1989)$ and Lakonishok et al. (1994) are among the best-known examples of such work. ${ }^{21}$ Baker and Wurgler (2007) document that empirical measures of investor sentiment predict cross-sectional return patterns and also aggregate returns.

Apart from stock markets, other asset markets may also be influenced by biased beliefs. For instance, Greenwood and Hanson (2010) document patterns in bond risk premia that can be explained by investors extrapolating recent returns or default rates. Periods of high returns on corporate bonds are followed by a decline in issuer quality and low or negative excess returns on corporate debt in a highly predictable manner. Also, biased (extrapolative) beliefs have been advanced as a key explanation behind the recent housing bubble as well as earlier boom-bust cycles (Abraham and Hendershott, 1996; Muellbauer and Murphy, 1997; Case and Shiller, 2003; Gerardi et al., 2008; Goetzmann, Peng, and Yen, 2009; Piazzesi and Schneider, 2009; Glaeser, Gottlieb, and Gyourko, 2010). Finally, Ball (2000) and Tortorice (2011) show that misspecified models can explain empirically observed inflation persistence and unemployment expectations, respectively.

A variety of "behavioral" models have been proposed to explain stock return patterns, including DeLong et al. (1990), Barberis et al. (1998), Daniel, Hirshleifer, and Subrahmanya (1998) and Hong and Stein (1999). Closely related are models in which investors continuously update

\footnotetext{
${ }^{20}$ La Porta (1996) finds a negative relation between analysts' long-term growth estimates and future one-year riskadjusted returns. Bergman and Roychowdhury (2008) document a positive relation between the consumer confidence index (a proxy for market sentiment) and the error in long-horizon earnings estimates of financial analysts, consistent with the idea that when times are good, market participants may insufficiently adjust for subsequent mean reversion.

${ }^{21}$ More recently, Chen, Moise, and Zhao (2009) argue that myopic extrapolation can also explain momentum, if investors completely miss the hump-shaped dynamics of firm-specific earnings shocks and simply treat current earnings shocks as permanent. They point out that apart from cognitive biases, the practice of pricing securities using earnings multiples can also contribute to this phenomenon.
} 
their belief about future dividend growth or other parameters. This learning, which can be interpreted as behavioral or fully rational (similar to our model), generates predictability in returns as well as excess volatility. Among the best-known papers in this literature are Barsky and DeLong (1993) and Timmermann (1993). While our approach is closely related to these earlier papers, most previous authors consider simpler setups (often partial equiliibrium valuation models without consumption) to illustrate the consequences of biased beliefs or learning, and do not study the interrelation between asset prices and other macroeconomic variables. An exception to this, and similar in spirit to our exercise, is a paper by Cecchetti, Lam, and Mark (2000). They show that distorted beliefs about the growth rate of the aggregate endowment can generate high, volatile, and predictable excess returns on equity, as in the data. ${ }^{22}$ Similarly, Lansing (2006), Choi (2006) and Adam and Marcet (2010) study economies where some or all investors hold extrapolative beliefs, or learn about the return process, in otherwise standard Lucas tree economies with CRRA utility, and show that this can generate realistic asset price dynamics.

More generally, a large literature in macroeconomics and finance, surveyed by Sargent (1993), Evans and Honkapohja (2001, 2011), and Pastor and Veronesi (2009), assumes that agents are rational (in the sense that they form their beliefs in the statistically optimal way) but need to learn the relevant parameters of the reduced form equations governing the economy over time. ${ }^{23}$ While the early papers in this literature mostly focused on whether expectations would ultimately converge to the rational expectations equilibrium, more recent work has considered what happens if agents have misspecified models or down-weight older data, and finds that this can generate additional volatility and persistence of shocks in asset prices and/or the economy (e.g., Branch and Evans, 2007, 2010; Hong, Stein, and Yu, 2007; Huang, Liu, and Zha, 2009; Eusepi and Preston, 2011). In these models, "misspecification" means that agents omit a relevant variable from their forecasting equation, while in our model, it means that they may not include enough lags of the variable they are trying to forecast. ${ }^{24}$

An alternative modeling approach assumes that agents evaluate different forecasting mod-

\footnotetext{
${ }^{22}$ The type of distortion that Cecchetti et al. focus on has agents underestimate the persistence of good and bad shocks to endowment growth (see Gourinchas and Tornell, 2004 for a related model in an international finance context), while our "natural expectations" agents will overestimate the persistence of shocks to earnings growth.

${ }^{23}$ For an early example, see Friedman (1979).

${ }^{24}$ The downweighting of old data is often captured by assuming "constant gain" rather than "decreasing gain" (least squares) learning. Some papers, such as Marcet and Nicolini (2003), endogenize agents' choice between constant and decreasing gain based on recent prediction errors.
} 
els' past performance in order to (probabilistically) select among these models. This approach is frequently used in the agent-based literature (for example, LeBaron, Arthur, and Palmer, 1999; Tesfatsion and Judd, 2006; De Grauwe, 2010; LeBaron, 2010). An advantage of such models, which are usually analyzed computationally, is that they generate heterogeneity in beliefs across agents, something that is not present in our model. Such heterogeneity allows for instance the study of wealth dynamics and trading volume. ${ }^{25}$

Finally, there is a very large literature that studies asset pricing and macroeconomic dynamics under the assumption of perfect rationality and knowledge of the economy's structure. ${ }^{26}$ While basic rational models are rather unsuccessful in generating realistic asset pricing patterns, more elaborate versions can generate a high equity premium, volatile asset prices, and predictable excess returns. Perhaps the most successful and influential consumption-based models over the past fifteen years are a) Campbell and Cochrane's (1999) habit model, which matches many of the main observed empirical asset pricing phenomena through counter-cyclical and (on average) high effective risk aversion, and b) the "long-run risks" model by Bansal and Yaron (2004), who engage in an exercise somewhat similar to ours: they assume that the world is characterized by a driving process for which evidence is statistically rather weak (namely, a consumption growth process with a small predictable component as well as time-varying volatility) and study the implications for asset pricing (in their case, using Epstein-Zin-Weil preferences with an elasticity of intertemporal substitution above 1).

\section{Consumption Model with Asset Pricing}

We now illustrate our approach by characterizing equilibrium in an economy in which agents hold natural expectations. This is an extension of the model analyzed in $?^{27}$

We study an open endowment economy with two assets. The first asset is foreign debt, $b_{t}$, which is borrowed at a fixed international (gross) interest rate $R .^{28}$ We introduce foreign debt

\footnotetext{
${ }^{25}$ See Hong and Stein (2007) for a discussion of models of disagreement in a finance context.

${ }^{26}$ See Campbell (2003) and Cochrane (2007) for surveys of the rational asset pricing literature.

${ }^{27}$ The current model differs in five ways. We now assume CARA preferences instead of limiting risk neutral preferences (in the quadratic utility class). We now assume a consumption habit. We now assume a general $\operatorname{ARIMA}(p, 1,0)$ process for the dividend tree instead of an $\mathrm{AR}(2)$. We also allow our natural expectations agents to have general $\operatorname{ARIMA}\left(p^{\prime}, 1,0\right)$ beliefs, instead of $\operatorname{ARIMA}(1,1,0)$ beliefs. Finally, we introduce a zero measure of agents with rational expectations.

${ }^{28}$ In a closed version of our economy, the risk-free rate would also be nearly constant, since, in our preferred calibra-
} 
since we do not want a mechanistic linkage between production and consumption. The second asset is a Lucas-style domestic equity tree, which generates a dividend, $d_{t}$, that is stationary in first differences. In other words, $\Delta d_{t}$ follows an $\operatorname{AR}(n)$ process,

$$
\Delta d_{t}=\rho_{1} \Delta d_{t-1}+\ldots+\rho_{n} \Delta d_{t-n}+\sigma \varepsilon_{t}
$$

where $\varepsilon_{t}$ is an iid Gaussian shock with unit variance. ${ }^{29}$ We assume that the equity tree must be held by domestic agents. ${ }^{30}$ We will distinguish between the "true" data-generating process for dividends, and the perceived data-generating process for dividends. When the true data-generating process matches the perceived data-generating process, agents hold rational expectations. Our focus, however, is on cases in which the perceived data-generating process has fewer lags than the true data-generating processes. As discussed in Section 2, this can occur for various reasons, and we will refer to this as "natural expectations."

Our timing conventions and wealth definitions follow. Period $t$ is divided into the following sequential subperiods. We describe the model using a "quarterly" frequency, since this is the calibration that we will use, but the model can be calibrated for any period of observation.

1. On the first day of the quarter - "January 1 " - households start with debt, $b_{t}$, and $\theta_{t-1}$ units of claims to the risky asset.

2. Time passes and production occurs from January 1 to March 31. Households make no additional choices until the end of the quarter: March 31.

3. At the end of the quarter - March 31 - the dividend of the equity tree is realized and paid to households: $d_{t}$ per unit of claim. So each household receives $\theta_{t-1} d_{t}$ units of output.

4. The tree is priced (ex-dividend): $p_{t}$ per unit of claim (where output units are the numeraire). So households can sell the tree for $\theta_{t-1} p_{t}$ units of output.

tions, agents (mistakenly) perceive the endowment to be approximately a random walk with drift.

${ }^{29}$ Without loss of generality, we assume that the process has no deterministic drift. Adding deterministic drift would not change any of our results on comovement.

${ }^{30}$ If the equity tree were held by foreign investors, this would drastically dilute the associated risk. Domestic ownership can be motivated by home bias. 
5. Wealth, $w_{t}$, is measured at the end of the quarter,

$$
w_{t}=-R b_{t}+\theta_{t-1} d_{t}+\theta_{t-1} p_{t}
$$

Wealth is measured after production has occurred in the period but before consumption is chosen.

6. Consumption is chosen: $c_{t}$.

7. Asset allocation takes place: agent buys $\theta_{t}$ units of equity at price $p_{t}$.

8. End-of-quarter debt, after these transactions, is

$$
b_{t+1}=c_{t}+\theta_{t} p_{t}-w_{t} .
$$

9. Households start the next quarter (beginning on April 1, which is period $t+1$ ), with this level of debt.

Period $t+1$ continues and the cycle of subperiods restarts.

\subsection{Preferences and the Bellman Equation}

We have two desiderata for preferences. We want preferences that generate a closed form solution. We also want preferences_or technology_that will generate slow aggregate adjustment in consumption without assuming procyclical risk tolerance. For evidence on the slow adjustment of consumption when responding to wealth shocks, see Dynan and Maki (2001), Gabaix and Laibson (2002), Parker (2001), and Carroll, Sommer, and Slacalek (2011).

Motivated by these goals, we use exponential preferences (e.g., Caballero, 1990) with habits, as introduced by Alessie and Lusardi (1997):

$$
u\left(c_{t}, c_{t-1}\right)=-\frac{1}{\alpha} \exp \left(-\alpha\left[c_{t}-\gamma c_{t-1}\right]\right)
$$

The parameter $\gamma \in[0,1]$ reflects the strength of the habit. As we show below, in this formulation habits only serve to slow down consumption adjustments. If we did not include habits, our model 
would imply counterfactually rapid adjustment in consumption. Our habits are not operating as in Campbell and Cochrane (1999), where the habit is constructed in a way that generates countercyclical relative risk aversion.

Utility flows are weighted with discount factor $\delta$, so that lifetime utility is given by:

$$
\sum_{s=0}^{\infty} \delta^{s} u\left(c_{t+s}, c_{t+s-1}\right)
$$

Lifetime utility is maximized with respect to the dynamic budgets constraints summarized above. Here is the decentralized Bellman Equation, which includes the state variables that we have already introduced as well as the vector of historical dividends, $\vec{d}_{t}$ :

$$
\begin{aligned}
V\left(c_{t-1}, w_{t}, p_{t}, \vec{d}_{t}\right)=\sup _{\theta_{t}, c_{t}} u\left(c_{t}, c_{t-1}\right)+ & E_{t}\left[\delta V \left(c_{t},\left(w_{t}-c_{t}-\theta_{t} p_{t}\right) R+\right.\right. \\
& \left.\left.+\theta_{t}\left(d_{t+1}+p_{t+1}\right), p_{t+1}, \vec{d}_{t+1}\right)\right],
\end{aligned}
$$

since

$$
w_{t+1}=\left(w_{t}-c_{t}-\theta_{t} p_{t}\right) R+\theta_{t}\left(d_{t+1}+p_{t+1}\right) .
$$

For now, we will not pin down the conditional expectation operator, $E_{t}$. It depends only on the perceived data-generating process for dividends. We will study the predictions of the model under rational expectations and a large set of specifications for natural expectations.

The social planner's Bellman Equation (which eliminates the asset allocation issue and eliminates price-based wealth measurement) is the following:

$$
V\left(c_{t-1}, b_{t}, \vec{d}_{t}\right)=\sup _{c_{t}} u\left(c_{t}, c_{t-1}\right)+E_{t}\left[\delta V\left(c_{t},\left(c_{t}+R b_{t}-d_{t}\right), \vec{d}_{t+1}\right)\right]
$$

since

$$
b_{t+1}=c_{t}+R b_{t}-d_{t}
$$

\subsection{Value Functions, Policy Functions, and Asset Pricing}

We first study the representative household's problem, since we here assume that the economy is populated by homogeneous households. In Section 5, we introduce a zero measure of rational 
expectations agents and study their policy functions.

For the representative agent's problem, we can ignore the asset allocation decision as well as asset pricing. Appendix A shows that:

$$
c_{t}=\frac{\gamma}{R} c_{t-1}+\left(1-\frac{\gamma}{R}\right) x_{t}-\psi
$$

where

$$
\begin{gathered}
x_{t}=\frac{R-1}{R}\left[-R b_{t}+\sum_{s=0}^{\infty} \frac{E_{t} d_{t+s}}{R^{s}}\right] \\
\psi=\frac{1}{R-1}\left[\frac{1}{\alpha} \ln (R \delta)+\frac{\alpha}{2} \operatorname{Var}_{t}\left(\Delta c_{t+1}\right)\right] .
\end{gathered}
$$

This implies that consumption is a weighted average of lagged consumption and the (risk-neutral) annuity value of perceived future dividends, $x_{t}$, down-shifted by an additive constant $\psi$ (a precautionary savings effect).

For the planner, the value function takes a simple form:

$$
V\left(c_{t-1}, b_{t}, \vec{d}_{t}\right)=-\frac{R}{\alpha(R-1)} \exp \left(-\alpha\left[c_{t}-\gamma c_{t-1}\right]\right)
$$

where $c_{t}$ is given by equation (1).

To calculate the equilibrium price of the Lucas tree, we consider the asset-allocation problem (as opposed to the planner's problem). We then solve for the asset price that leads the representative agent to hold one unit of the equity tree. These calculations are provided in Appendix B, where we show that the equilibrium price of the Lucas tree is given by:

$$
p_{t}=\sum_{s=1}^{\infty} \frac{E_{t} d_{t+s}}{R^{s}}-\frac{R \alpha \times \operatorname{Var}_{t}\left(\Delta c_{t+1}\right)}{\left(1-\frac{\gamma}{R}\right)(R-1)^{2}} .
$$

Appendix $B$ also provides a closed form expression as a function of the dividend history. Note that this is not bounded below, since earnings are not bounded below in this arithmetic (exponential utility) model.

Using the asset pricing relationship it is possible to re-express the consumption function in terms of total wealth, $w_{t}=-R b_{t}+d_{t}+p_{t}$. Here we are studying a representative agent economy 
so that $\theta_{t}=1$ for all $t$.

$$
\begin{aligned}
c_{t} & =\frac{\gamma}{R} c_{t-1}+\left(1-\frac{\gamma}{R}\right) x_{t}-\psi \\
& =\frac{\gamma}{R} c_{t-1}+\left(1-\frac{\gamma}{R}\right)\left(\frac{R-1}{R}\left[-R b_{t}+d_{t}+p_{t}+\frac{R \alpha \times \operatorname{Var}_{t}\left(\Delta c_{t+1}\right)}{\left(1-\frac{\gamma}{R}\right)(R-1)^{2}}\right]\right)-\psi \\
& =\frac{\gamma}{R} c_{t-1}+\left(1-\frac{\gamma}{R}\right)\left(\frac{R-1}{R}\right) w_{t}+\Lambda
\end{aligned}
$$

where

$$
\Lambda=\frac{\alpha}{2} \frac{\operatorname{Var}_{t}\left(\Delta c_{t+1}\right)}{R-1}-\frac{1}{R-1} \frac{1}{\alpha} \ln (R \delta)
$$

We can rewrite the value function in the following simplified form (redefining the earlier value function notation):

$$
V\left(c_{t-1}, w_{t}\right)=-\frac{R}{\alpha(R-1)} \exp \left(-\alpha\left[c_{t}-\gamma c_{t-1}\right]\right)
$$

Relative risk aversion is given by:

$$
\begin{aligned}
C R R A & =-\frac{w V_{w w}}{V_{w}} \\
& =w \alpha \frac{\partial c_{t}}{\partial w_{t}} \\
& =w \alpha\left(1-\frac{\gamma}{R}\right)\left(\frac{R-1}{R}\right) \\
& \simeq c \alpha\left(1-\frac{\gamma}{R}\right) .
\end{aligned}
$$

\subsection{Calibration}

To match historical data, we assume that the quarterly risk free (world) interest rate is $R=1.0025$, implying that the annualized (net) rate is 0.01 . We set the product of the discount factor and the gross interest rate to unity: $\delta R=1$. The (quarterly) habit parameter is set to $\gamma=0.9$, implying a half-life of adjustment of about 6 quarters. Finally, we set the curvature of the utility function so 
that relative risk aversion (at initialization) is approximately four: ${ }^{31}$

$$
\alpha=\frac{4}{d_{0}\left(1-\frac{\gamma}{R}\right)} .
$$

The curvature of the utility function only affects three of the moments that we study: the equity premium, the standard deviation of equity returns, and the standard deviation of consumption growth. Hence, this parameter is not important for most of what follows.

The stochastic driving process is exogenous capital income, which is calibrated using real capital income from the NIPA accounts. ${ }^{32}$ We use capital income from the NIPA accounts because it is seasonally adjusted (unlike corporate earnings) and is not artificially smoothed (like corporate dividends ${ }^{33}$ ). Figure 1 plots the natural log of real capital income at a quarterly frequency from 1947:1 to $2010: 3$.

Using this data, Figure 2 plots the impulse response functions resulting from estimating a range of $\operatorname{ARIMA}(p, 1,0)$ models, with $p=1,10,20,30,40$. We will henceforth refer to these as $\operatorname{AR}(p)$ models, omitting the full notation $\operatorname{ARIMA}(p, 1,0)$. Figure 2 reveals that the order of the model is critical in determining inferences about persistence. Low-order models $(p=1$ and 10) generate persistence estimates that are greater than or equal to 1 . As the order of the model increases, estimated persistence falls dramatically. For an AR(40) model, estimated persistence after 40 quarters is about $1 / 3$.

For $\operatorname{AR}(p)$ models with $p \leq 20$, there is a substantial gap between the persistence implied by the estimated model and the persistence implied by what we are assuming to be the true model, the $\mathrm{AR}(40)$. Hence, parsimonious $\operatorname{AR}(p)$ models yield a form of extrapolation bias in levels (not growth rates). In other words, "low-order" $\mathrm{AR}(p)$ models imply that shocks are far more persistent than they are actually likely to be; low-order models imply excess optimism in good times and excess pessimism in bad times.

\footnotetext{
${ }^{31}$ At initialization, with $b_{0}=0$, relative risk aversion in our CARA economy is

$$
\left(\frac{R-1}{R}\right) w \alpha\left(1-\frac{\gamma}{R}\right) \simeq c_{0} \alpha\left(1-\frac{\gamma}{R}\right) \simeq d_{0} \alpha\left(1-\frac{\gamma}{R}\right)
$$

${ }^{32}$ Specifically, we study the natural log of real net operating surplus of private enterprises as reported in the U.S. National Income and Product Accounts (Bureau of Economic Analysis, 1947:1 to 2010:3). The net operating surplus of private enterprises is reported in NIPA Table 1.10, line 12. This definition is net of capital depreciation. To adjust for inflation, we use the GDP deflator.

${ }^{33}$ Dividends also have the problem that they miss cash flow that is returned to shareholders through buy-backs.
} 
The associated coefficient estimates from the five $\operatorname{AR}(p)$ models in Figure 2 are reported in Table 1. There are few significant coefficients after the 10th lag. ${ }^{34}$

In what follows, we will always assume that the true data-generating process is the $\mathrm{AR}(40)$ estimated in the final column of Table 1 and plotted as an impulse response function in Figure 2. We are not loyal to this particular specification. It is merely a convenient way of capturing humpshaped dynamics: short-run momentum and long-run partial mean reversion. We will assume that this is the true data-generating process because this case is interesting, and not because we believe that there is strong evidence for this specification. We only wish to argue that this humpshaped process - the point estimate from the AR(40) case-is plausible.

The only remaining task is to specify is the beliefs of the agents in the economy. We don't have strong views about this either. We will therefore study the beliefs generated by every $\operatorname{AR}(p)$ model with $p=1,2, \ldots, 40$. In other words, we will assume that the true model is the $\operatorname{AR}(40)$ estimate in the last column of Table 1, but that agents believe some $\operatorname{AR}(p)$ model which may not be the AR(40) model. We will study the properties of all of these belief assumptions: $p=1, \ldots, 40$. When we assume $p=40$, we are implicitly assuming that the agents know the true model; $p=40$ is the rational expectations benchmark. When $p<40$, we are assuming that agents use a simpler model than the true model.

The agents in our model act as if the model on which their beliefs are based is the true model, even though it is actually misspecified. This dogmatic belief in the wrong model is a limiting case of overconfidence (e.g. Lichtenstein et al., 1982). An alternative approach, which would be more realistic and less tractable, would be to assume that agents take the possibility of misspecification into account when making decisions (for such an approach, see the literature on robustness; e.g., Hansen, 2007; Hansen and Sargent, 2007, 2010).

\section{Simulation and Empirical Evaluation}

To characterize the qualitative predictions of our model, we begin by reporting two impulse response functions—one for asset returns and one for consumption— that summarize the key mech-

\footnotetext{
${ }^{34}$ It is well-known that estimating AR coefficients in small samples yields biased coefficients (e.g., Shaman and Stine, 1988). Monte Carlo simulations indicate that with our sample size, this does not significantly affect estimated persistence.
} 
anisms in the model. We then describe eight empirical moments that enable us to quantitatively evaluate the model's predictions. These empirical moments characterize the joint evolution of asset prices and consumption. The moments are chosen to test the anomalous predictions that the model makes-e.g., cyclical fluctuations in asset returns and consumption growth. We find that these anomalous predictions match the empirical evidence well. Specifically, when agents hold beliefs generated by an $\operatorname{AR}(p)$ process with $p \leq 20$, and unlike in the rational expectations benchmark, the model provides a good quantitative fit to the empirical moments.

\subsection{Impulse Response Functions}

We begin by reporting the impulse response function for cumulative excess returns. In our economy with exponential (CARA) utility, the excess return is more naturally expressed as an "excess gain," $g_{t}$, which is defined as:

$$
g_{t}=p_{t}+d_{t}-R p_{t-1}
$$

Note that:

$$
\begin{aligned}
\frac{g_{t}}{p_{t-1}} & =\frac{p_{t}+d_{t}-R p_{t-1}}{p_{t-1}} \\
& =\frac{p_{t}+d_{t}}{p_{t-1}}-R,
\end{aligned}
$$

which is the standard definition of excess return, since $R$ is the gross risk-free rate. We study $g_{t}$, without dividing through by scaling factor $p_{t-1}$ since prices can fall below zero in our CARA economy (assuming no free disposal of negative earnings), so the usual definition of excess return (3) is not appropriate. Henceforth, we will refer to excess gains-equation (2)—when studying asset returns in our model, but the reader should intuitively think of excess gains as excess returns, since excess gains are an appropriately rescaled version of excess returns.

Figure 3 reports the impulse response function for the 'cumulative excess gain' following a positive (one-unit) shock to the earnings process at date zero. The cumulative excess gain is defined as:

$$
\text { cumulative excess gain } t \text { periods after the shock }=\sum_{s=0}^{t} g_{s} .
$$

The cumulative excess gain is the CARA analog of the cumulative excess return from date 0 to 
date $t$.

In Figure 3, the impulse response function is reported for five simulated economies. In every case, the true process for earnings growth is the same-the AR(40) model described in section 3.3. The economies differ only with respect to the beliefs that agents hold. Figure 3 analyzes economies in which agents generate forecasts using the following $\operatorname{AR}(p)$ models for earnings growth: $p=$ $1,10,20,30,40$.

Since the true data-generating process is an $\mathrm{AR}(40)$, let's start with the rational expectations case in which agents use the same model, an AR(40), to form beliefs. The impulse response function in this economy is the flat line in Figure 3; i.e., the cumulative excess gain jumps up at date zero and immediately plateaus. In the rational expectations case, an impulse at date zero does not forecast additional excess returns in periods after date zero.

When agents generate beliefs from an $\operatorname{AR}(p)$ model with $p<40$, the natural expectations case, excess gains become more volatile and predictable. For example, when agents use an AR(1) model, they mistakenly infer that earnings impulses are highly persistent (cf. Figure 2). This belief in persistence causes the asset price to jump up more than it should at date zero. Thereafter, the asset price tends to decline, and this decline is not foreseen by the agents. This decline is easy to see on the impulse response function, since there is only one impulse at date 0 and no impulse at any other point in time. In a full-blown simulation of the economy, the stream of negative excess gains would be largely masked by subsequent shocks in the economy. Hence, the predictable negative excess gains would be hard to infer.

As the order of the estimated $\operatorname{AR}(p)$ model rises from $p=1$ to $p=40$, the impulse response functions look more and more like the rational expectations impulse response function. As $p$ rises, the initial jump in the asset price becomes smaller, since agents with high-order models correctly anticipate more mean reversion in the true data-generating process. As $p$ rises, the magnitude of the negative excess returns gets smaller.

Hence, models with low levels of $p$ are characterized by a high degree of overreaction in asset prices. Models with $p$ equal to or near 40 are characterized by little or no overreaction and little or no predictability of excess gains.

Figure 4 reports the impulse response function for consumption following a positive (oneunit) shock to the earnings process at date zero, and mimics the reporting conventions of Figure 3. 
Specifically, the impulse response function is reported for five simulated economies. In every case, the true process for earnings growth is the AR(40) model described in section 3.3, while agents generate forecasts using an $\operatorname{AR}(p)$ model. We again plot the cases $p=1,10,20,30,40$.

Let's again start with the case in which agents have AR(40) beliefs, which is the rational expectations case. In this world, a shock at date 0 would forecast a slow rise in consumption because the agents in our setting have a preference for slow adjustment, due to the habit term in their utility function. On the other hand, if the habit parameter, $\gamma$, were zero, the consumption series would jump up at date zero and immediately plateau.

When agents have natural expectations (i.e. they hold beliefs generated from an $\operatorname{AR}(p)$ model with $p<40$ ), the impulse response function for consumption tends to become hump-shaped. For example, when agents use an AR(1) model, they mistakenly infer that the earnings impulse is highly persistent, leading them to overreact to the earnings impulse (despite their preference for slow adjustment). About ten quarters after the initial impulse, they realize that they have gone too far and begin to reduce consumption. Over the long run, consumption falls from its peak level as households realize that their wealth is not as great as they initially thought (mirroring the negative excess gains in Figure 3). Since the NPV of these consumption responses must be the same across the $p$ values - a consequence of the budget constraint-the long-run consumption asymptotes are different, reflecting pay-back for the short-run over-consumption.

As the estimated $\operatorname{AR}(p)$ model rises from $p=1$ to $p=40$ in Figure 4, the impulse response functions again move towards the rational expectations benchmark. The initial growth in consumption becomes smaller, since agents that use high- $p$ models believe in more mean reversion in the earnings process and therefore don't believe that the impulse to earnings has made them much more wealthy. Therefore, as $p$ increases, the magnitude of the predictable fall in consumption also gets smaller.

In summary, models with low levels of $p$ generate overreaction of consumption. Models with $p$ equal to or near 40 are characterized by little or no overreaction and little or no eventual declines in consumption. 


\subsection{Empirical Moments for Model Evaluation}

We use the following eight moments to evaluate the empirical performance of our model under different assumptions. All data is annual, and goes from 1929 to 2010 (we use annual data so we can go further back in time, as the quarterly series in NIPA only start in 1947). To distinguish this annual data from the quarterly observation frequency of the model/calibration, we use the new time subscript $\tau$.

The moments reveal evidence for reversals that start around two years after an initial impulse. Our model predicts that these reversals will be delayed for two reasons. First, equity prices won't mean revert until agents start to notice a break between their forecasts and the realizations of earnings (see Figure 2). For the simple models that we estimate, this divergence tends to occur about two years after an initial impulse. Second, consumption growth in the short-run is positively auto-correlated because of habits (see Figure 4). The presence of habits delays the onset of mean reversion in consumption and slows down the process of mean reversion. Because it takes longer for the consumption dynamics to play out, we always extend the consumption analysis an extra year beyond the window of the asset price analysis. After an initial impulse at date $\tau$, the asset price dynamics are measured from $\tau+2$ to $\tau+5$. The consumption dynamics are measured from $\tau+2$ to $\tau+6$. The key empirical moments we study are:

1. The correlation between excess returns of equity over the risk-free rate in year $\tau$ and cumulative excess returns from year $\tau+2$ to year $\tau+5$. This equals $-0.22 .{ }^{35}$

2. The correlation between the ratio of S\&P price at the end of year $\tau$ and average earnings over years $\tau-9$ to $\tau$ (the $P / E_{10}$ ratio) and excess returns from year $\tau+2$ to year $\tau+5$. This equals $-0.38 .^{36}$

3. The correlation between the one-year change in log consumption (i.e., $\left.\ln \left(c_{\tau}\right)-\ln \left(c_{\tau-1}\right)\right)$ and

\footnotetext{
${ }^{35}$ Excess returns are defined as "the value-weight return on all NYSE, AMEX, and NASDAQ stocks (from CRSP) minus the one-month Treasury bill rate (from Ibbotson Associates)." (source: Ken French's online data library). Early evidence on long-term mean reversion in stock prices was presented in Fama and French (1988a) and Poterba and Summers (1988). The significance of this evidence was subsequently challenged on statistical grounds, e.g. by Richardson (1993). Cutler, Poterba, and Summers (1991) look at a variety of stocks, bonds and foreign exchange markets and find a relatively slight negative autocorrelation in returns in many markets over a horizons of 3 to 5 years. Balvers, Wu, and Gilliland (2000) consider a panel of 18 countries and document strong mean reversion in national equity indexes relative to the world index.

${ }^{36}$ Data on stock prices and earnings come from Robert Shiller's website. Earnings and dividend yields as predictors of future returns are studied by e.g. Campbell and Shiller (1988a,b, 2005) and Fama and French (1988b).
} 
cumulative excess returns from year $\tau+2$ to year $\tau+5$. This equals $-0.30 .^{37}$

4. The correlation between the $\mathrm{P} / \mathrm{E}_{10}$ ratio and the change in log consumption from year $\tau+2$ to year $\tau+6$ (i.e., $\left.\ln \left(c_{\tau+6}\right)-\ln \left(c_{\tau+2}\right)\right)$. This equals -0.17 .

5. The correlation between $\ln \left(c_{\tau}\right)-\ln \left(c_{\tau-1}\right)$ and $\ln \left(c_{\tau+6}\right)-\ln \left(c_{\tau+2}\right)$. This equals -0.25 .

6. The mean annual excess return of equity over the risk-free rate (the "equity premium"). This equals $7.44 \%$.

7. The standard deviation of annual excess return of equity over the risk-free rate. This equals $20.83 \%$.

8. The standard deviation of $\ln \left(c_{\tau}\right)-\ln \left(c_{\tau-1}\right)$. This equals 0.022 .

While the directions and magnitudes of the correlations reported under 1) to 5) are suggestive, one has to be careful with the interpretation: as investigated in the finance literature by Stambaugh (1999), Valkanov (2003) and others, predictive regressions in short samples and with overlapping data can yield biased coefficients, and standard statistical inference may not be valid..$^{38}$

To get an idea of the statistical significance of our results as well as the magnitude of a potential bias, we conduct a series of bootstrap exercises (similar to e.g. Nelson and Kim, 1993). For moment 1), we draw repeatedly (with replacement) from the observed realization of excess returns under the assumption that excess returns are not serially correlated, and construct the measure of subsequent cumulative excess returns that we use in the empirical data. We then calculate the correlation between the two series and repeat this 10,000 times for samples of length 75 (corresponding to our empirical sample size), so we can construct a confidence interval under the null of independent returns. For moment 5), we instead assume one-period log consumption growth follows an AR(1) process. ${ }^{39}$ We estimate this process and then simulate time series of consumption (of length equal to our empirical sample) by repeatedly drawing from the residuals. From this

\footnotetext{
${ }^{37}$ For our consumption measure, we use real per capita expenditures on non-durable consumption and services, from NIPA. The nominal data on expenditures are in NIPA table 2.3.5, while price indices are in table 2.3.4. The population data come from table 2.1. Consumption growth is a relatively little studied predictor for excess returns. However, in recent work, Moller (2008) and Moller and Rangvid (2011) show that high consumption growth between quarters 3 and 4 significantly predicts low excess returns over the following year.

${ }^{38}$ See Lettau and Ludvigson (2010) for an overview of the issues as well as potential remedies.

${ }^{39}$ This is the approximate process that consumption growth should follow when a consumer has habit preferences; see e.g. Dynan (2000).
} 
series, we construct the change in log consumption between years $\tau+2$ and $\tau+6$, and correlate it with the one-period change in log consumption. Again, this is repeated 10,000 times, and we construct confidence intervals based on the obtained correlations.

For moments 2) to 4), we proceed in a similar manner: e.g. for 2), i) we assume and estimate an $\mathrm{AR}(1)$ process for $\mathrm{P} / \mathrm{E}_{10}$ (accounting for the small-sample bias in the autoregression coefficient); ii) we assume that excess returns are independently distributed (the null); and iii) draw residual pairs under the null (with replacement), construct the predicted variable we use in the data (for a sample of equal length to our data), and estimate the correlation between the two series. We again repeat this 10,000 times and construct $90 \%$ and $95 \%$ confidence intervals for the correlation coefficient.

The results in Table 2 show that the correlations 3) and 5) are outside of the $90 \%$ confidence interval constructed under the null, but not outside the 95\% interval. The "long-horizon autocorrelation" of excess returns (1) as well as the correlation of $\mathrm{P} / \mathrm{E}_{10}$ with subsequent excess returns (2) are not quite significant at 10\%, while the correlation between $\mathrm{P} / \mathrm{E}$ and subsequent consumption growth (4) is far from significant. ${ }^{40}$

These relatively "weak" results do not come as a surprise, as a large literature in finance has established that predictability patterns that had appeared highly statistically significant in the early (1980s) literature are much less significant once statistical complications are accounted for. That said, our use of annual rather than quarterly data (as is more common in the literature) presumably weakens our statistical power. Furthermore, there exist more sophisticated ways of testing for predictability, and overall the finance literature seems to have concluded that "despite complexities with statistical inference in return predictability regressions, it is difficult to reconcile the historical behavior of the U.S. stock market without admitting some degree of predictability in excess returns" (Lettau and Ludvigson, 2010, p. 620). Finally, even where we cannot reject the null hypothesis of no predictability, we certainly also cannot reject an alternative null with economically high predictability — the currently available data just do not allow us to know.

\footnotetext{
${ }^{40}$ The wide confidence intervals for 2) and 4) may seem surprising; they are due to the high persistence of the $\mathrm{P} / \mathrm{E}_{10}$ and the use of overlapping data for consumption growth and excess returns (see Boudoukh, Richardson, and Whiltelaw, 2008).
} 


\subsection{Asset Return Predictability}

For the next eight exhibits, we will illustrate the implications of the model for the full range of natural expectations cases. Specifically, beliefs about earnings are generated for all AR( $p)$ models, for $p=1, \ldots, 40$. As usual, we always assume that the true model generating earnings is an $\mathrm{AR}(40)$. The rational expectations case therefore coincides with the case $p=40$; natural expectations correspond to the cases $1 \leq p<40$. It turns out that when $p$ is between 10 and 20 the natural expectations model does a good job of matching the point estimates for the eight empirical moments.

In the exhibits that follow, we always study simulations with 328 periods of quarterly data, matching the duration of our available empirical data (annual U.S. data since 1929). We then calculate the eight moments on these 328 simulated periods. We repeat this exercise 200 times and average the eight moments over these 200 (independent) simulations. We match the sample duration of our empirical data and the sample duration of our simulated data to make finite sample biases comparable across the empirical and simulated moments.

Figure 5 studies the correlation between excess returns in year $\tau$ and cumulative excess returns from year $\tau+2$ to $\tau+5$. The empirical correlation is -0.22 . For low values of $p$, the simulated moment is about -0.3 , rising to about -0.15 as $p$ rises to 20 . For the rational expectations case, $p=40$, the correlation is approximately ${ }^{41}$ zero.

Similarly, Figure 6 studies the correlation between the $\mathrm{P} / \mathrm{E}_{10}$ ratio at year-end $\tau$ and cumulative excess returns from year $\tau+2$ to $\tau+5$. The empirical correlation is -0.38 . For low values of $p$, the simulated moment is about -0.5 , rising to about -0.35 as $p$ rises to 20 . For the rational expectations case, $p=40$, the correlation is again approximately zero.

The natural expectations model matches these moments, because good earnings news at date zero generates overreaction in asset prices (and increase the $\mathrm{P} / \mathrm{E}_{10}$ ratio, since the denominator is relatively unresponsive given that it is averaged over 40 quarters). Over the next five years, some of that initial return will be reversed as agents discover that the good earnings news was not as persistent as they had anticipated.

In our model, Lettau and Ludvigson's (2001) cay variable is positively correlated with ex-

\footnotetext{
${ }^{41}$ The rational expectations benchmark is slightly below zero due to a variant of Hurwicz bias.
} 
cess returns (for the same reason that $\mathrm{P} / \mathrm{E}$ predicts future excess returns). The cay variable is constructed by identifying the co-integration residual between consumption and wealth: cay $_{t}=$ $c_{t}-\Psi w_{t}$. In our model, a positive earnings shock raises asset values but does relatively little to consumption in the short run (due to slow adjustment). Thus a positive earnings shock causes cay to fall. Over the next five years, asset returns will tend to be low, due to unanticipated mean reversion in earnings. Hence, our model provides an alternative explanation for the observed positive correlation between cay and future excess returns. ${ }^{42}$

Figure 7 studies the correlation between consumption growth at year $\tau$ and equity returns from year $\tau+2$ to $\tau+5$. The empirical correlation is -0.30 . For low values of $p$, the simulated moment is about -0.5 , rising to about -0.35 as $p$ rises to 20 . For the rational expectations case, $p=40$, the correlation is approximately zero. ${ }^{43}$ A high level of lagged consumption growth is a proxy for a positive earnings shock (at that date or some preceding date). Natural expectations agents subsequently discover that the earnings news was not as persistent as they had anticipated, leading to below average excess gains/returns.

\subsection{Consumption Growth Predictability}

Figure 8 studies the correlation between the $\mathrm{P} / \mathrm{E}_{10}$ ratio at year-end $\tau$ and consumption growth from year $\tau+2$ to $\tau+6$. The empirical correlation is -0.17 . For low values of $p$, the simulated moment is about -0.35 , rising to about -0.15 as $p$ rises to 20 . For the rational expectations case, $p=40$, the simulated correlation is approximately +0.25 ; this large positive value in the rational expectations case is due to habit formation and slow adjustment in consumption. For the natural expectations agents, $p<40$, the negative correlations arise because unanticipated mean reversion in earnings swamps the effects of habit formation. Good earnings news increases the P/E ratio, since the denominator is relatively unresponsive given that it is averaged over 40 quarters. Over the next five years, some of that initial return will be reversed as natural expectations agents discover that the earnings news was not as persistent as they had anticipated. This causes consumption to decline from year $\tau+2$ to $\tau+6$ for the natural expectations agents. This decline is

\footnotetext{
${ }^{42}$ The classical explanation, derived from the intertemporal budget constraint, is that rational, forward-looking consumers will consume little today relative to their wealth if they expect future returns to be low. In our model, cay correlates with future excess returns only because expectations overreact to shocks; the future returns expected by our agents are always constant.

${ }^{43}$ Once again, Hurwicz bias lowers the rational expectations correlation below zero.
} 
strong enough to overcome the positive correlation that would otherwise arise because of habit formation. The consumption impulse response function-Figure 4-illustrates the effects of the countervailing forces of unanticipated mean reversion and habit formation. For the natural expectations agents, unanticipated mean reversion offsets the pure effects of habit formation.

Figure 9 studies the correlation between consumption growth at year $\tau$ and consumption growth from year $\tau+2$ to $\tau+6$. The empirical correlation is -0.25 . For low values of $p$, the simulated moment is about -0.3 , rising to about -0.2 as $p$ rises to 20 . For the rational expectations case, $p=40$, the simulated correlation is approximately +0.15 ; once again, the positive correlation in the rational expectations case is due to habit formation. The consumption of natural expectations agents $(p<40)$ initially overreacts to a positive earnings shock. Subsequently, they realize that the initial positive earnings shock was not as persistent as they had anticipated, which in turn causes consumption to decline from year $\tau+2$ to $\tau+6$. This decline is strong enough to overcome the positive correlation that would otherwise arise because of slow habit-based adjustment.

The fact that consumption growth is only relatively weakly predicted by lagged equity prices is a strength of our model. ${ }^{44}$ Beeler and Campbell (2009) point out that Bansal and Yaron's (2004) long-run risks model is problematic because it implies much more predictability of consumption growth from lagged price/dividend ratios than is present in the data, while at the same time generating too little excess return predictability. ${ }^{45}$ Beeler and Campbell also note the empirical evidence for medium-run mean reversion in the level of consumption, while the long-run risks model implies that all autocorrelations of consumption growth should be positive.

\subsection{The Equity Premium and Standard Deviations}

In the natural expectations economy, agents perceive that equities are much riskier than they actually are. Specifically, agents with natural expectations believe in asset-price dynamics that imply that long-run risk in equity markets, $\operatorname{cov}\left(\Delta_{h} c_{t+h}, \tilde{R}_{t, t+h}\right) / h$, is an order of magnitude larger than it actually is (for large $h) .{ }^{46}$ In our calibrated simulations this normalized covariance $\left(\operatorname{cov}\left(\Delta_{h} c_{t+h}, \tilde{R}_{t, t+h}\right) / h\right)$

\footnotetext{
${ }^{44}$ On the other hand, as there is only one source of shocks in our model, equity returns and consumption growth, as well as the $\mathrm{P} / \mathrm{E}$ ratio and consumption growth, display a higher contemporaneous correlation than in the data. A more realistic model would incorporate other aggregate shocks (e.g., labor income) which would reduce these correlations without qualitatively changing the economy's other properties.

${ }^{45}$ For an alternative view, see Bansal, Kiku, and Yaron (2009), who argue that consumption growth becomes much more predictable once additional predictor variables are considered.

${ }^{46}$ In this expression, $\Delta_{h} c_{t+h}$ is the $h$-year growth rate in consumption and $\tilde{R}_{t, t+h}$ is the $h$-year excess return.
} 
rises steeply for $h \leq 4$, and then falls as $h$ rises beyond this horizon, generating a strong humpshaped pattern. The normalized covariance falls at long horizons, because earnings mean revert more than anticipated by the agents in the economy. Mean reverting asset prices and mean reverting consumption jointly pull down the long-horizon (large $h$ ) normalized covariance. Actual U.S. data also displays a hump-shaped pattern for the normalized covariance. ${ }^{47}$ In contrast, in the rational expectations version of our economy (with or without habits), the normalized covariance rises monotonically with $h$, which is empirically counterfactual.

As explained above, agents believe that earnings innovations are highly persistent, equity returns are highly volatile, and consumption growth will therefore covary strongly with equity returns in the long run. This leads agents with low values of $p$ to require a high premium to hold equities. By contrast, when $p=40$ - the rational expectations case - the equity premium is only $1 / 10$ of $1 \%$. Figure 10 plots the (annual) equity premium for different values of $p$ as well as the historical premium of $7.4 \%{ }^{48}$

Finally, we are able to roughly match the equity premium without generating counterfactually high levels of asset return volatility - see Figure 11 - or consumption volatility - see Figure 12. No matter what the order of the forecasting model, the standard deviation of consumption volatility is less than the historical standard deviation of consumption volatility. We don't see this as a substantial problem for two reasons. First, we can raise the standard deviation of consumption changes by lowering the (high) level of the habit: e.g., set $\gamma=0.75$ rather than the calibrated value of 0.9. Second, the post-War variation in consumption is substantially lower than the full-sample variation, which is used to generate the empirical line in the figure.

\section{Agents with Rational Expectations}

Starting with the natural expectations economy described above (with $p<40$ ), we now add a vanishingly small measure of agents with rational expectations. These 'RE agents' know all of the coefficients in the true data-generating process for dividends-the AR(40) model. This perfect

\footnotetext{
${ }^{47}$ In the annual U.S. data we use throughout, the normalized covariance takes on the following values for $h=$ $1,2, \ldots, 10$ years: $0.0006,0.0015,0.0019,0.0013,0.0007,0.0002,-0.0004,-0.0006,-0.0006,-0.0006$. See related analyses in Parker (2001), and Gabaix and Laibson (2002).

${ }^{48}$ See Appendix B for the formulae that we use to calculate the equity premium. The X marks on the upper edge of Figure 10 represent equity premia that exceed the vertical scale of the figure.
} 
knowledge is meant to proxy for the more plausible assumption that these new agents have a high degree of sophistication relative to the agents with natural expectations.

We solve for the behavior of the RE agents assuming that they have no effect on equilibrium prices. This small mass assumption is made for tractability. Future work should consider equilibria in which the rational agents are wealthy enough to influence equilibrium prices. The current analysis is a limit case of the results that will apply in that more realistic case.

Appendix $\mathrm{C}$ derives the optimal asset allocation and consumption policy functions of the RE agents. Later in this section, we present the optimal policy rules for the RE agent. Those policy rules take a large set of other objects as inputs. We now discuss and define those inputs before turning to the key result of this section.

Let $\Phi$ be the vector of true autoregressive coefficients in the earnings process, which as always is an $\mathrm{AR}(40)$ process. Let $\hat{\Phi}$ be the vector of autoregressive coefficients in the earnings process as perceived by the NE agents. Let $\sigma_{\varepsilon}$ be the true standard deviation of shocks to the dividend process. Let $\hat{\sigma}_{c}^{2}$ be the conditional variance of consumption changes as perceived by the NE agents. Let $e_{1, p}=\left[\begin{array}{llllll}1 & 0 & 0 & \ldots & 0\end{array}\right]^{\prime}$ be a standard basis vector of length $p$. We define the following variables, which will appear in the policy functions:

$$
\begin{gathered}
\sigma_{g}=\frac{R}{R-1} \sigma_{\varepsilon} e_{1, p}^{\prime}\left(I-\frac{1}{R} \hat{\Phi}\right)^{-1} e_{1, p} . \\
\mu=\frac{R \alpha}{\left(1-\frac{\gamma}{R}\right)(R-1)} \hat{\sigma}_{c}^{2} . \\
M=\frac{R}{R-1} e_{1, p}^{\prime}\left[\Phi-\hat{\Phi}\left(I-\frac{1}{R} \hat{\Phi}\right)^{-1}\left(I-\frac{1}{R} \Phi\right)\right] . \\
B=\frac{1}{2 R\left(1-\frac{\gamma}{R}\right) \alpha \sigma_{g}^{2}} \sum_{k=0}^{\infty} R^{-k} \hat{\Phi}^{\prime k} M^{\prime} M \hat{\Phi}^{k} . \\
A^{\prime}=\frac{2 \mu}{R \sigma_{g}}\left(\frac{1}{2\left(1-\frac{\gamma}{R}\right) \alpha \sigma_{g}} M+\sigma_{\varepsilon} e_{1, p}^{\prime} B \hat{\Phi}^{\prime}\right)\left(I-\frac{1}{R} \hat{\Phi}\right)^{-1} . \\
\lambda=\frac{\left.\lambda=\frac{\gamma}{R}\right) \sigma_{\varepsilon}^{2} e_{1, p}^{\prime} B e_{1, p}}{2(R-1)\left(1-\frac{\gamma}{R}\right) \alpha \sigma_{g}^{2}} \mu^{2}-\frac{\mu \sigma_{\varepsilon}}{\sigma_{g}(R-1)} A^{\prime} e_{1, p}+\frac{1}{2 \alpha(R-1)\left(1-\frac{\gamma}{R}\right)} \ln (1+2 \alpha \lambda) .
\end{gathered}
$$


We can now describe the policy function of RE agents. We introduce a new variable, $\theta_{t}$, which is the quantity of units of the Lucas tree held by an RE agent. By comparison, the quantity of units of the Lucas tree held by an NE agent is normalized to one. Hence, when $\theta_{t}>1$, each RE agent holds more equities than each NE agent.

Theorem 1 For an agent with rational expectations, the optimal asset allocation, $\theta_{t}$, is given by

$$
\theta_{t}=\frac{R}{R-1} \frac{1}{\sigma_{g}}\left(\frac{\mu+M \Delta \vec{d}_{t}}{\left(1-\frac{\gamma}{R}\right) \alpha \sigma_{g}}+\frac{2 \mu \sigma_{\varepsilon}^{2}}{\sigma_{g}} e_{1, p}^{\prime} B e_{1, p}-\sigma_{\varepsilon} A^{\prime} e_{1, p}-2 \sigma_{\varepsilon} e_{1, p}^{\prime} B \hat{\Phi} \Delta \vec{d}_{t}\right)
$$

and the optimal consumption rule is given by:

$$
c_{t}=\left(1-\frac{\gamma}{R}\right)\left(\frac{R-1}{R} w_{t}+A^{\prime} \Delta \vec{d}_{t}+\Delta \vec{d}_{t}^{\prime} B \Delta \vec{d}_{t}+q\right)+\frac{\gamma}{R} c_{t-1} .
$$

The proof is provided in Appendix C. The consumption policy rule implies that consumption is still a weighted average of the annuity value of wealth and lagged consumption, with weights $\left(1-\frac{\gamma}{R}\right)$ and $\frac{\gamma}{R}$. There are two additional terms in the consumption policy, reflecting the impact of dividend shocks beyond their direct effect on prices and hence wealth. These two additional terms represent the ability of the fully informed investor to predict future "returns" (gains), and adjust consumption accordingly. In our setting, the rational agent knows about mean reversion that is not "priced in" to asset prices. In our calibration, the first order effect $\left(A^{\prime} \Delta \vec{d}_{t}\right)$ tends to partially offset the effect of wealth shocks: a rational agent changes her consumption less than a wealth shock would imply since the agent recognizes that mean reversion will reverse part of the original wealth shock. The second order effect $\left(\Delta \vec{d}_{t}^{\prime} B \Delta \vec{d}_{t}\right)$ is strictly positive and increasing in the scale of $\Delta \vec{d}_{t}$, because the benefit of being able to predict returns is greater when large shocks have occurred in the past.

The asset allocation result is harder to interpret than the consumption rule, though it is also a linear function of the dividend history. However, we can derive a simple lower bound on the average equity holding:

Corollary 2 On average, rational agents will hold a quantity of equities greater than

$$
\bar{\theta}_{\min }=\frac{\widehat{\sigma}_{\varepsilon}^{2}}{\sigma_{\varepsilon}^{2}}
$$


Note that $\frac{\widehat{\sigma}_{\varepsilon}^{2}}{\sigma_{\varepsilon}^{2}}$ is the ratio of variances of impulses to earnings. The numerator, $\widehat{\sigma}_{\varepsilon}^{2}$, is the variance perceived by the NE agents. The denominator, $\sigma_{\varepsilon}^{2}$, is the variance perceived by the RE agents. Since the NE agents estimate a simpler model than the (true) model used by the RE agents, it follows that $\widehat{\sigma}_{\varepsilon}^{2}>\sigma_{\varepsilon}^{2}$.

The average value of $\theta_{t}$ (given in Appendix $C$ ) includes two terms related to the consumption policy matrices $A$ and $B$. These terms reflect the contrarian nature of the consumption policy: because dividend shocks have a muted effect on consumption via $A$, and because shocks of any sort increase consumption via $B$, the Lucas tree is less risky for the rational investors than would otherwise be the case, and the equilibrium outcome is for them to hold even more equities than the natural expectations agents. Because both of these terms have a positive impact on average equity holdings, discarding them generates the lower bound described above.

The lower bound can also be interpreted as the policy of an agent who knows there is an equity premium, but is not able to time returns. In our framework, this would occur if $\hat{\sigma}_{\varepsilon}>\sigma_{\varepsilon}$ but $M=0$.

In Figure 13, we report the average asset allocation, and this lower bound, over different model orders chosen by the NE agents. The extent to which NE agents choose low-order models determines both the excessive variance they perceive, and the ability of rational agents to predict returns, and it is therefore unsurprising that the equity holdings for rational agents is generally decreasing in the order of model chosen by the NE agents.

Finally, RE agents will make counter-cyclical equity investments. Because of overreaction among the NE agents, the (rational) expected return on equities falls after positive shocks, leading the RE agents to lower their equity exposure during good times. Conversely the RE agents increase their equity exposure during bad times.

\section{Conclusion}

This paper examines an open endowment economy in which (1) fundamentals have hump-shaped dynamics (momentum in the short run and partial mean reversion in the long run), and (2) agents don't know these dynamics and generate beliefs by fitting parsimonious models. We show that these two assumptions have a large set of empirically valid implications: endogenous extrapolation bias; pro-cyclical excess optimism; overreaction in asset pricing; mean reversion in returns; 
amplified dynamics in consumption; cyclical dynamics in consumption; a high equity premium; relatively highly levered equity exposure among sophisticated investors; and counter-cyclical asset allocation among sophisticated investors. The framework that we have described provides a parsimonious and psychologically plausible explanation for these stylized facts.

We believe that our two assumptions also characterize other 'macro' markets. For example, the same approach could be used to study dynamics in housing prices, residential investment, non-residential investment, inventory accumulation, international capital flows, bond markets, or commodity prices. ${ }^{49}$ Wherever our two assumptions apply, markets will be characterized by amplified cycles, overreaction, excess volatility, and asset returns that are negatively autocorrelated over the medium-run.

Finally, we wish to highlight a gap in our analysis. Our model is about belief formation, but all of our evidence about beliefs is indirect - for instance, consumption and asset price dynamics. We believe that researchers should also measure beliefs directly. Some research on bubbles has moved in this direction (e.g., Case and Shiller, 2003; Vissing-Jorgensen, 2003; Shiller, 2005; Piazzesi and Schneider, 2009, 2011) and we hope that more will do so in the future.

\footnotetext{
${ }^{49}$ For some alternative approaches, see for example Lansing (2009), Hassan and Mertens (2010), Adam and Marcet (2010), LeBaron (2010), Burnside, Eichenbaum, and Rebelo (2011), and Piazzesi and Schneider (2011).
} 


\section{References}

Abraham, J. M. And P. H. Hendershott (1996): “Bubbles in Metropolitan Housing Markets," Journal of Housing Research, 7, 191-207.

AdAM, K. AND A. MARCET (2010): "Booms and Busts in Asset Prices," Bank of Japan IMES Discussion Paper Series 2010-E-2.

Alessie, R. AND A. LUSARDi (1997): “Consumption, saving and habit formation,” Economic Letters, 55, 103-108.

Bacchetta, P., E. Mertens, And E. VAN Wincoop (2009): "Predictability in financial markets: What do survey expectations tell us?" Journal of International Money and Finance, 28, 406-426.

BAKER, M. AND J. WURGLER (2007): “Investor Sentiment in the Stock Market," Journal of Economic Perspectives, 21, 129-151.

BALL, L. (2000): ““Near-Rationality and Inflation in Two Monetary Regimes"," NBER Working Paper 7988.

BALVERS, R., Y. WU, AND E. GILliLAND (2000): “Mean Reversion across National Stock Markets and Parametric Contrarian Investment Strategies," Journal of Finance, 55, 745-772.

BANSAL, R., D. KIKU, AND A. YARON (2009): “An Empirical Evaluation of the Long-Run Risks Model for Asset Prices," Working Paper.

BANSAL, R. AND A. YARON (2004): "Risks for the Long Run: A Potential Resolution of Asset Pricing Puzzles," Journal of Finance, 59, 1481-1509.

BARberis, N. C. (2010): "Psychology and the Financial Crisis of 2007-2008," Working Paper, Yale School of Management.

BArberis, N. C., A. Shleifer, And R. W. Vishny (1998): “A Model of Investor Sentiment," Journal of Financial Economics, 49, 307-343.

BARSKY, R. B. AND J. B. DeLong (1993): “Why Does the Stock Market Fluctuate?" Quarterly Journal of Economics, 108, 291-311.

BeEler, J. AND J. Y. CAMPBell (2009): “The Long-Run Risks Model and Aggregate Asset Prices: An Empirical Assessment," NBER Working Paper 14788.

BENARTZI, S. (2001): "Excessive Extrapolation and the Allocation of 401(k) Accounts to Company Stock," Journal of Finance, 56, 1747-1764.

Benartzi, S. AND R. H. Thaler (2007): "Heuristics and Biases in Retirement Savings Behavior," Journal of Economic Perspectives, 21, 81-104.

Bergman, N. AND S. RoychowdHuRy (2008): “Investor Sentiment and Corporate Disclosure," Journal of Accounting Research, 46, 1057-1083.

Boudoukh, J., M. Richardson, And R. F. WhiltelaW (2008): “The Myth of Long-Horizon Predictability," Review of Financial Studies, 21, 1577-1605. 
BRANCH, W. A. AND G. W. EvANS (2007): "Model uncertainty and endogenous volatility," Review of Economic Dynamics, 10, 207-37.

(2010): “Asset Return Dynamics and Learning," Review of Financial Studies, 23, 1651-1680.

BRaV, A. And J. Heaton (2002): “Competing Theories of Financial Anomalies," Review of Financial Studies, 15, 575-606.

BulKLeY, G. AND R. D. F. HARRIS (1997): “Irrational Analysts' Expectations as a Cause of Excess Volatility in Stock Prices," Economic Journal, 107, 359-371.

Burnside, C., M. EICHEnbaum, AND S. Rebelo (2011): “Understanding Booms and Busts in Housing Markets," Working Paper.

CABAllero, R. J. (1990): “Consumption puzzles and precautionary savings," Journal of Monetary Economics, 25, 113-136.

CAmpbell, J. Y. (2003): “Consumption-Based Asset Pricing," in Handbook of the Economics of Finance Vol. IB, ed. by M. H. George Constantinides and R. Stulz, Amsterdam: North Holland, chap. 13, 803-887.

CAmpbell, J. Y. AND J. H. COChrane (1999): "By Force of Habit: A Consumption-Based Explanation of Aggregate Stock Market Behavior," Journal of Political Economy, 107, 205-251.

CAmpbell, J. Y. AND N. G. MAnKIW (1987): “Are Output Fluctuations Transitory?" Quarterly Journal of Economics, 102, 857-880.

Campbell, J. Y. And R. J. Shiller (1988a): “Stock Prices, Earnings, and Expected Dividends," Journal of Finance, 43, 661-676.

(1988b): “The Dividend-Price Ratio and Expectations of Future Dividends and Discount Factors," Review of Financial Studies, 1, 195-228.

(2005): "Valuation Ratios and the Long-Run Stock Market Outlook: An Update," in Advances in Behavioral Finance, ed. by R. H. Thaler, Princeton University Press, vol. II, 173-201.

CARroll, C. D., M. Sommer, AND J. SlacaleK (2011): “International Evidence on Sticky Consumption Growth," Review of Economics and Statistics, forthcoming.

CASE, K. E. AND R. J. Shiller (2003): “Is There a Bubble in the Housing Market?" Brookings Papers on Economic Activity, 2, 299-342.

Cecchetti, S. G., P.-S. LAM, And N. C. MARK (2000): “Asset Pricing with Distorted Beliefs: Are Equity Returns Too Good to Be True?" American Economic Review, 90, 787-804.

Chalmers, J. And J. Reuter (2009): “How Do Retirees Value Life Annuities? Evidence from Public Employees." NBER Working Paper 15608.

ChAN, L. K. C., J. KARCESKI, AND J. LAKONISHOK (2003): “The Level and Persistence of Growth Rates." Journal of Finance, 58, 643-684.

Chen, L., C. E. Moise, AND X. S. ZhAO (2009): “Myopic Extrapolation, Price Momentum, and Price Reversal," Working Paper. 
Chevalier, J. A. AND G. Ellison (1997): "Risk Taking by Mutual Funds as a Response to Incentives," Journal of Political Economy, 105, 1167-1200.

CHOI, J. J. (2006): “Extrapolative Expectations and the Equity Premium,” Working Paper.

Choi, J. J., D. I. LAibson, B. C. MAdrian, AND A. Metrick (2004): “Employees' Investment Decisions About Company Stock," in Pension Design and Structure: New Lessons from Behavioral Finance, ed. by O. S. Mitchell and S. P. Utkus, New York: Oxford University Press, 121-136.

— (2009): "Reinforcement Learning and Savings Behavior," Journal of Finance, 64, 2515-2534.

Cochrane, J. H. (1988): “How Big is the Random Walk in GNP?" Journal of Political Economy, 96, 893-920.

(2007): "Financial Markets and the Real Economy," in Handbook of the Equity Premium, ed. by R. Mehra, Amsterdam: North Holland, 273-325.

Cutler, D. M., J. M. Poterba, And L. H. Summers (1991): “Speculative Dynamics," Review of Economic Studies, 58, 529-546.

Daniel, K. D., D. Hirshleifer, AND A. Subrahmanya (1998): “Investor psychology and security market under- and overreactions," Journal of Finance, 53, 1839-1886.

DE BondT, W. F. M. (1993): “Betting on Trends: Intuitive Forecasts of Financial Risk and Return," International Journal of Forecasting, 9, 355-371.

De Bondt, W. F. M. And R. H. Thaler (1985): “Does the Stock Market Overreact?" Journal of Finance, 40, 793-805.

(1989): “Anomalies: A Mean-Reverting Walk Down Wall Street," Journal of Economic Perspectives, 3, 189-202.

_ (1990): “Do Security Analysts Overreact?" American Economic Review, 80, 52-57.

De Grauwe, P. (2010): “Top-Down versus Bottom-Up Macroeconomics,” CESifo Working Paper 3020.

Delong, J. B., A. Shleifer, L. H. Summers, And R. Waldmann (1990): "Positive Feedback Investment Strategies and Destabilizing Rational Speculation," Journal of Finance, 45, 379-395.

Dwyer, G. P., A. W. Williams, R. C. Battalio, And T. I. Mason (1993): “Tests of Rational Expectations in a Stark Setting," Economic Journal, 103, 586-601.

DYNAN, K. E. (2000): "Habit Formation in Consumer Preferences: Evidence from Panel Data," American Economic Review, 90, 391-406.

DYNAN, K. E. AND D. M. MAKI (2001): “Does Stock Market Wealth Matter for Consumption?" FEDS Discussion Paper No. 2001-23.

EAsterwood, J. C. AND S. R. NutT (1999): “Inefficiency in Analysts' Earnings Forecasts: Systematic Misreaction or Systematic Optimism?" Journal of Finance, 54, 1777-1797.

EUSEPI, S. AND B. PReston (2011): "Expectations, Learning and Business Cycle Fluctuations," American Economic Review, forthcoming. 
Evans, G. W. AND S. HonKapOHJA (2001): Learning and Expectations in Macroeconomics, Princeton: Princeton University Press.

(2011): “Learning as a Rational Foundation for Macroeconomics and Finance," Working Paper.

FAMA, E. AND K. FRENCH (1988a): "Permanent and temporary components of stock prices," Journal of Political Economy, 96, 246-273. 23-49.

FRIEDMAN, B. (1979): “Optimal Expectations and the Extreme Information Assumptions of 'Rational Expectations' Macromodels," Journal of Monetary Economics, 5, 23-41.

Fuster, A., D. Laibson, AND B. Mendel (2010): “Natural Expectations and Macroeconomic Fluctuations," Journal of Economic Perspectives, 24, 67-84.

GABAIX, X. (2011): “A Sparsity-Based Model of Bounded Rationality,” NBER Working Paper 16911.

Gabaix, X., D. Laibson, G. Moloche, And S. Weinberg (2006): "Costly Information Acquisition: Experimental Analysis of a Boundedly Rational Model," American Economic Review, 96, 1043-1068.

Gabaix, X. And D. I. LAibson (2002): “The 6D Bias and the Equity Premium Puzzle," NBER Macroeconomics Annual, 16, 257-311.

Gerardi, K. S., A. Lehnert, S. M. Sherlund, And P. S. Willen (2008): "Making Sense of the Subprime Crisis," Brookings Papers on Economic Activity, 2008, 69-145.

Gigerenzer, G. AND D. G. Goldstein (1996): "Reasoning the fast and frugal way: Models of bounded rationality," Psychological Review, 103, 650-669.

Glaeser, E. L., J. D. Gottlieb, And J. Gyourko (2010): “Can Cheap Credit Explain the Housing Boom?" NBER Working Paper 16230.

Goetzmann, W. N., L. Peng, And J. Yen (2009): “The Subprime Crisis and House Price Appreciation," NBER Working Paper 15334.

Gourinchas, P.-O. AND A. TORnell (2004): "Exchange rate puzzles and distorted beliefs," Journal of International Economics, 64, 303-333.

GREenWOOD, R. AND S. G. HANSON (2010): “Issuer Quality and Corporate Bond Returns,” Working Paper, Harvard University.

HANNAN, E. (1980): “The Estimation of the Order of an ARMA Process," Annals of Statistics, 8, 1071-1081.

HANSEN, L. P. (2007): “Beliefs, Doubts and Learning: Valuing Macroeconomic Risk," American Economic Review, 97, 1-30.

Hansen, L. P. And T. J. SARgent (2007): Robustness, Princeton NJ: Princeton University Press. (2010): "Fragile beliefs and the price of uncertainty," Quantitative Economics, 1, 129-162. 
HaRuvy, E., Y. LAHAV, AND C. N. NOUSSAIR (2007): “Traders' Expectations in Asset Markets: Experimental Evidence," American Economic Review, 97, 1901-1920.

Hassan, T. A. And T. M. Mertens (2010): “The Social Cost of Near-Rational Investment,” Working Paper.

Hey, J. D. (1994): “Expectations Formation: Rational or Adaptive or ...?" Journal of Economic Behavior and Organization, 25, 329-349.

Hommes, C., J. Sonnemans, J. Tulnstra, And H. VAn De Velden (2008): "Expectations and Bubbles in Asset Pricing Experiments," Journal of Economic Behavior and Organization, 67, 116133.

HonG, H. AND J. C. STEIN (1999): “A Unified Theory of Underreaction, Momentum Trading, and Overreaction in Asset Markets," Journal of Finance, 54, 2143-2184.

- (2007): “Disagreement and the Stock Market," Journal of Economic Perspectives, 21, 109-128.

Hong, H., J. C. Stein, AND J. Yu (2007): "Simple Forecasts and Paradigm Shifts," Journal of Finance, 62, 1207-1242.

HuAnG, K. X., Z. LiU, AND T. ZHA (2009): “Learning, Adaptive Expectations and Technology Shocks," Economic Journal, 119, 377-405.

Kahneman, D. And A. N. Tversky (1973): “On the Psychology of Prediction," Psychological Review, 80, 237-251.

LA PORTA, R. (1996): "Expectations and the Cross-Section of Stock Returns," Journal of Finance, $51,1715-42$.

LAKONISHOK, J., A. SHLeIfER, AND R. W. ViShNy (1994): "Contrarian Investment, Extrapolation, and Risk," Journal of Finance, 49, 1541-1578.

LANSING, K. J. (2006): "Lock-in of extrapolative expectations in an asset pricing model," Macroeconomic Dynamics, 10, 317-348.

- (2009): "Speculative Growth, Overreaction, and the Welfare Cost of Technology-Driven Bubbles," Federal Reserve Bank of San Francisco Working Paper 2008-08.

LeBARON, B. (2010): "Heterogeneous Gain Learning and the Dynamics of Asset Prices," Working Paper, Brandeis University.

LeBaron, B., W. B. Arthur, And R. G. Palmer (1999): “Time Series Properties of an Artificial Stock Market," Journal of Economic Dynamics and Control, 23, 1487-1516.

LeRoy, S. F. AND R. D. PORTER (1981): “The present value relation: Tests based on implied variance bounds," Econometrica, 49, 555-574.

Lettau, M. And S. C. Ludvigson (2001): “Consumption, Aggregate Wealth and Expected Stock Returns," Journal of Finance, 56, 815-849.

(2010): "Measuring and Modeling Variation in the Risk-Return Tradeoff," in Handbook of Financial Econometrics, ed. by Y. Ait-Sahalia and L. P. Hansen, Elsevier Science B.V., North Holland, Amsterdam, vol. 1, 617-690. 
Lichtenstein, S., B. FischHOFF, AND L. Philips (1982): “Calibration of Probabilities: The State of the Art to 1980," in Judgment Under Uncertainty: Heuristics and Biases, ed. by D. Kahneman, P. Slovic, and A. Tversky, Cambridge: Cambridge University Press.

LiM, T. (2001): “Rationality and Analysts' Forecast Bias," Journal of Finance, 56, 369- 385.

MAlmendieR, U. AND S. NAGel (2011): “Depression Babies: Do Macroeconomic Experiences Affect Risk Taking?" Quarterly Journal of Economics, 126, 373-416.

Marcet, A. AND J. P. Nicolini (2003): “Recurrent Hyperinflations and Learning," American Economic Review, 93, 1476-1498.

MCQuARrie, A. D. AND C.-L. TSAi (1998): Regression and Time Series Model Selection, Singapore: World Scientific Publishing.

MOller, S. V. (2008): “Consumption growth and time-varying expected stock returns," Finance Research Letters, 5, 129-136.

MOLlER, S. V. AND J. RANGVID (2011): “The fourth-quarter consumption growth rate and expected returns," Working Paper, Aarhus School of Business and Copenhagen Business School.

Morley, J., C. Nelson, AND E. Zivot (2003): “Why are Beveridge-Nelson and unobservedcomponent decompositions of GDP so different?" Review of Economics and Statistics, 85, 235-243.

Muellbauer, J. N. AND A. Murphy (1997): “Booms and Busts in the UK Housing Market," Economic Journal, 107, 1701-1727.

NeAth, A. AND J. CAVAnAugh (1997): "Regression and time series model selection using variants of the Schwarz information criterion," Communications in Statistics - Theory and Methods, 26, 559-580.

Nelson, C. AND M. Kim (1993): “Predictable Stock Returns: The Role of Small Sample Bias," Journal of Finance, 48, 641-661.

PARKER, J. A. (2001): “The Consumption Risk of the Stock Market," Brookings Papers on Economic Activity, 2, 279-348.

PAStOR, L. AND P. Veronesi (2009): “Learning in Financial Markets," Annual Review of Financial Economics, 1, 361-381.

PERRON, P. AND T. WADA (2009): “Let's take a break: Trends and cycles in US real GDP," Journal of Monetary Economics, 56, 749-765.

Piazzesi, M. AND M. SChneIder (2009): “Momentum Traders in the Housing Market: Survey Evidence and a Search Model," American Economic Review, 99, 406-411.

— (2011): "Trend and Cycle in Bond Premia," Working Paper.

Poterba, J. M. And L. H. Summers (1988): “Mean reversion in stock prices: Evidence and Implications," Journal of Financial Economics, 22, 27-59.

Previtero, A. (2010): “Stock Market Returns and Annuitization," Working Paper.

RABIN, M. (2002): "Inference by Believers in the Law of Small Numbers," Quarterly Journal of Economics, 117, 775-816. 
RABIN, M. AND D. VAYANOS (2010): “The Gambler's and Hot-Hand Fallacies: Theory and Applications," Review of Economic Studies, 77, 730-778.

Reinhart, C. And K. Rogoff (2009): This Time is Different: Eight Centuries of Financial Folly, Princeton NJ: Princeton University Press.

Richardson, M. (1993): “Temporary Components of Stock Prices: A Skeptic's View," Journal of Business E Economic Statistics, 11, 199-207.

SARGENT, T. J. (1993): Bounded Rationality in Macroeconomics, Oxford: Oxford University Press.

Shaman, P. AND R. A. STINE (1988): “The Bias of Autoregressive Coefficient Estimators," Journal of the American Statistical Association, 83, 842-848.

SHILlER, R. J. (1981): “Do stock prices move too much to be justified by subsequent changes in dividends?" American Economic Review, 71, 421-436.

- (2005): Irrational Exuberance, Second Edition, Princeton: Princeton University Press.

SIMS, C. (1998): “Stickiness," Carnegie-Rochester Conference Series on Public Policy, 49, 317-356. (2003): “Implications of Rational Inattention," Journal of Monetary Economics, 50, 665-690.

SiRRI, E. R. AND P. TUFANO (1998): "Costly Search and Mutual Fund Flows," Journal of Finance, $53,1589-1622$.

Stambaugh, R. F. (1999): “Predictive Regressions," Journal of Financial Economics, 54, 375-421.

StocK, J. H. (1994): "Unit Roots, Structural Breaks and Trends," in Handbook of Econometrics, ed. by R. F. Engle and D. McFadden, Elsevier, vol. IV, chap. 46, 2739-2841.

Tesfatsion, L. S. AND K. L. JudD, eds. (2006): Handbook of Computational Economics: Agent-Based Computational Economics, vol. 2, Amsterdam: North-Holland Publishing Company.

TimmermanN, A. G. (1993): "How learning in financial markets generates excess volatility and predictability in stock prices," Quarterly Journal of Economics, 108, 1135-1145.

TORTORICE, D. L. (2011): “Unemployment Expectations and the Business Cycle,” Working Paper.

TVErsky, A. N. And D. Kahneman (1973): “Availability: A Heuristic for Judging Frequency and Probabilities," Cognitive Psychology, 5, 207-232.

_ (1974): “Judgment under Uncertainty: Heuristics and Biases," Science, 185, 1124-1131.

VALKANOV, R. (2003): “Long-Horizon Regressions: Theoretical Results and Applications," Journal of Financial Economics, 68, 201-232.

Vissing-Jorgensen, A. (2003): "Perspectives on Behavioral Finance: Does 'Irrationality' Disappear With Wealth? Evidence from Expectations and Actions," NBER Macroeconomics Annual, 18, 139-194.

WoOdFord, M. (2009): “Information-Constrained State-Dependent Pricing," Journal of Monetary Economics, 56, 100-124. 


\section{Appendices}

\section{A Matrix Representation of Consumption Model}

In this section, we solve for the optimal consumption policy for beliefs based on an $\operatorname{ARIMA}(p, 1,0)$ model:

$$
\Delta d_{t}=\Phi(L) \Delta d_{t}+\sigma_{\varepsilon} \varepsilon_{t}
$$

We can represent this system as an $\operatorname{AR}(1)$ system with evolution operator $\Phi$ :

$$
\left[\begin{array}{c}
\Delta d_{t} \\
\Delta d_{t-1} \\
\ldots \\
\Delta d_{t-p+1}
\end{array}\right]=\left[\begin{array}{cccc}
\phi_{1} & \phi_{2} & \ldots & \phi_{p} \\
1 & 0 & \ldots & 0 \\
0 & 1 & \ldots & 0 \\
\ldots & & & \\
0 & 0 & \ldots & 0
\end{array}\right]\left[\begin{array}{c}
\Delta d_{t-1} \\
\Delta d_{t-2} \\
\ldots \\
\Delta d_{t-p}
\end{array}\right]+\left[\begin{array}{c}
\sigma_{\varepsilon} \\
0 \\
\ldots \\
0
\end{array}\right] \varepsilon_{t}
$$

There is also the foreign debt variable, $b_{t}$, which evolves as

$$
b_{t+1}=c_{t}+R b_{t}-d_{t}-y .
$$

Here we analyze a slightly more general version of the model, which includes constant labor income $y$. We also assume that $R$ is constant. Define the $\operatorname{AR}(1)$ representation state vector:

$$
z_{t}=\left[\begin{array}{llllllllll}
b_{t} & c_{t-1} & 1 & y & d_{t} & \Delta d_{t} & \Delta d_{t-1} & \ldots & \Delta d_{t-p+1}
\end{array}\right]^{\prime}
$$

We use CARA utility with habits, as in Alessie and Lusardi (1997):

$$
u\left(c_{t}, c_{t-1}\right)=-\frac{1}{\alpha} \exp \left(-\alpha\left(c_{t}-\gamma c_{t-1}\right)\right)
$$

Now, guess a linear policy function, $c_{t}=P^{\prime} z_{t}$. Because the policy function is linear, we can define the AR(1) evolution operator:

$$
M=\bar{M}+N P^{\prime}=\left[\begin{array}{cccccc}
R & 0 & 0 & -1 & -1 & \overrightarrow{0} \\
0 & 0 & 0 & 0 & 0 & \overrightarrow{0}^{\prime} \\
0 & 0 & 1 & 0 & 0 & \overrightarrow{0}^{\prime} \\
0 & 0 & 0 & 1 & 0 & \overrightarrow{0}^{\prime} \\
0 & 0 & 0 & 0 & 1 & e_{1, p}^{\prime} \Phi \\
\overrightarrow{0} & \overrightarrow{0} & \overrightarrow{0} & \overrightarrow{0} & \overrightarrow{0} & \Phi
\end{array}\right]+\left(e_{1, p+5}+e_{2, p+5}\right) P^{\prime}
$$

where $e_{i, n}$ is the $i^{\prime} t h$ basis vector of length $n$. This satisfies

$$
z_{t}=M z_{t-1}+C \varepsilon_{t}
$$

where $C=\left(e_{5, p+5}+e_{6, p+5}\right) \sigma_{\varepsilon}$, i.e. $C$ is a column vector that applies the random shock to $d_{t}$ and $\Delta d_{t}$ and is otherwise empty. An alternative evolution equation is

$$
z_{t}=\bar{M} z_{t-1}+N c_{t-1}+C \varepsilon_{t}
$$


We guess that the value function is of the form

$$
V\left(z_{t}\right)=-\frac{\Psi}{\alpha} \exp \left(-\alpha\left(c_{t}-\gamma c_{t-1}\right)\right)
$$

Define $\tilde{P}=P-\gamma e_{2, p+5}$, and plug into the Bellman equation:

$$
-\frac{\Psi}{\alpha} e^{-\alpha \tilde{P}^{\prime} z_{t}}=-\frac{1}{\alpha} e^{-\alpha \tilde{P}^{\prime} z_{t}}+\delta E\left[-\frac{\Psi}{\alpha} e^{-\alpha \tilde{P}^{\prime} z_{t+1}}\right]
$$

The expectation for $\tilde{P}^{\prime} z_{t+1}$ is $\tilde{P}^{\prime} M z_{t}$, and the variance is $C^{\prime} \tilde{P} \tilde{P}^{\prime} C$. So the Bellman equation simplifies to:

$$
-\frac{\Psi}{\alpha} e^{-\alpha \tilde{P}^{\prime} z_{t}}=-\frac{1}{\alpha} e^{-\alpha \tilde{P}^{\prime} z_{t}}-\delta \frac{\Psi}{\alpha} e^{-\alpha\left(\tilde{P}^{\prime} M z_{t}-\frac{\alpha}{2} C^{\prime} \tilde{P} \tilde{P}^{\prime} C\right)}
$$

Now, without worrying about optimality, we solve the Bellman equation. Dividing through by common terms,

$$
\Psi=1+\delta \Psi e^{-\alpha\left(\tilde{P}^{\prime}(M-I) z_{t}-\frac{\alpha}{2} C^{\prime} \tilde{P} \tilde{P}^{\prime} C\right)}
$$

For this equation to be solved for all $z_{t}$, it must be that for some constant $\kappa$,

$$
\tilde{P}^{\prime}(M-I) z_{t}=\kappa
$$

Next, we need to derive an optimality condition for $c_{t}$. The first-order condition is that

$$
\exp \left(-\alpha \tilde{P}^{\prime} z_{t}\right)+\delta E\left[\Psi \exp \left(-\alpha \tilde{P}^{\prime} z_{t+1}\right) \tilde{P}^{\prime} N\right]=0
$$

Expanding the expectation, and noting that $\tilde{P}^{\prime} N$ is a scalar constant,

$$
\exp \left(-\alpha \tilde{P}^{\prime} z_{t}\right)+\delta \Psi \tilde{P}^{\prime} N \exp \left(-\alpha\left(\tilde{P}^{\prime} M z_{t}-\frac{\alpha}{2} C^{\prime} \tilde{P} \tilde{P}^{\prime} C\right)=0\right.
$$

Dividing through,

$$
0=1+\delta \Psi \tilde{P}^{\prime} N \exp \left(-\alpha\left(\tilde{P}^{\prime}(M-I) z_{t}-\frac{\alpha}{2} C^{\prime} \tilde{P} \tilde{P}^{\prime} C\right)\right.
$$

Again, note that if $\tilde{P}(M-I) z_{t}=\kappa$ for all $t$, this equation can be satisfied for some constant $\Psi$. Combining the two equations, we can see that

$$
0=1+\tilde{P}^{\prime} N(\Psi-1)
$$

Solving,

$$
\Psi=1-\frac{1}{\tilde{P}^{\prime} N}
$$

At this point, we will try to guess $P$ and show that our guess satisfies the equations above. For some constants $K$ and $Q$,

$$
P=\left[\begin{array}{c}
-(R-1)\left(1-\frac{\gamma}{R}\right) \\
\frac{\gamma}{R} \\
Q \\
\frac{R-\gamma}{R} \\
\frac{R-\gamma}{R} \\
{\left[K e_{1, p}^{\prime}\left(I-\frac{1}{R} \Phi\right)^{-1} \frac{1}{R} \Phi\right]^{\prime}}
\end{array}\right]
$$


We can first solve for $\tilde{P}^{\prime} N$.

$$
\tilde{P}^{\prime} N=\left(P-\gamma e_{2, p+5}\right) N=-(R-1)\left(1-\frac{\gamma}{R}\right)+\frac{\gamma}{R}-\gamma=1-R
$$

Therefore,

$$
\Psi=1-\frac{1}{1-R}=\frac{R}{R-1}
$$

Returning to the first order condition,

$$
0=1-R \delta e^{-\alpha\left(\tilde{P}^{\prime}(M-I) z_{t}-\frac{\alpha}{2} C^{\prime} \tilde{P} \tilde{P}^{\prime} C\right)}
$$

Next, we need to confirm that $\tilde{P}^{\prime}(M-I) z_{t}=\kappa$ for all $t$.

$$
\begin{aligned}
& M-I=\bar{M}-I+N P^{\prime}=\left[\begin{array}{cccccc}
R-1 & 0 & 0 & -1 & -1 & \overrightarrow{0} \\
0 & -1 & 0 & 0 & 0 & \overrightarrow{0}^{\prime} \\
0 & 0 & 0 & 0 & 0 & \overrightarrow{0}^{\prime} \\
0 & 0 & 0 & 0 & 0 & \overrightarrow{0}^{\prime} \\
0 & 0 & 0 & 0 & 0 & e_{1, p}^{\prime} \Phi \\
\overrightarrow{0} & \overrightarrow{0} & \overrightarrow{0} & \overrightarrow{0} & \overrightarrow{0} & \Phi-I
\end{array}\right]+N P^{\prime} \\
& N P^{\prime}=\left[\begin{array}{cccccc}
-(R-1)\left(1-\frac{\gamma}{R}\right) & \frac{\gamma}{R} & Q & \frac{R-\gamma}{R} & \frac{R-\gamma}{R} & K e_{1, p}^{\prime}\left(I-\frac{1}{R} \Phi\right)^{-1} \frac{1}{R} \Phi \\
-(R-1)\left(1-\frac{\gamma}{R}\right) & \frac{\gamma}{R} & Q & \frac{R-\gamma}{R} & \frac{R-\gamma}{R} & K e_{1, p}^{\prime}\left(I-\frac{1}{R} \Phi\right)^{-1} \frac{1}{R} \Phi \\
0 & 0 & 0 & 0 & 0 & \overrightarrow{0}^{\prime} \\
0 & 0 & 0 & 0 & 0 & \overrightarrow{0}^{\prime} \\
0 & 0 & 0 & 0 & 0 & \overrightarrow{0}^{\prime} \\
\overrightarrow{0} & \overrightarrow{0} & \overrightarrow{0} & \overrightarrow{0} & \overrightarrow{0} & 0
\end{array}\right] \\
& M-I=\left[\begin{array}{cccccc}
(R-1) \frac{\gamma}{R} & \frac{\gamma}{R} & Q & \frac{-\gamma}{R} & \frac{-\gamma}{R} & K e_{1, p}^{\prime}\left(I-\frac{1}{R} \Phi\right)^{-1} \frac{1}{R} \Phi \\
-(R-1)\left(1-\frac{\gamma}{R}\right) & \frac{-R+\gamma}{R} & Q & \frac{R-\gamma}{R} & \frac{R-\gamma}{R} & K e_{1, p}^{\prime}\left(I-\frac{1}{R} \Phi\right)^{-1} \frac{1}{R} \Phi \\
0 & 0 & 0 & 0 & 0 & \overrightarrow{0}^{\prime} \\
0 & 0 & 0 & 0 & 0 & \overrightarrow{0}^{\prime} \\
0 & 0 & 0 & 0 & 0 & e_{1, p}^{\prime} \Phi \\
\overrightarrow{0} & \overrightarrow{0} & \overrightarrow{0} & \overrightarrow{0} & \overrightarrow{0} & \Phi-I
\end{array}\right]
\end{aligned}
$$

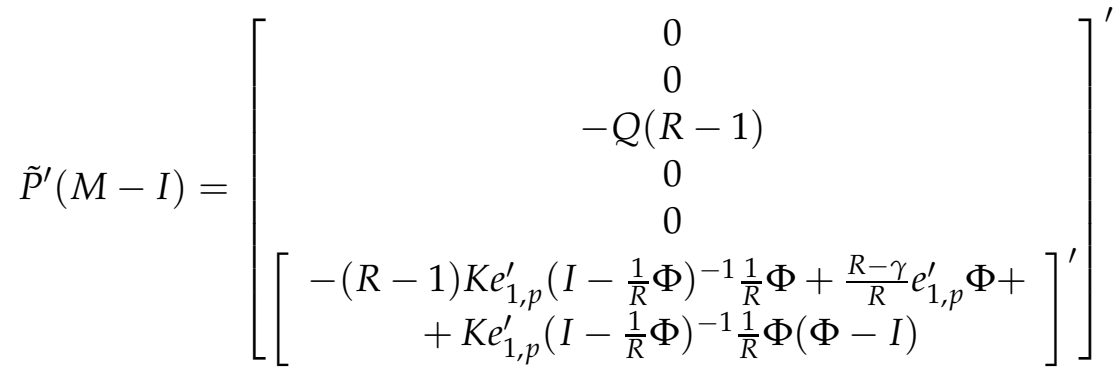

We need to solve for $K$ so that the last element becomes zero. Simplifying,

$$
0=-R K e_{1, p}^{\prime}\left(I-\frac{1}{R} \Phi\right)^{-1} \frac{1}{R} \Phi+\frac{R-\gamma}{R} e_{1, p}^{\prime} \Phi+R K e_{1, p}^{\prime}\left(I-\frac{1}{R} \Phi\right)^{-1} \frac{1}{R} \Phi \frac{1}{R} \Phi
$$


Noting that

$$
\left(I-\frac{1}{R} \Phi\right)^{-1} \frac{1}{R} \Phi \frac{1}{R} \Phi=\left(I-\frac{1}{R} \Phi\right)^{-1} \frac{1}{R} \Phi-\frac{1}{R} \Phi
$$

We can simplify to

$$
0=\frac{R-\gamma}{R} e_{1, p}^{\prime} \Phi-R K e_{1, p}^{\prime} \frac{1}{R} \Phi
$$

Solving,

$$
K=\frac{R-\gamma}{R}=\left(1-\frac{\gamma}{R}\right)
$$

For this value of $K$, and any value of $Q, \tilde{P}(M-I) z_{t}=\kappa=-Q(R-1)$ for all $t$. To solve for $Q$, we can rewrite the FOC, replacing for our value of $\Psi$,

$$
\begin{gathered}
0=1-\exp \left(\alpha\left[\frac{1}{\alpha} \ln (R \delta)+Q(R-1)+\frac{\alpha}{2} C^{\prime} \tilde{P} \tilde{P}^{\prime} C\right]\right) \\
\tilde{P}^{\prime} C=\sigma_{\varepsilon}\left(1-\frac{\gamma}{R}\right) e_{1, p}^{\prime}\left(I-\frac{1}{R} \Phi\right)^{-1} e_{1, p}=\sigma_{c} \\
Q=\frac{1}{R-1}\left[-\frac{1}{\alpha} \ln (R \delta)-\frac{\alpha}{2} \sigma_{c}^{2}\right]
\end{gathered}
$$

We have now fully solved for the linear policy function, and shown that it is optimal. In the body of the paper we impose the additional restriction, $y_{t}=0$.

\section{B Asset Pricing}

Next, we derive a price for the dividend stream. Our timing convention is that the price at time $t$ does not include the dividend at time $t$. To calculate the equilibrium price of the Lucas tree, we consider the asset allocation problem (as opposed to the planner's problem). We then solve for the asset price that leads the representative agent to hold one unit of the equity tree.

Start with the Bellman Equation:

$$
\begin{aligned}
V\left(c_{t-1}, w_{t}, p_{t}, \vec{d}_{t}\right)=\sup _{\theta_{t}, c_{t}} u\left(c_{t}, c_{t-1}\right)+ & E_{t} \delta V\left(c_{t},\left(w_{t}-c_{t}-\theta_{t} p_{t}\right) R+\right. \\
& \left.+\theta_{t}\left(d_{t+1}+p_{t+1}\right), p_{t+1}, \vec{d}_{t+1}\right),
\end{aligned}
$$

or alternatively

$$
V\left(c_{t-1}, x_{t}, p_{t}, \vec{d}_{t}\right)=\frac{-R}{\alpha(R-1)} \exp \left(-\alpha\left[c_{t}-\gamma c_{t-1}\right]\right)
$$

where

$$
c_{t}=\frac{\gamma}{R} c_{t-1}+\left(1-\frac{\gamma}{R}\right) x_{t}-\psi
$$

Consumption is a weighted average of lagged consumption and the (risk-neutral) annuity value of future dividends, $x_{t}$, shifted down by an additive constant $\psi$. Let's write $x_{t}$ so that we allow the 
agent to buy more or less of the risky tree. Buying more means raising $\theta$ above unity.

$$
\begin{gathered}
x_{t}=\frac{R-1}{R}\left[-R b_{t}-(\theta-1) p_{t}+d_{t}+\theta \sum_{s=1}^{\infty} \frac{E_{t} d_{t+s}}{R^{s}}\right] \\
\psi=\frac{1}{R-1}\left[\frac{1}{\alpha} \ln (R \delta)+\frac{\alpha}{2} \operatorname{Var}_{t}\left(\Delta c_{t+1}\right)\right] .
\end{gathered}
$$

In equilibrium, $\theta=1$ (supply equals demand). The associated first-order condition is:

$$
\frac{d V}{d \theta}=0 \text { at } \theta=1
$$

We can expand this derivative:

$$
\frac{d V}{d \theta}=\frac{\partial V}{\partial c_{t}}\left[\frac{\partial c_{t}}{\partial x_{t}} \frac{\partial x_{t}}{\partial \theta}+\frac{\partial c_{t}}{\partial \psi} \frac{\partial \psi}{\partial \theta}\right]=0
$$

which implies that the asset price, $p_{t}$, is chosen such that

$$
\frac{\partial c_{t}}{\partial x_{t}} \frac{\partial x_{t}}{\partial \theta}+\frac{\partial c_{t}}{\partial \psi} \frac{\partial \psi}{\partial \theta}=0 \text { at } \theta=1
$$

Let's evaluate each of these partial derivatives in turn:

$$
\begin{aligned}
\frac{\partial c_{t}}{\partial x_{t}} & =\left(1-\frac{\gamma}{R}\right) \\
\frac{\partial x_{t}}{\partial \theta} & =\frac{R-1}{R}\left[-p_{t}+\sum_{s=1}^{\infty} \frac{E_{t} d_{t+s}}{R^{s}}\right] \\
\frac{\partial c_{t}}{\partial \psi} & =-1 \\
\frac{\partial \psi}{\partial \theta_{t}} & =\frac{1}{R-1} \frac{\alpha}{2} \frac{\partial \operatorname{Var}_{t}\left(\Delta c_{t+1}\right)}{\partial \theta} \\
& =\frac{1}{R-1} \frac{\alpha}{2} 2 \theta \operatorname{Var}_{t}\left(\Delta c_{t+1}\right)
\end{aligned}
$$

Now we are ready to use our equilibrium condition (equation (4)):

$$
\begin{aligned}
\frac{\partial c_{t}}{\partial x} \frac{\partial x}{\partial \theta} & =-\frac{\partial c_{t}}{\partial \psi} \frac{\partial \psi}{\partial \theta} \quad(\text { evaluated at } \theta=1) \\
\left(1-\frac{\gamma}{R}\right) \frac{R-1}{R}\left[-p_{t}+\sum_{s=1}^{\infty} \frac{E_{t} d_{t+s}}{R^{s}}\right] & =\frac{1}{R-1} \frac{\alpha}{2} 2 \operatorname{Var}_{t}\left(\Delta c_{t+1}\right)
\end{aligned}
$$

Rearrange to get

$$
\begin{aligned}
-p_{t}+\sum_{s=1}^{\infty} \frac{E_{t} d_{t+s}}{R^{s}} & =\frac{R \alpha \times \operatorname{Var}_{t}\left(\Delta c_{t+1}\right)}{\left(1-\frac{\gamma}{R}\right)(R-1)^{2}} \\
p_{t} & =\sum_{s=1}^{\infty} \frac{E_{t} d_{t+s}}{R^{s}}-\frac{R \alpha \times \operatorname{Var}_{t}\left(\Delta c_{t+1}\right)}{\left(1-\frac{\gamma}{R}\right)(R-1)^{2}}
\end{aligned}
$$


We can also express the expectation of the discounted stream of dividends using our earlier matrix notation, implying that

$$
p_{t}=\frac{1}{R-1} d_{t}+\frac{R}{R-1} e_{1, p}^{\prime}\left(I-\frac{1}{R} \Phi\right)^{-1} \frac{1}{R} \Phi \Delta \vec{d}_{t}-\frac{R \alpha}{\left(1-\frac{\gamma}{R}\right)(R-1)^{2}} \sigma_{c}^{2}
$$

\section{B.1 Equity Premium}

The mathematical expectation of the equity premium does not exist in our economy, since equity prices are not bounded below by zero. Instead of characterizing the expected equity premium, we characterize the equity premium conditional on a history in which all dividends take on their expected value. Specifically, assume that $d_{t}=d$ and $\Delta \vec{d}_{t}=0$. The average quarterly return conditional on this history is $\frac{d}{p_{t}}$, where

$$
p_{t}=\frac{d}{R-1}-\frac{R \alpha}{\left(1-\frac{\gamma}{R}\right)(R-1)^{2}} \sigma_{c}^{2} .
$$

Hence,

$$
\frac{d}{p}=\frac{d}{\frac{d}{R-1}-\frac{R \alpha}{\left(1-\frac{\gamma}{R}\right)(R-1)^{2}} \sigma_{c}^{2}}
$$

Therefore the annualized equity premium when dividends have a flat history (i.e., $\Delta \vec{d}_{t}=0$ ) is given by

$$
4 \times\left[\frac{d}{\frac{d}{R-1}-\frac{R \alpha}{\left(1-\frac{\gamma}{R}\right)(R-1)^{2}} \sigma_{c}^{2}}-(R-1)\right]
$$

\section{Rational Expectations Investors}

\section{C.1 Excess Gains with Natural Expectations}

We start with the definition of the price in the natural expectations framework:

$$
p_{t}=\frac{1}{R-1} d_{t}+\frac{R}{R-1} e_{1, p}^{\prime}\left(I-\frac{1}{R} \Phi\right)^{-1} \frac{1}{R} \Phi \Delta \vec{d}_{t}-\frac{R \alpha}{\left(1-\frac{\gamma}{R}\right)(R-1)^{2}} \sigma_{c}^{2}
$$

We would like to understand the gains process, defined as

$$
g_{t+1}=p_{t+1}+d_{t+1}-R p_{t}
$$

We replace the $\Phi$ matrix and $\sigma_{c}$ with their 'hat' equivalents, to denote misspecification. Expanding the definitions of $p_{t}$ and $p_{t+1}$, we find that

$$
\begin{aligned}
& g_{t+1}=d_{t+1}+\frac{1}{R-1}\left(d_{t+1}-R d_{t}\right)+ \\
& \quad \frac{R}{R-1} e_{1, p}^{\prime}\left(I-\frac{1}{R} \hat{\Phi}\right)^{-1} \frac{1}{R} \hat{\Phi}\left(\Delta \vec{d}_{t+1}-R \Delta \vec{d}_{t}\right)+\frac{R \alpha}{\left(1-\frac{\gamma}{R}\right)(R-1)} \hat{\sigma}_{c}^{2}
\end{aligned}
$$


Define

$$
\mu=\frac{R \alpha}{\left(1-\frac{\gamma}{R}\right)(R-1)} \hat{\sigma}_{c}^{2}
$$

Using the definition of the AR process driving $d_{t}$, we can rewrite this as

$$
\begin{aligned}
g_{t+1}= & \frac{R}{R-1} e_{1, p}^{\prime}\left(\Phi \Delta \vec{d}_{t}+\sigma_{e} \varepsilon_{t+1} e_{1, p}\right)+ \\
& +\frac{R}{R-1} e_{1, p}^{\prime}\left(I-\frac{1}{R} \hat{\Phi}\right)^{-1} \hat{\Phi}\left(\frac{1}{R} \Phi \Delta \vec{d}_{t}-\Delta \vec{d}_{t}+\frac{1}{R} \sigma_{\varepsilon} \varepsilon_{t+1} e_{1, p}\right)+\mu
\end{aligned}
$$

Regrouping terms,

$$
\begin{aligned}
g_{t+1}= & \frac{R}{R-1} e_{1, p}^{\prime}\left(\Phi-\hat{\Phi}\left(I-\frac{1}{R} \hat{\Phi}\right)^{-1}\left(I-\frac{1}{R} \Phi\right)\right) \Delta \vec{d}_{t}+ \\
& +\frac{R}{R-1} \sigma_{\mathcal{\varepsilon}} e_{1, p}^{\prime}\left(I-\frac{1}{R} \hat{\Phi}\right)^{-1} e_{1, p} \varepsilon_{t+1}+\mu
\end{aligned}
$$

We can define the vector $M$ and constant $\sigma_{g}$ so that the equation above is

$$
g_{t+1}=M \Delta \vec{d}_{t}+\sigma_{g} \varepsilon_{t+1}+\mu
$$

\section{C.2 Budget Constraint}

Let $w_{t}$ be the agent's wealth in period $t$ before consumption is chosen. Assume the agent can hold either risk-free assets with return $R$, or a risky asset. There are no shorting/leverage constraints. The agent's budget constraint is

$$
\begin{aligned}
w_{t+1} & =\left(w_{t}+y-c_{t}-\theta_{t} p_{t}\right) R+\theta_{t}\left(d_{t+1}+p_{t+1}\right) \\
& =\left(w_{t}+y-c_{t}\right) R+\theta_{t} g_{t+1}
\end{aligned}
$$

where the choice variables are consumption $\left(c_{t}\right)$ and dollar amount in the risky asset $\left(\theta_{t}\right)$. We can rewrite the budget constraint in terms of the evolution of $g_{t}$,

$$
w_{t+1}=R\left(w_{t}+y-c_{t}\right)+\theta_{t} M \Delta \vec{d}_{t}+\theta_{t} \sigma_{g} \varepsilon_{t+1}+\theta_{t} \mu .
$$

It will be helpful to solve for an inter-temporal budget constraint. The transversality condition is

$$
\lim _{k \rightarrow \infty} E_{t}\left[R^{-k} w_{t+k}\right]=0
$$

Seeing that

$$
\begin{aligned}
E_{t}\left[w_{t+2}\right]= & E_{t}\left[R\left(w_{t+1}-c_{t+1}+y\right)+\theta_{t+1} M \Delta \vec{d}_{t+1}+\theta_{t+1} \mu\right] \\
= & E_{t}\left[R^{2}\left(w_{t}-c_{t}+y\right)+R\left(-c_{t+1}+y\right) \theta_{t+1} M \Delta \vec{d}_{t+1}+\right. \\
& \left.+\theta_{t+1} \mu+R \theta_{t} M \Delta \vec{d}_{t}+R \mu\right]
\end{aligned}
$$


We conjecture that

$$
E_{t}\left[R^{-k} w_{t+k}\right]=w_{t}+\frac{1}{R} \sum_{j=0}^{k-1} R^{-j} E_{t}\left[\theta_{t+j} M \Delta \vec{d}_{t+j}+\theta_{t+j} \mu-R c_{t+j}+R y\right]
$$

This holds trivially for $k=1$ and $k=2$. Assume it holds for $k>1$ :

$$
\begin{aligned}
E_{t}\left[R^{-k-1} w_{t+k+1}\right]= & E_{t}\left[R^{-k} w_{t+k}-R^{-k} c_{t+k}+R^{-k} y+\right. \\
& \left.+R^{-k-1} \theta_{t+k} M \Delta \vec{d}_{t+k}+R^{-k-1} \theta_{t+k} \mu\right] \\
= & w_{t}+\frac{1}{R} \sum_{j=0}^{k} R^{-j} E_{t}\left[\theta_{t+j} M \Delta \vec{d}_{t+j}+\theta_{t+j} \mu-R c_{t+j}+R y\right]
\end{aligned}
$$

By induction, it holds in the limit, and therefore the inter-temporal budget constraint is

$$
\sum_{j=0}^{\infty} E_{t}\left[R^{-j} c_{t+j}\right]=w_{t}+\frac{R}{R-1} y+\sum_{j=0}^{\infty} E_{t}\left[R^{-j-1} \theta_{t+j} M \Delta \vec{d}_{t+j}+R^{-j-1} \theta_{t+j} \mu\right]
$$

We can rewrite the sum of $c_{t+j}$ in terms of $\hat{c}_{t+j}=c_{t+j}-\gamma c_{t+j-1}$.

$$
\begin{aligned}
\sum_{j=0}^{\infty} E_{t}\left[R^{-j} c_{t+j}\right] & =\sum_{j=0}^{\infty} E_{t}\left[R^{-j}\left(\hat{c}_{t+j}+\gamma c_{t+j-1}\right)\right] \\
& =\gamma c_{t-1}+\sum_{j=0}^{\infty} E_{t}\left[R^{-j} \hat{c}_{t+j}\right]+\frac{\gamma}{R} \sum_{j=1}^{\infty} E_{t}\left[R^{-j+1} c_{t+j-1}\right] \\
& =\gamma c_{t-1}+\sum_{j=0}^{\infty} E_{t}\left[R^{-j} \hat{c}_{t+j}\right]+\frac{\gamma}{R} \sum_{k=0}^{\infty} E_{t}\left[R^{-k} c_{t+k}\right]
\end{aligned}
$$

We can then solve to see that

$$
\sum_{j=0}^{\infty} E_{t}\left[R^{-j} c_{t+j}\right]=\frac{1}{1-\frac{\gamma}{R}}\left(\gamma c_{t-1}+\sum_{j=0}^{\infty} E_{t}\left[R^{-j} \hat{c}_{t+j}\right]\right)
$$

Rewriting the inter-temporal budget constraint,

$$
\begin{aligned}
\sum_{j=0}^{\infty} E_{t}\left[R^{-j} \hat{c}_{t+j}\right]=-\gamma c_{t-1}+\left(1-\frac{\gamma}{R}\right)\left(w_{t}+\frac{R}{R-1} y\right. & \\
& \left.+\sum_{j=0}^{\infty} E_{t}\left[R^{-j-1} \theta_{t+j} M \Delta \vec{d}_{t+j}+R^{-j-1} \theta_{t+j} \mu\right]\right)
\end{aligned}
$$

\section{C.3 Utility and Value Functions}

The agent has flow utility of the form

$$
u\left(c_{t}, c_{t-1}\right)=-\frac{1}{\alpha} e^{-\alpha\left(c_{t}-\gamma c_{t-1}\right)}
$$


It is convenient to define

$$
\hat{c}_{t}=c_{t}-\gamma c_{t-1}
$$

The state is captured entirely by $w_{t}, c_{t-1}$, and $\Delta \vec{d}_{t}$. The Bellman equation is

$$
V\left(w_{t}, c_{t-1}, \Delta \vec{d}_{t}\right)=\max _{\hat{c}_{t}, \theta_{t}} u\left(\hat{c}_{t}\right)+\delta E_{t}\left[V\left(w_{t+1}, \hat{c}_{t}+\gamma c_{t-1}, \Delta \vec{d}_{t+1}\right)\right]
$$

The first order conditions are

$$
u^{\prime}\left(\hat{c}_{t}\right)=\delta E_{t}\left[R \frac{\partial V_{t+1}}{\partial w_{t+1}}-\frac{\partial V_{t+1}}{\partial c_{t}}\right]
$$

and

$$
\delta E_{t}\left[\frac{\partial V_{t+1}}{\partial w_{t+1}}\left(M \Delta \vec{d}_{t}+\mu+\sigma_{g} \varepsilon_{t+1}\right)\right]=0
$$

The envelope condition for $w_{t}$ is

$$
\frac{\partial V_{t}}{\partial w_{t}}=\delta E_{t}\left[\frac{\partial V_{t+1}}{\partial w_{t+1}} R\right]
$$

From the inter-temporal budget constraint (5),

$$
\frac{\partial V_{t}}{\partial c_{t-1}}=\frac{-\gamma}{1-\frac{\gamma}{R}} \frac{\partial V_{t}}{\partial w_{t}}
$$

We use this to derive the Euler equations, which will be verified after deriving a solution. Rewriting (6), and then using (7),

$$
\begin{aligned}
u^{\prime}\left(\hat{c}_{t}\right) & =\delta E_{t}\left[R \frac{\partial V_{t+1}}{\partial w_{t+1}}+\frac{\gamma}{1-\frac{\gamma}{R}} \frac{\partial V_{t+1}}{\partial w_{t+1}}\right] \\
\left(1-\frac{\gamma}{R}\right) u^{\prime}\left(\hat{c}_{t}\right) & =\delta E_{t}\left[R \frac{\partial V_{t+1}}{\partial w_{t+1}}\right]=\frac{\partial V_{t}}{\partial w_{t}}
\end{aligned}
$$

Advancing time by one unit, and taking expectations,

$$
\left(1-\frac{\gamma}{R}\right) E_{t}\left[u^{\prime}\left(\hat{c}_{t+1}\right)\right]=E_{t}\left[\frac{\partial V_{t+1}}{\partial w_{t+1}}\right]
$$

The consumption Euler equation, assuming $\delta R=1$, is therefore

$$
u^{\prime}\left(\hat{c}_{t}\right)=E_{t}\left[u^{\prime}\left(\hat{c}_{t+1}\right)\right]
$$

The asset Euler equation is

$$
0=E_{t}\left[\left(1-\frac{\gamma}{R}\right) u^{\prime}\left(\hat{c}_{t+1}\right)\left(M \Delta \vec{d}_{t}+\mu+\sigma_{g} \varepsilon_{t+1}\right)\right]
$$

\section{C.4 Guess and Check}

We guess that

$$
\hat{c}_{t}=D c_{t-1}+\left(1-\frac{\gamma}{R}\right)\left(\frac{R-1}{R} w_{t}+A^{\prime} \Delta \vec{d}_{t}+\Delta \vec{d}_{t}^{\prime} B \Delta \vec{d}_{t}+q\right),
$$


where $A$ is a vector and $B$ is a matrix. From this guess, it follows that

$$
\hat{c}_{t+1}=D c_{t}+\left(1-\frac{\gamma}{R}\right)\left(\frac{R-1}{R} w_{t+1}+A^{\prime} \Delta \vec{d}_{t+1}+\Delta \vec{d}_{t+1}^{\prime} B \Delta \vec{d}_{t+1}+q\right)
$$

From the budget constraint and the evolution of $\Delta \vec{d}_{t}$,

$$
\hat{c}_{t+1}=D c_{t}+
$$

$$
\left(1-\frac{\gamma}{R}\right)\left[\begin{array}{c}
\frac{R-1}{R}\left(R\left(w_{t}-c_{t}\right)+\theta_{t} M \Delta \vec{d}_{t}+\theta_{t} \mu+\theta_{t} \sigma_{g} \varepsilon_{t+1}\right)+A^{\prime} \Phi \Delta \vec{d}_{t}+ \\
+A^{\prime} e_{1, p} \sigma_{\varepsilon} \varepsilon_{t+1}+\left(\Phi \Delta \vec{d}_{t}+e_{1, p} \sigma_{\varepsilon} \varepsilon_{t+1}\right)^{\prime} B\left(\Phi \Delta \vec{d}_{t}+e_{1, p} \sigma_{\varepsilon} \varepsilon_{t+1}\right)+q
\end{array}\right]
$$

Taking expectations,

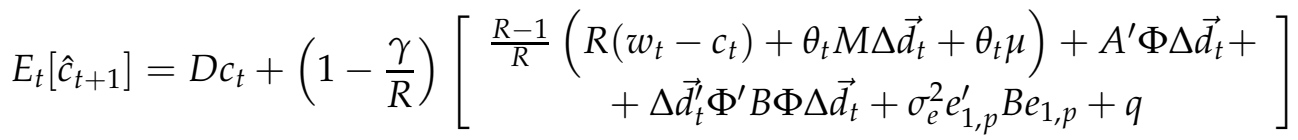

We can then write

$$
\begin{aligned}
& \hat{c}_{t+1}=E\left[\hat{c}_{t+1}\right]+ \\
& \left(1-\frac{\gamma}{R}\right)\left[\begin{array}{c}
\left(\frac{R-1}{R} \theta_{t} \sigma_{g}+\sigma_{\varepsilon} A^{\prime} e_{1, p}+\sigma_{\varepsilon} e_{1, p}^{\prime} B \Phi \Delta \vec{d}_{t}+\sigma_{\varepsilon} \Delta \vec{d}_{t}^{\prime} \Phi^{\prime} B e_{1, p}\right) \varepsilon_{t+1}+ \\
-\sigma_{\varepsilon}^{2} e_{1, p}^{\prime} B e_{1, p}+\sigma_{\varepsilon}^{2} e_{1, p}^{\prime} B e_{1, p} \varepsilon_{t+1}^{2}
\end{array}\right]
\end{aligned}
$$

Define the following constants:

$$
\begin{aligned}
k_{t} & =\left(1-\frac{\gamma}{R}\right)\left(\frac{R-1}{R} \theta_{t} \sigma_{g}+\sigma_{\varepsilon} A^{\prime} e_{1, p}+\sigma_{\varepsilon} e_{1, p}^{\prime} B \Phi \Delta \vec{d}_{t}+\sigma_{\varepsilon} \Delta \vec{d}_{t}^{\prime} \Phi^{\prime} B e_{1, p}\right) \\
\lambda & =\left(1-\frac{\gamma}{R}\right) \sigma_{\varepsilon}^{2} e_{1, p}^{\prime} B e_{1, p} .
\end{aligned}
$$

We can rewrite $u^{\prime}\left(\hat{c}_{t+1}\right)$ as

$$
u^{\prime}\left(\hat{c}_{t+1}\right)=e^{-\alpha\left(E\left[\hat{c}_{t+1}\right]-\lambda+k_{t} \varepsilon_{t+1}+\lambda \varepsilon_{t+1}^{2}\right)},
$$

and compute expectations to get

$$
E\left[u^{\prime}\left(\hat{c}_{t+1}\right)\right]=e^{-\alpha\left(E\left[\hat{c}_{t+1}\right]-\lambda\right)} \times \int_{-\infty}^{\infty} \frac{1}{\sqrt{2 \pi}} e^{-\alpha k_{t} x-\alpha \lambda x^{2}} e^{-\frac{x^{2}}{2}} d x
$$

Define another constant,

$$
s=\sqrt{\frac{1}{1+2 \alpha \lambda}}
$$

We can complete the square on the integral as follows:

$$
\begin{gathered}
-\alpha k_{t} x-\alpha \lambda x^{2}-0.5 x^{2}=-\frac{x^{2}+2 \alpha k_{t} s^{2} x}{2 s^{2}}=-\frac{\left(x+\alpha k_{t} s^{2}\right)^{2}}{2 s^{2}}+\frac{\alpha^{2}}{2} k_{t}^{2} s^{2} \\
E\left[u^{\prime}\left(\hat{c}_{t+1}\right)\right]=e^{-\alpha\left(E\left[\hat{c}_{t+1}\right]-\lambda-\frac{1}{2} \alpha k_{t}^{2} s^{2}\right)} s \int_{-\infty}^{\infty} \frac{1}{\sqrt{2 \pi s^{2}}} e^{-\frac{\left(x+\alpha k_{t} s^{2}\right)^{2}}{2 s^{2}}} d x
\end{gathered}
$$


We therefore conclude that

$$
E\left[u^{\prime}\left(\hat{c}_{t+1}\right)\right]=e^{-\alpha\left(E\left[\hat{c}_{t+1}\right]-\lambda-\frac{1}{2} \alpha k_{t}^{2} s^{2}-\frac{1}{2 \alpha} \ln s^{2}\right)}
$$

Next, consider the integral from the second Euler equation.

$$
E\left[u^{\prime}\left(\hat{c}_{t+1}\right) \sigma_{g} \varepsilon_{t+1}\right]=e^{-\alpha\left(E\left[\hat{c}_{t+1}\right]-\lambda-\frac{1}{2} \alpha k_{t}^{2} s^{2}\right)} \times \int_{-\infty}^{\infty} \frac{1}{\sqrt{2 \pi}} \sigma_{g} x e^{-\frac{\left(x+\alpha k_{t} s^{2}\right)^{2}}{2 s^{2}}} d x
$$

For the integral, use the following transformation:

$$
\begin{gathered}
u=\frac{x+\alpha k_{t} s^{2}}{s} \\
\int_{-\infty}^{\infty} \frac{1}{\sqrt{2 \pi}} \sigma_{g} x e^{-\frac{\left(x+\alpha k_{t} s^{2}\right)^{2}}{2 s^{2}}} d x=\int_{-\infty}^{\infty} \frac{1}{\sqrt{2 \pi}} \sigma_{g}\left(s u-\alpha k_{t} s^{2}\right) e^{-\frac{u^{2}}{2}} s d u=-\alpha \sigma_{g} k_{t} s^{3}
\end{gathered}
$$

We combine (8) and the equation above to see that

$$
e^{-\alpha\left(E_{t}\left[\hat{c}_{t+1}\right]-\lambda-\frac{1}{2} \alpha k_{t}^{2} s^{2}-\frac{1}{2 \alpha} \ln s^{2}\right)}\left(\mu+M \Delta \vec{d}_{t}\right)=e^{-\alpha\left(E_{t}\left[\hat{c}_{t+1}\right]-\lambda-\frac{1}{2} \alpha k_{t}^{2} s^{2}\right)} \alpha \sigma_{g} k_{t} s^{3}
$$

Simplifying,

$$
\mu+M \Delta \vec{d}_{t}=\alpha \sigma_{g} k_{t} s^{2}
$$

\section{C.5 Solving for the Policy Rules}

Next, we use consumption Euler equation to see that

$$
\hat{c}_{t}=E_{t}\left[\hat{c}_{t+1}\right]-\lambda-\frac{1}{2} \alpha k_{t}^{2} s^{2}-\frac{1}{2 \alpha} \ln s^{2}
$$

From our conjecture about $\hat{c}_{t}$ (equation (10)), we can expand $\hat{c}_{t+1}$ :

$$
\begin{aligned}
& \hat{c}_{t}+\lambda+\frac{1}{2} \alpha k_{t}^{2} s^{2}+\frac{1}{2 \alpha} \ln s^{2}= \\
&\left(1-\frac{\gamma}{R}\right)\left(\frac{R-1}{R} E_{t}\left[w_{t+1}\right]+A^{\prime} E_{t}\left[\Delta \vec{d}_{t+1}\right]+E_{t}\left[\Delta \vec{d}_{t+1}^{\prime} B \Delta \vec{d}_{t+1}\right]+q\right)+D c_{t}
\end{aligned}
$$

or

$$
\begin{aligned}
\hat{c}_{t}+\frac{1}{2} \alpha k_{t}^{2} s^{2}+\frac{1}{2 \alpha} \ln s^{2}= \\
\\
\left(1-\frac{\gamma}{R}\right)\left(\frac{R-1}{R} E_{t}\left[w_{t+1}\right]+A^{\prime} \Phi \Delta \vec{d}_{t}+\Delta \vec{d}_{t}^{\prime} \Phi^{\prime} B \Phi \Delta \vec{d}_{t}+q\right)+D c_{t}
\end{aligned}
$$

Expanding using the budget constraint,

$$
\begin{aligned}
& \hat{c}_{t}-D c_{t}+\frac{1}{2} \alpha k_{t}^{2} s^{2}+ \frac{1}{2 \alpha} \ln s^{2}= \\
&\left(1-\frac{\gamma}{R}\right)\left(\frac{R-1}{R} E_{t}\left[g_{t+1}\right] \theta_{t}+(R-1)\left(w_{t}-c_{t}\right)+A^{\prime} \Phi \Delta \vec{d}_{t}+\Delta \vec{d}_{t}^{\prime} \Phi^{\prime} B \Phi \Delta \vec{d}_{t}+q\right)
\end{aligned}
$$


Simplifying, and replacing $c_{t}$ with $\hat{c}_{t}+\gamma c_{t-1}$,

$$
\begin{aligned}
\hat{c}_{t}\left(1-D+\left(1-\frac{\gamma}{R}\right)\right. & (R-1))+ \\
& +\left(\left(1-\frac{\gamma}{R}\right)(R-1)-D\right) \gamma c_{t-1}+\frac{1}{2} \alpha k_{t}^{2} s^{2}+\frac{1}{2 \alpha} \ln s^{2}= \\
& \left(1-\frac{\gamma}{R}\right)\left(\frac{R-1}{R}\left(M \Delta \vec{d}_{t}+\mu\right) \theta_{t}+(R-1) w_{t}+A^{\prime} \Phi \Delta \vec{d}_{t}+\Delta \vec{d}_{t}^{\prime} \Phi^{\prime} B \Phi \Delta \vec{d}_{t}+q\right)
\end{aligned}
$$

Let $Q=1-D+\left(1-\frac{\gamma}{R}\right)(R-1)$. Simplifying, and expanding the terms of $\hat{c}_{t}$,

$$
\begin{gathered}
((Q-1) \gamma+Q D) c_{t-1}+Q\left(1-\frac{\gamma}{R}\right)\left(\frac{R-1}{R} w_{t}+A^{\prime} \Delta \vec{d}_{t}+Q \Delta \vec{d}_{t}^{\prime} B \Delta \vec{d}_{t}+Q q\right)+ \\
+\frac{1}{2} \alpha k_{t}^{2} s^{2}+\frac{1}{2 \alpha} \ln s^{2}= \\
\left(1-\frac{\gamma}{R}\right)\left((R-1) w_{t}+\frac{R-1}{R}\left(M \Delta \vec{d}_{t}+\mu\right) \theta_{t}+A^{\prime} \Phi \Delta \vec{d}_{t}+\Delta \vec{d}_{t}^{\prime} \Phi^{\prime} B \Phi \Delta \vec{d}_{t}+q\right)
\end{gathered}
$$

We guess that

$$
D=\frac{\gamma}{R}-\gamma
$$

and see that this simplifies nicely:

$$
\begin{aligned}
Q & =R \\
(Q-1) \gamma+Q D & =0
\end{aligned}
$$

Therefore, noting that $w_{t}$ cancels,

$$
\begin{aligned}
& R\left(1-\frac{\gamma}{R}\right)\left(A^{\prime} \Delta \vec{d}_{t}+\Delta \vec{d}_{t}^{\prime} B \Delta \vec{d}_{t}+q\right)+\frac{1}{2} \alpha k_{t}^{2} s^{2}+\frac{1}{2 \alpha} \ln s^{2}= \\
& \left(1-\frac{\gamma}{R}\right)\left(\frac{R-1}{R}\left(M \Delta \vec{d}_{t}+\mu\right) \theta_{t}+A^{\prime} \Phi \Delta \vec{d}_{t}+\Delta \vec{d}_{t}^{\prime} \Phi^{\prime} B \Phi \Delta \vec{d}_{t}+q\right)
\end{aligned}
$$

Using the asset allocation Euler result, we see that

$$
\frac{1}{2} \alpha k_{t}^{2} s^{2}=\frac{1}{2 \alpha \sigma_{g}^{2} s^{2}}\left(\mu^{2}+2 \mu M \Delta \vec{d}_{t}+\Delta \vec{d}_{t}^{\prime} M^{\prime} M \Delta \vec{d}_{t}\right)
$$

Expanding using the definition of $s$,

$$
\frac{1}{2} \alpha k_{t}^{2} s^{2}=\frac{1+2 \alpha \lambda}{2 \alpha \sigma_{g}^{2}}\left(\mu^{2}+2 \mu M \Delta \vec{d}_{t}+\Delta \vec{d}_{t}^{\prime} M^{\prime} M \Delta \vec{d}_{t}\right)
$$

We also need to replace $\theta_{t}$ using the asset allocation Euler equation:

$$
\begin{aligned}
\mu+M \Delta \vec{d}_{t}=\alpha \sigma_{g} s^{2} k_{t}= & \\
& \left(1-\frac{\gamma}{R}\right) \alpha \sigma_{g} s^{2}\left(\frac{(R-1)}{R} \theta_{t} \sigma_{g}+\sigma_{\varepsilon} A^{\prime} e_{1, p}+\sigma_{e} e_{1, p}^{\prime} B \Phi \Delta \vec{d}_{t}+\sigma_{\varepsilon} \Delta \vec{d}_{t}^{\prime} \Phi^{\prime} B e_{1, p}\right)
\end{aligned}
$$


Solving,

$$
\theta_{t}=\frac{R}{R-1} \frac{1}{\sigma_{g}}\left(\frac{\mu+M \Delta \vec{d}_{t}}{\left(1-\frac{\gamma}{R}\right) \alpha \sigma_{g} s^{2}}-\sigma_{\varepsilon} A^{\prime} e_{1, p}-\sigma_{\varepsilon} e_{1, p}^{\prime} B \Phi \Delta \vec{d}_{t}-\sigma_{e} \Delta \vec{d}_{t}^{\prime} \Phi^{\prime} B e_{1, p}\right)
$$

To replace the term in the consumption equation,

$$
\begin{aligned}
\frac{R-1}{R}\left(M \Delta \vec{d}_{t}+\mu\right) \theta_{t}= & \frac{1}{\left(1-\frac{\gamma}{R}\right) \alpha \sigma_{g}^{2} s^{2}}\left(\mu^{2}+2 \mu M \Delta \vec{d}_{t}+\Delta \vec{d}_{t}^{\prime} M^{\prime} M \Delta \vec{d}_{t}\right)- \\
& -\frac{\mu \sigma_{\varepsilon}}{\sigma_{g}} A^{\prime} e_{1, p}-\frac{\sigma_{\varepsilon}}{\sigma_{g}}\left(A^{\prime} e_{1, p} M+\mu e_{1, p}^{\prime}\left(B+B^{\prime}\right) \Phi\right) \Delta \vec{d}_{t}- \\
& -\frac{\sigma_{\varepsilon}}{\sigma_{g}} \Delta \vec{d}_{t}^{\prime} M^{\prime} e_{1, p}^{\prime} B \Phi \Delta \vec{d}_{t}-\frac{\sigma_{\varepsilon}}{\sigma_{g}} \Delta \vec{d}_{t}^{\prime} \Phi^{\prime} B e_{1, p} M \Delta \vec{d}_{t}
\end{aligned}
$$

We can now substitute all of these results:

$$
\begin{aligned}
& R\left(1-\frac{\gamma}{R}\right)\left(A^{\prime} \Delta \vec{d}_{t}+\Delta \vec{d}_{t}^{\prime} B \Delta \vec{d}_{t}+q\right)+\frac{1}{2} \alpha k_{t}^{2} s^{2}+\frac{1}{2 \alpha} \ln s^{2}=\alpha k_{t}^{2} s^{2}+ \\
&\left(1-\frac{\gamma}{R}\right)\left[\begin{array}{c}
-\frac{\mu \sigma_{\varepsilon}}{\sigma_{g}} A^{\prime} e_{1, p}-\frac{\sigma_{\varepsilon}}{\sigma_{g}}\left(A^{\prime} e_{1, p} M+\mu e_{1, p}^{\prime}\left(B+B^{\prime}\right) \Phi\right) \Delta \vec{d}_{t}- \\
-\frac{\sigma_{\varepsilon}}{\sigma_{g}} \Delta \vec{d}_{t}^{\prime} M^{\prime} e_{1, p}^{\prime} B \Phi \Delta \vec{d}_{t}-\frac{\sigma_{\varepsilon}}{\sigma_{g}} \Delta \vec{d}_{t}^{\prime} \Phi^{\prime} B e_{1, p} M \Delta \vec{d}_{t}+ \\
+A^{\prime} \Phi \Delta \vec{d}_{t}+\Delta \vec{d}_{t}^{\prime} \Phi^{\prime} B \Phi \Delta \vec{d}_{t}+q
\end{array}\right]
\end{aligned}
$$

The final version of the system is:

$$
\begin{gathered}
R\left(1-\frac{\gamma}{R}\right)\left(A^{\prime} \Delta \vec{d}_{t}+\Delta \vec{d}_{t}^{\prime} B \Delta \vec{d}_{t}+q\right)+\frac{1}{2 \alpha} \ln s^{2}= \\
\frac{1+2 \alpha \lambda}{2 \alpha \sigma_{g}^{2}}\left(\mu^{2}+2 \mu M \Delta \vec{d}_{t}+\Delta \vec{d}_{t}^{\prime} M^{\prime} M \Delta \vec{d}_{t}\right)+ \\
\left(1-\frac{\gamma}{R}\right)\left[\begin{array}{c}
-\frac{\mu \sigma_{\varepsilon}}{\sigma_{g}} A^{\prime} e_{1, p}-\frac{\sigma_{\varepsilon}}{\sigma_{g}}\left(A^{\prime} e_{1, p} M+\mu e_{1, p}^{\prime}\left(B+B^{\prime}\right) \Phi\right) \Delta \vec{d}_{t}+ \\
+\Delta \vec{d}_{t}^{\prime}\left(\Phi-\frac{\sigma_{\varepsilon}}{\sigma_{g}} e_{1, p} M\right)^{\prime} B \Phi \Delta \vec{d}_{t}+\Delta \vec{d}_{t}^{\prime} \Phi^{\prime} B\left(\Phi-\frac{\sigma_{\varepsilon}}{\sigma_{g}} e_{1, p} M\right) \Delta \vec{d}_{t}- \\
-\Delta \vec{d}_{t}^{\prime} \Phi^{\prime} B \Phi \Delta \vec{d}_{t}+A^{\prime} \Phi \Delta \vec{d}_{t}+q
\end{array}\right]
\end{gathered}
$$

This equation must hold for all value of $\Delta \vec{d}_{t}$, so we use term matching. Note that $\lambda$ is actually the upper left element of $B$, scaled by $\left(1-\frac{\gamma}{R}\right) \sigma_{\varepsilon}^{2}$. Beginning with the second order terms,

$$
\Delta \vec{d}_{t}^{\prime}\left(R B-\frac{1+2 \alpha \lambda}{2\left(1-\frac{\gamma}{R}\right) \alpha \sigma_{g}^{2}} M^{\prime} M-\left(\Phi-\frac{\sigma_{\varepsilon}}{\sigma_{g}} e_{1, p} M\right)^{\prime} B \Phi\right.
$$

$$
\left.-\Phi^{\prime} B\left(\Phi-\frac{\sigma_{\varepsilon}}{\sigma_{g}} e_{1, p} M\right)+\Phi^{\prime} B \Phi\right) \Delta \vec{d}_{t}=0
$$

Define

$$
\Lambda=\Phi-\hat{\Phi}
$$


and note that

$$
\begin{aligned}
M & =\frac{R}{R-1} e_{1, p}^{\prime}\left[\Phi-\hat{\Phi}\left(I-\frac{1}{R} \hat{\Phi}\right)^{-1}\left(I-\frac{1}{R} \Phi\right)\right] \\
& =\frac{R}{R-1} e_{1, p}^{\prime}\left[\Lambda+\hat{\Phi}-\hat{\Phi}\left(I-\frac{1}{R} \hat{\Phi}\right)^{-1}\left(I-\frac{1}{R} \hat{\Phi}-\frac{1}{R} \Lambda\right)\right] \\
& =\frac{R}{R-1} e_{1, p}^{\prime}\left[\Lambda+\hat{\Phi}\left(I-\frac{1}{R} \hat{\Phi}\right)^{-1} \frac{1}{R} \Lambda\right] \\
& =\frac{R}{R-1} e_{1, p}^{\prime}\left(I-\frac{1}{R} \hat{\Phi}\right)^{-1} \Lambda
\end{aligned}
$$

Because $\Lambda$ has non-zeros only in the top row, and $e_{1, p} e_{1, p}^{\prime}$ has non-zeros only in the upper left element, which is one,

$$
\Lambda=e_{1, p} e_{1, p}^{\prime} \Lambda
$$

Therefore,

$$
\begin{aligned}
e_{1, p} M & =\frac{R}{R-1} e_{1, p} e_{1, p}^{\prime}\left(I-\frac{1}{R} \hat{\Phi}\right)^{-1} e_{1, p} e_{1, p}^{\prime} \Lambda \\
& =\frac{\sigma_{g}}{\sigma_{\varepsilon}} \Lambda
\end{aligned}
$$

and

$$
\Phi-\frac{\sigma_{\varepsilon}}{\sigma_{g}} e_{1, p} M=\Phi-\Lambda=\hat{\Phi}
$$

The equation for $B$ can be rewritten:

$$
\Delta \vec{d}_{t}^{\prime}\left(R B-\frac{1+2 \alpha \lambda}{2\left(1-\frac{\gamma}{R}\right) \alpha \sigma_{g}^{2}} M^{\prime} M-\hat{\Phi}^{\prime} B \Phi-\Phi^{\prime} B \hat{\Phi}+\Phi^{\prime} B \Phi\right) \Delta \vec{d}_{t}=0
$$

Substituting for $\lambda$ and regrouping terms,

$$
\Delta \vec{d}_{t}^{\prime}\left(R B-\frac{1}{2\left(1-\frac{\gamma}{R}\right) \alpha \sigma_{g}^{2}} M^{\prime} M-\frac{\sigma_{\varepsilon}^{2}}{\sigma_{g}^{2}} M^{\prime} e_{1, p}^{\prime} B e_{1, p} M-\hat{\Phi}^{\prime} B \hat{\Phi}+\Lambda^{\prime} B \Lambda\right) \Delta \vec{d}_{t}=0
$$

By our earlier result relating $e_{1, p} M$ and $\Lambda$, and assuming that this holds for all $\Delta \vec{d}_{t}$,

$$
B=\frac{1}{2 R\left(1-\frac{\gamma}{R}\right) \alpha \sigma_{g}^{2}} M^{\prime} M+\frac{1}{R} \hat{\Phi}^{\prime} B \hat{\Phi}
$$

This is a discrete time Lyapunov equation. We can apply the standard convergence results to see that, because the eigenvalues of $\frac{1}{\sqrt{R}} \hat{\Phi}$ are entirely less than 1 (no unit root), convergence is certain. Therefore,

$$
B=\frac{1}{2 R\left(1-\frac{\gamma}{R}\right) \alpha \sigma_{g}^{2}} \sum_{k=0}^{\infty} R^{-k} \hat{\Phi}^{\prime k} M^{\prime} M \hat{\Phi}^{k}
$$


From this, we can easily solve for

$$
\lambda=\left(1-\frac{\gamma}{R}\right) \sigma_{\varepsilon}^{2} e_{1, p}^{\prime} B e_{1, p}
$$

Moving on to the first order terms in equation (11), and using the symmetry of $B$,

$$
\begin{aligned}
\left(R\left(1-\frac{\gamma}{R}\right) A^{\prime}-\frac{1+2 \alpha \lambda}{2 \alpha \sigma_{g}^{2}} 2 \mu M-\left(1-\frac{\gamma}{R}\right) A^{\prime} \Phi\right. & \\
& \left.+\left(1-\frac{\gamma}{R}\right) \frac{\sigma_{\varepsilon}}{\sigma_{g}}\left(e_{1, p}^{\prime} A M+2 \mu e_{1, p}^{\prime} B \Phi\right)\right) \Delta \vec{d}_{t}=0
\end{aligned}
$$

Subsituting for $\lambda$, and regrouping,

$$
\begin{aligned}
\left(R A^{\prime}-\frac{1}{2\left(1-\frac{\gamma}{R}\right) \alpha \sigma_{g}^{2}} 2 \mu M-\frac{2 \mu \sigma_{\varepsilon}}{\sigma_{g}} \frac{\sigma_{\varepsilon}}{\sigma_{g}} e_{1, p}^{\prime} B e_{1, p} M-A^{\prime} \Phi\right. & \\
& \left.+\frac{\sigma_{\varepsilon}}{\sigma_{g}} A^{\prime} e_{1, p} M+\frac{2 \mu \sigma_{e}}{\sigma_{g}} e_{1, p}^{\prime} B \Phi\right) \Delta \vec{d}_{t}=0
\end{aligned}
$$

Again using the relation between $e_{1, p} M$ and $\Lambda$,

$$
\left(R A^{\prime}\left(I-\frac{1}{R} \hat{\Phi}\right)-\frac{1}{2\left(1-\frac{\gamma}{R}\right) \alpha \sigma_{g}^{2}} 2 \mu M+\frac{2 \mu \sigma_{\varepsilon}}{\sigma_{g}} e_{1, p}^{\prime} B \hat{\Phi}\right) \Delta \vec{d}_{t}=0
$$

This is solved by inversion:

$$
A^{\prime}=\frac{2 \mu}{R \sigma_{g}}\left(\frac{1}{2\left(1-\frac{\gamma}{R}\right) \alpha \sigma_{g}} M+\sigma_{\varepsilon} e_{1, p}^{\prime} B \hat{\Phi}\right)\left(I-\frac{1}{R} \hat{\Phi}\right)^{-1}
$$

Finally, we solve for the constants:

$$
(R-1)\left(1-\frac{\gamma}{R}\right) q-\frac{1+2 \alpha \lambda}{2 \alpha \sigma_{g}^{2}} \mu^{2}+\left(1-\frac{\gamma}{R}\right) \frac{\mu \sigma_{\varepsilon}}{\sigma_{g}} A^{\prime} e_{1, p}+\frac{1}{2 \alpha} \ln s^{2}=0
$$

Consequently,

$$
q=\frac{1+2 \alpha \lambda}{2(R-1)\left(1-\frac{\gamma}{R}\right) \alpha \sigma_{g}^{2}} \mu^{2}-\frac{\mu \sigma_{\varepsilon}}{\sigma_{g}(R-1)} A^{\prime} e_{1, p}+\frac{1}{2 \alpha(R-1)\left(1-\frac{\gamma}{R}\right)} \ln (1+2 \alpha \lambda) .
$$

Thus, we have proved that our guess for $c_{t}$ (equation (9)) was correct, with $A, B, D$ and $q$ as solved for in this section.

Next, it is worth simplifying the expression for asset allocation:

$$
\theta_{t}=\frac{R}{R-1} \frac{1}{\sigma_{g}}\left(\frac{\mu+M \Delta \vec{d}_{t}}{\left(1-\frac{\gamma}{R}\right) \alpha \sigma_{g} s^{2}}-\sigma_{e} A^{\prime} e_{1, p}-2 \sigma_{\varepsilon} e_{1, p}^{\prime} B \Phi \Delta \vec{d}_{t}\right)
$$


Applying the standard substitution for $s$ and then $\lambda$, we can write the optimal asset allocation as

$$
\theta_{t}=\frac{R}{R-1} \frac{1}{\sigma_{g}}\left(\frac{\mu+M \Delta \vec{d}_{t}}{\left(1-\frac{\gamma}{R}\right) \alpha \sigma_{g}}+\frac{2 \mu \sigma_{\varepsilon}^{2}}{\sigma_{g}} e_{1, p}^{\prime} B e_{1, p}-\sigma_{\varepsilon} A^{\prime} e_{1, p}-2 \sigma_{\varepsilon} e_{1, p}^{\prime} B \hat{\Phi} \Delta \vec{d}_{t}\right)
$$

The average value of $\theta$ (assuming $\Delta \vec{d}_{t}=0$ ) is

$$
\bar{\theta}=\frac{R}{R-1} \frac{\mu}{\left(1-\frac{\gamma}{R}\right) \alpha \sigma_{g}^{2}}+\frac{R}{R-1} \frac{2 \mu \sigma_{\varepsilon}^{2}}{\sigma_{g}^{2}} e_{1, p}^{\prime} B e_{1, p}-\frac{R}{R-1} \frac{\sigma_{\varepsilon}}{\sigma_{g}} A^{\prime} e_{1, p}
$$

Using results from appendices $\mathrm{A}$ and $\mathrm{B}$, we can show that,

$$
\begin{aligned}
\mu & =\frac{R \alpha}{\left(1-\frac{\gamma}{R}\right)(R-1)} \hat{\sigma}_{c}^{2} \\
\hat{\sigma}_{c} & =\frac{R-1}{R}\left(1-\frac{\gamma}{R}\right) \frac{\widehat{\sigma}_{\varepsilon}}{\sigma_{\varepsilon}} \sigma_{g} .
\end{aligned}
$$

Using these results, we can rewrite the average asset allocation as

$$
\bar{\theta}=\frac{\widehat{\sigma}_{\varepsilon}^{2}}{\sigma_{\varepsilon}^{2}}+\frac{R}{R-1} \frac{2 \mu \sigma_{\varepsilon}^{2}}{\sigma_{g}^{2}} e_{1, p}^{\prime} B e_{1, p}-\frac{R}{R-1} \frac{\sigma_{\varepsilon}}{\sigma_{g}} A^{\prime} e_{1, p}
$$


Table 1: Estimated Coefficients from $\operatorname{AR}(p)$ Models of Earnings Growth

\begin{tabular}{|c|c|c|c|c|c|c|c|c|c|c|c|}
\hline & & \multicolumn{2}{|c|}{$\operatorname{AR}(1)$} & \multicolumn{2}{|c|}{$\mathrm{AR}(10)$} & \multicolumn{2}{|c|}{$\operatorname{AR}(20)$} & \multicolumn{2}{|c|}{$\mathrm{AR}(30)$} & \multicolumn{2}{|c|}{$\mathrm{AR}(40)$} \\
\hline & & Coeff. & $t$ & Coeff. & $t$ & Coeff. & $t$ & Coeff. & $t$ & Coeff. & $t$ \\
\hline \multirow[t]{39}{*}{ Coeff. on lag } & 1 & 0.201 & 3.27 & 0.184 & 2.83 & 0.189 & 2.80 & 0.182 & 2.57 & 0.211 & 2.79 \\
\hline & 2 & & & 0.032 & 0.48 & 0.016 & 0.23 & 0.011 & 0.15 & -0.049 & -0.64 \\
\hline & 3 & & & 0.124 & 1.93 & 0.112 & 1.64 & 0.157 & 2.19 & 0.197 & 2.57 \\
\hline & 4 & & & -0.101 & -1.57 & -0.080 & -1.16 & -0.079 & -1.11 & -0.128 & -1.64 \\
\hline & 5 & & & -0.149 & -2.31 & -0.162 & -2.36 & -0.191 & -2.68 & -0.106 & -1.35 \\
\hline & 6 & & & -0.090 & -1.41 & -0.028 & -0.40 & -0.045 & -0.62 & -0.088 & -1.13 \\
\hline & 7 & & & 0.118 & 1.86 & 0.063 & 0.90 & 0.049 & 0.68 & 0.068 & 0.87 \\
\hline & 8 & & & -0.132 & -2.04 & -0.172 & -2.42 & -0.150 & -2.03 & -0.207 & -2.59 \\
\hline & 9 & & & 0.085 & 1.31 & 0.043 & 0.62 & 0.041 & 0.55 & 0.076 & 0.94 \\
\hline & 10 & & & -0.013 & -0.20 & 0.014 & 0.21 & -0.051 & -0.69 & -0.083 & -1.02 \\
\hline & 11 & & & & & -0.016 & -0.23 & -0.020 & -0.27 & -0.005 & -0.06 \\
\hline & 12 & & & & & -0.170 & -2.48 & -0.151 & -2.07 & -0.183 & -2.32 \\
\hline & 13 & & & & & -0.023 & -0.33 & 0.004 & 0.05 & 0.033 & 0.41 \\
\hline & 14 & & & & & -0.010 & -0.15 & -0.032 & -0.43 & -0.064 & -0.82 \\
\hline & 15 & & & & & -0.057 & -0.85 & -0.025 & -0.34 & -0.023 & -0.30 \\
\hline & 16 & & & & & 0.021 & 0.31 & -0.025 & -0.35 & -0.059 & -0.75 \\
\hline & 17 & & & & & -0.058 & -0.89 & -0.072 & -0.99 & -0.087 & -1.12 \\
\hline & 18 & & & & & 0.088 & 1.34 & 0.014 & 0.19 & 0.004 & 0.05 \\
\hline & 19 & & & & & -0.023 & -0.35 & -0.053 & -0.74 & -0.062 & -0.81 \\
\hline & 20 & & & & & -0.091 & -1.41 & -0.062 & -0.88 & -0.070 & -0.92 \\
\hline & 21 & & & & & & & -0.006 & -0.08 & -0.006 & -0.08 \\
\hline & 22 & & & & & & & -0.104 & -1.48 & -0.134 & -1.76 \\
\hline & 23 & & & & & & & 0.056 & 0.81 & 0.094 & 1.23 \\
\hline & 24 & & & & & & & -0.040 & -0.58 & -0.054 & -0.70 \\
\hline & 25 & & & & & & & -0.046 & -0.68 & -0.035 & -0.46 \\
\hline & 26 & & & & & & & -0.060 & -0.90 & -0.088 & -1.15 \\
\hline & 27 & & & & & & & 0.019 & 0.29 & 0.032 & 0.41 \\
\hline & 28 & & & & & & & 0.047 & 0.71 & -0.001 & -0.02 \\
\hline & 29 & & & & & & & -0.020 & -0.31 & -0.011 & -0.15 \\
\hline & 30 & & & & & & & -0.170 & -2.62 & -0.214 & -2.95 \\
\hline & 31 & & & & & & & & & 0.055 & 0.74 \\
\hline & 32 & & & & & & & & & -0.102 & -1.39 \\
\hline & 33 & & & & & & & & & 0.056 & 0.78 \\
\hline & 34 & & & & & & & & & -0.099 & -1.39 \\
\hline & 35 & & & & & & & & & 0.144 & 2.01 \\
\hline & 36 & & & & & & & & & -0.141 & -1.95 \\
\hline & 37 & & & & & & & & & -0.015 & -0.21 \\
\hline & 38 & & & & & & & & & -0.121 & -1.71 \\
\hline & 39 & & & & & & & & & 0.086 & 1.20 \\
\hline Coeff. on lag & 40 & & & & & & & & & -0.063 & -0.90 \\
\hline $\mathrm{N}$ & & \multicolumn{2}{|c|}{253} & \multicolumn{2}{|c|}{244} & \multicolumn{2}{|c|}{234} & \multicolumn{2}{|c|}{224} & \multicolumn{2}{|c|}{214} \\
\hline Adjusted $R^{2}$ & & \multirow{2}{*}{\multicolumn{2}{|c|}{0.037}} & \multicolumn{2}{|c|}{0.087} & \multicolumn{2}{|c|}{0.087} & \multicolumn{2}{|c|}{0.084} & \multicolumn{2}{|c|}{0.074} \\
\hline Root MSE & & & & \multirow{2}{*}{\multicolumn{2}{|c|}{$\begin{array}{l}0.024 \\
1.062\end{array}$}} & \multirow{2}{*}{\multicolumn{2}{|c|}{$\begin{array}{l}0.023 \\
0.745\end{array}$}} & \multirow{2}{*}{\multicolumn{2}{|c|}{$\begin{array}{l}0.022 \\
0.548\end{array}$}} & 0.0 & \\
\hline Persistence & & \multicolumn{2}{|c|}{$\begin{array}{l}0.025 \\
1.252\end{array}$} & & & & & & & 0.4 & \\
\hline
\end{tabular}

Notes: Data: Log of Real Net Operating Surplus of U.S. Private Enterprises from 1947Q1 to 2010Q3. Source: U.S. National Income and Product Accounts (Bureau of Economic Analysis), Table 1.10, line 12 (adjusted for inflation using the GDP deflator). "Persistence" is given by 1/(1-sum of AR coefficients). 
Table 2: Bootstrap confidence intervals under the null of no predictability

\begin{tabular}{l|r|ccc}
\hline & & \multicolumn{3}{|c}{ Bootstrap } \\
Moment & US data & Mean & $90 \%$ C.I. & $95 \%$ C.I. \\
\hline 1) $\operatorname{corr}\left(X R_{\tau}, X R_{\tau+2 \rightarrow \tau+5}\right)$ & -0.220 & -0.049 & {$[-0.249,0.165]$} & {$[-0.284,0.206]$} \\
2) $\operatorname{corr}\left(\left(P / E_{10}\right) \tau, X R_{\tau+2 \rightarrow \tau+5}\right)$ & -0.377 & -0.141 & {$[-0.432,0.192]$} & {$[-0.478,0.249]$} \\
3) $\operatorname{corr}\left(\ln \left(c_{\tau}\right)-\ln \left(c_{\tau-1}\right), X R_{\tau+2 \rightarrow \tau+5}\right)$ & -0.297 & -0.009 & {$[-0.267,0.254]$} & {$[-0.313,0.297]$} \\
$4) \operatorname{corr}\left(\left(P / E_{10}\right) \tau, \ln \left(c_{\tau+6}\right)-\ln \left(c_{\tau+2}\right)\right)$ & -0.167 & -0.022 & {$[-0.424,0.388]$} & {$[-0.493,0.450]$} \\
$5) \operatorname{corr}\left(\ln \left(c_{\tau}\right)-\ln \left(c_{\tau-1}\right), \ln \left(c_{\tau+6}\right)-\ln \left(c_{\tau+2}\right)\right)$ & -0.245 & 0.008 & {$[-0.237,0.257]$} & {$[-0.283,0.302]$} \\
\hline
\end{tabular}

Note: Sources for empirical moments and bootstrap procedures are described in the text. 
Figure 1: Log of Real Net Operating Surplus (“Earnings") of U.S. Private Enterprises from 1947Q1 to 2010Q3

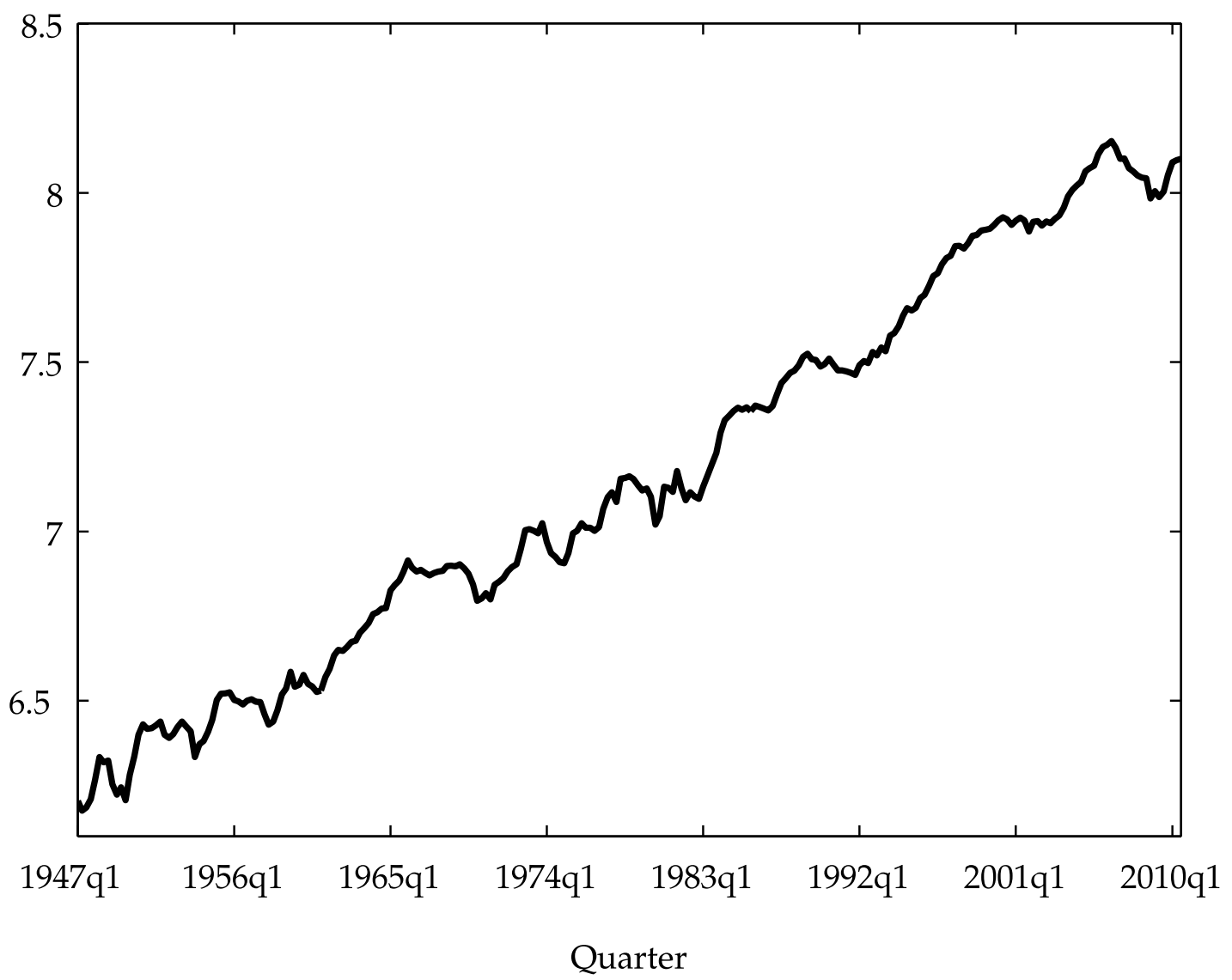

Source: U.S. National Income and Product Accounts (Bureau of Economic Analysis), Table 1.10, line 12. Adjusted for inflation using the GDP deflator. 
Figure 2: Estimated Impulse Response Function for Earnings (in Levels), for Different AR( $p)$ Models of Earnings Growth

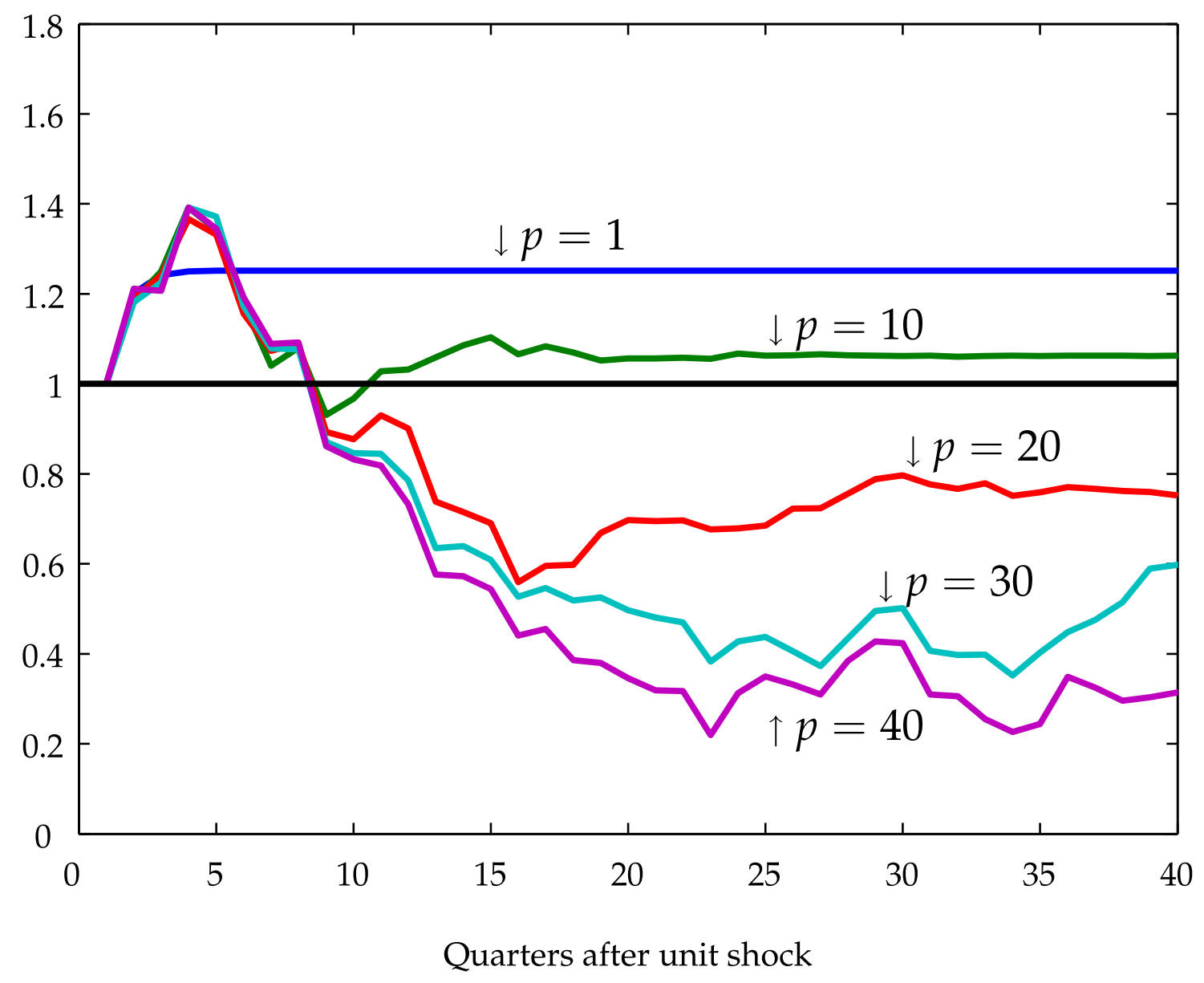


Figure 3: Cumulative Impulse Response Function for Gains, for Different $\operatorname{AR}(p)$ Models of Earnings Growth

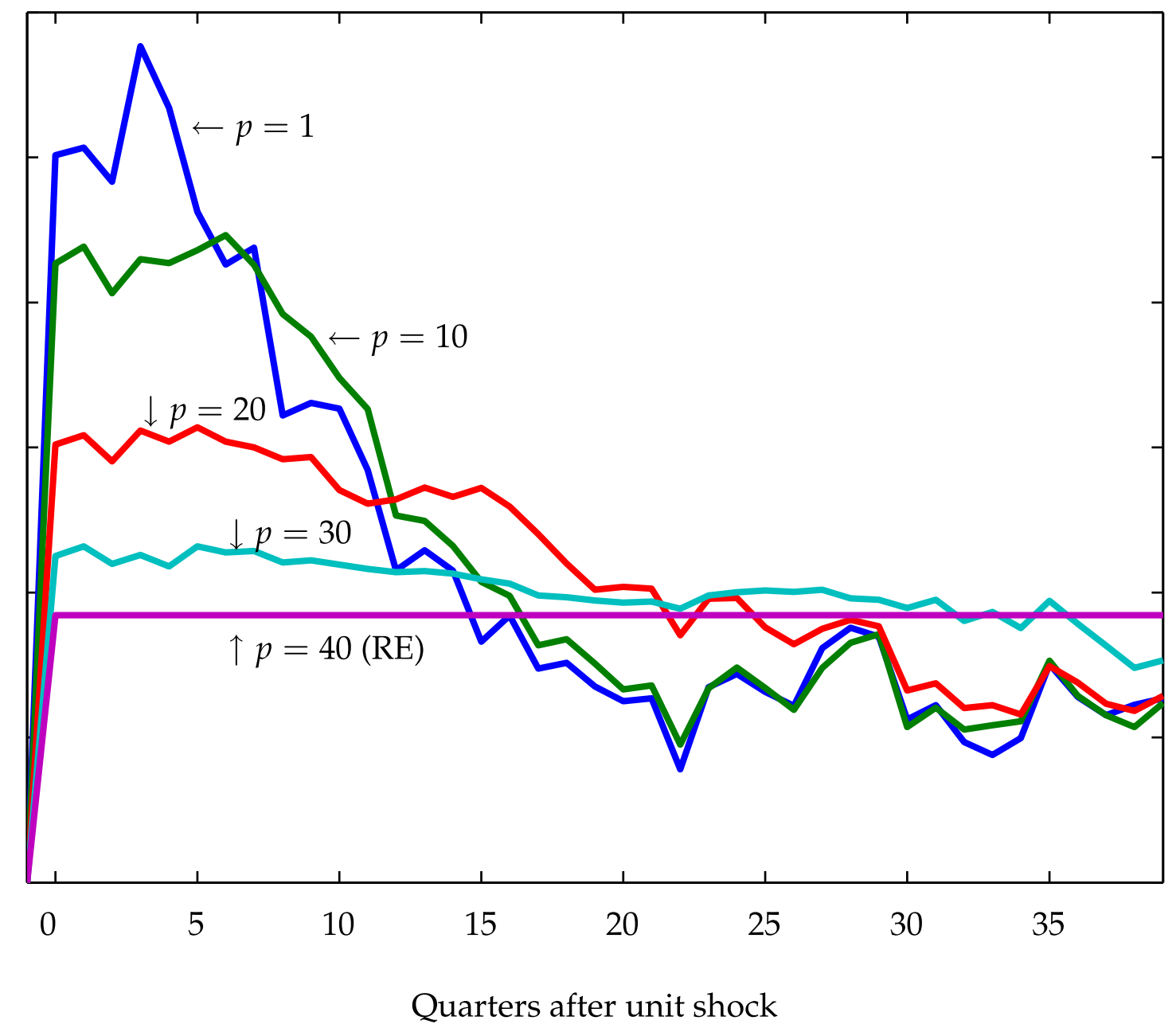


Figure 4: Impulse Response Function for Consumption, for Different $\operatorname{AR}(p)$ Models of Earnings Growth

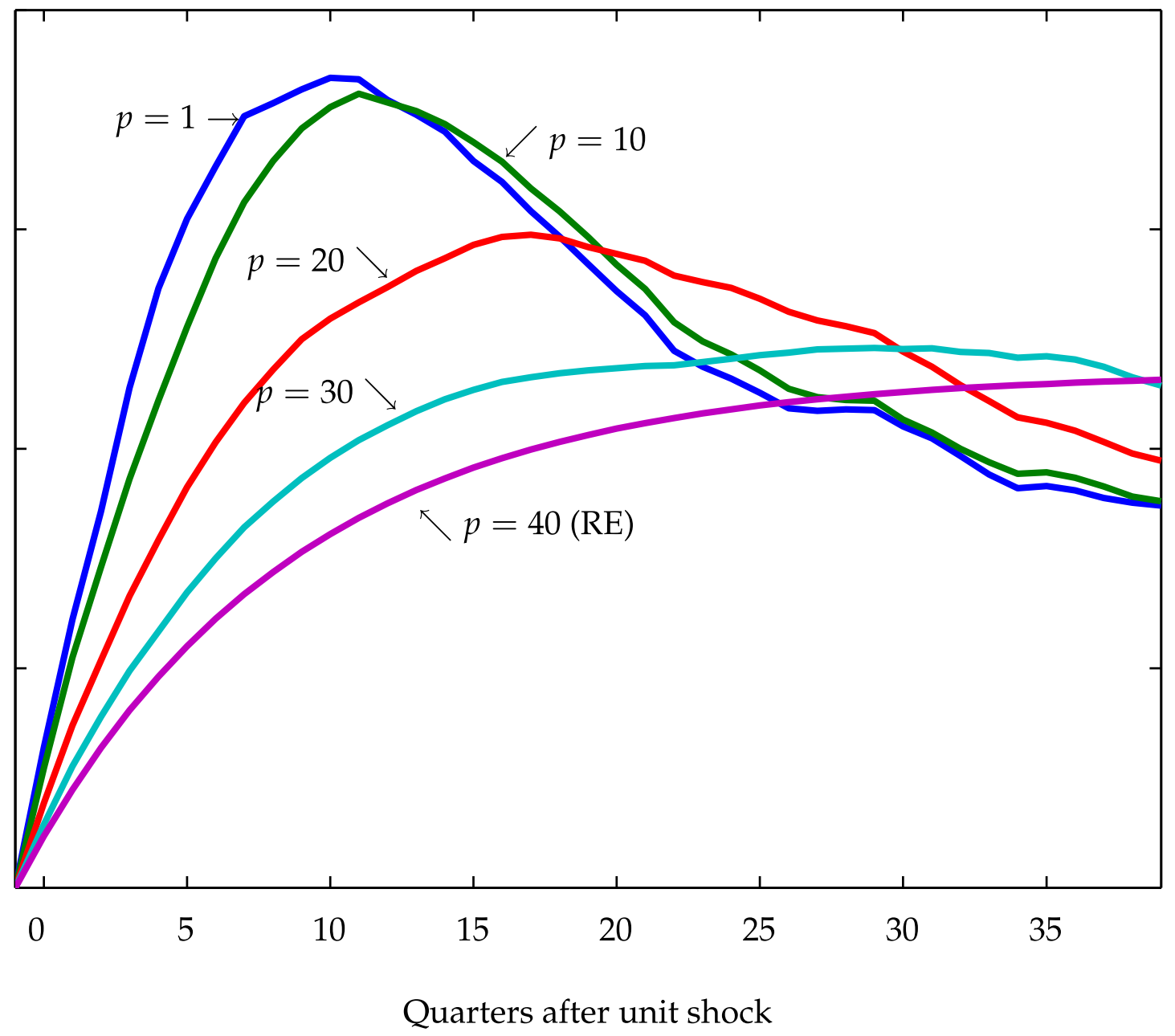


Figure 5: Correlation of Excess Returns in Year $\tau$ with Cumulative Excess Returns for Years $\tau+2$ to $\tau+5$, for Different $\operatorname{AR}(p)$ Models of Earnings Growth

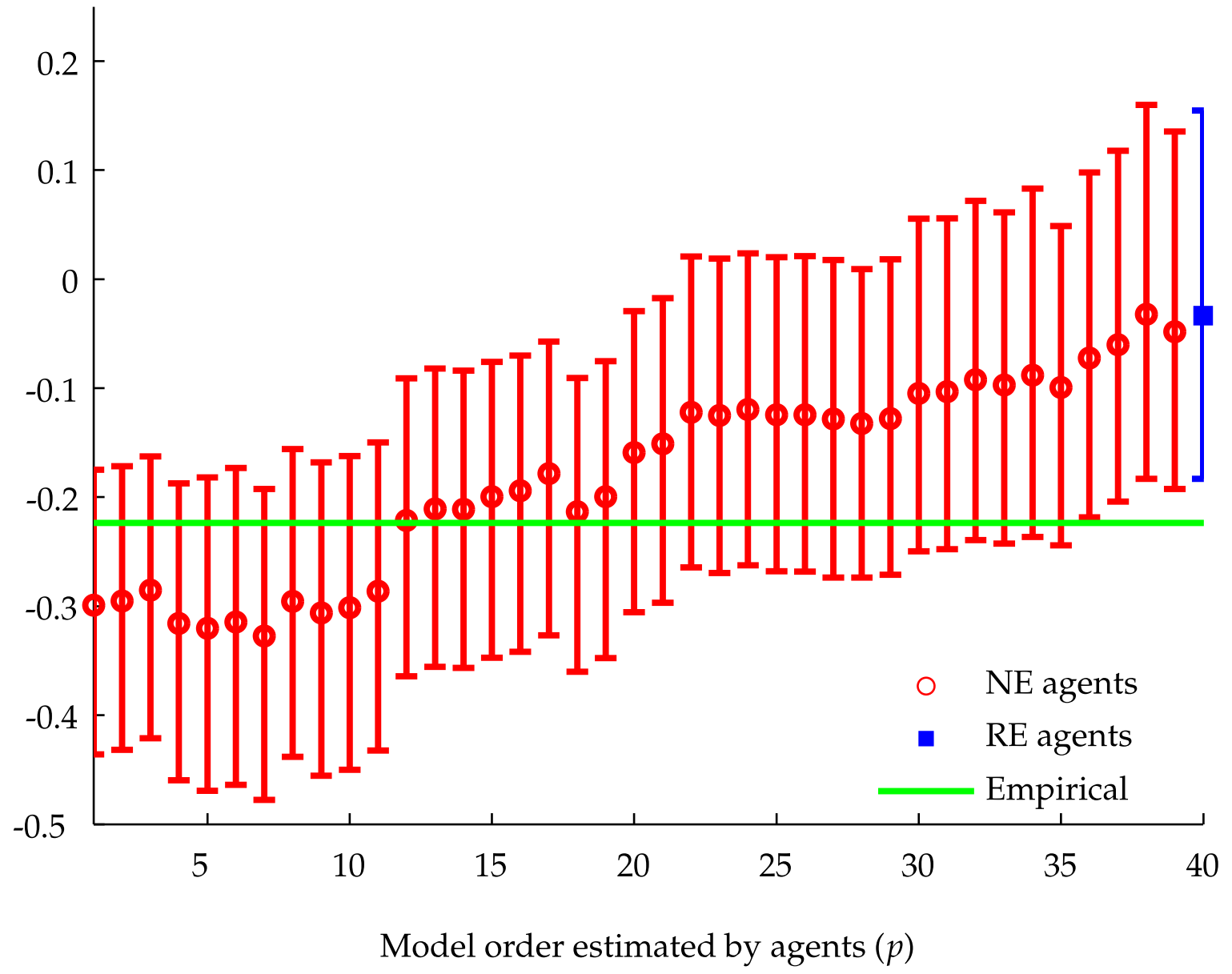

Notes: Circles depict mean correlations over 200 simulations of length equal to the empirical sample, while bars depict the 5th and 95th percentile of simulated values. "NE agents" use models with too few lags (AR(1) to AR(39)) while "RE agents" use the correct (AR(40)) model for earnings growth. 
Figure 6: Correlation of the $\mathrm{P} / \mathrm{E}_{10}$ Ratio in Year $\tau$ with Cumulative Excess Returns for Years $\tau+2$ to $\tau+5$, for Different $\operatorname{AR}(p)$ Models of Earnings Growth

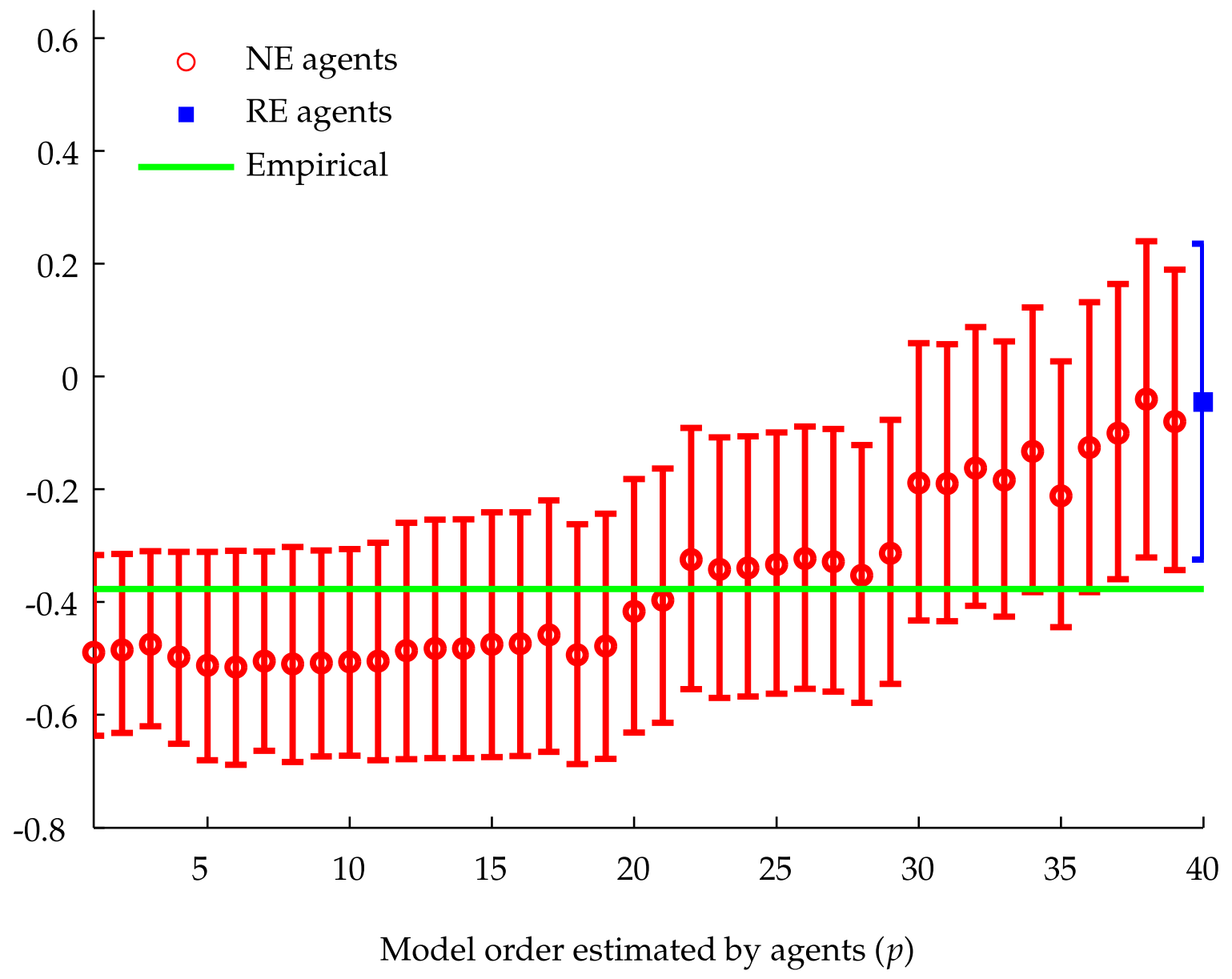

Notes: Same as for Figure 5. 
Figure 7: Correlation of Consumption Growth in Year $\tau$ with Cumulative Excess Returns for Years $\tau+2$ to $\tau+5$, for Different $\operatorname{AR}(p)$ Models of Earnings Growth

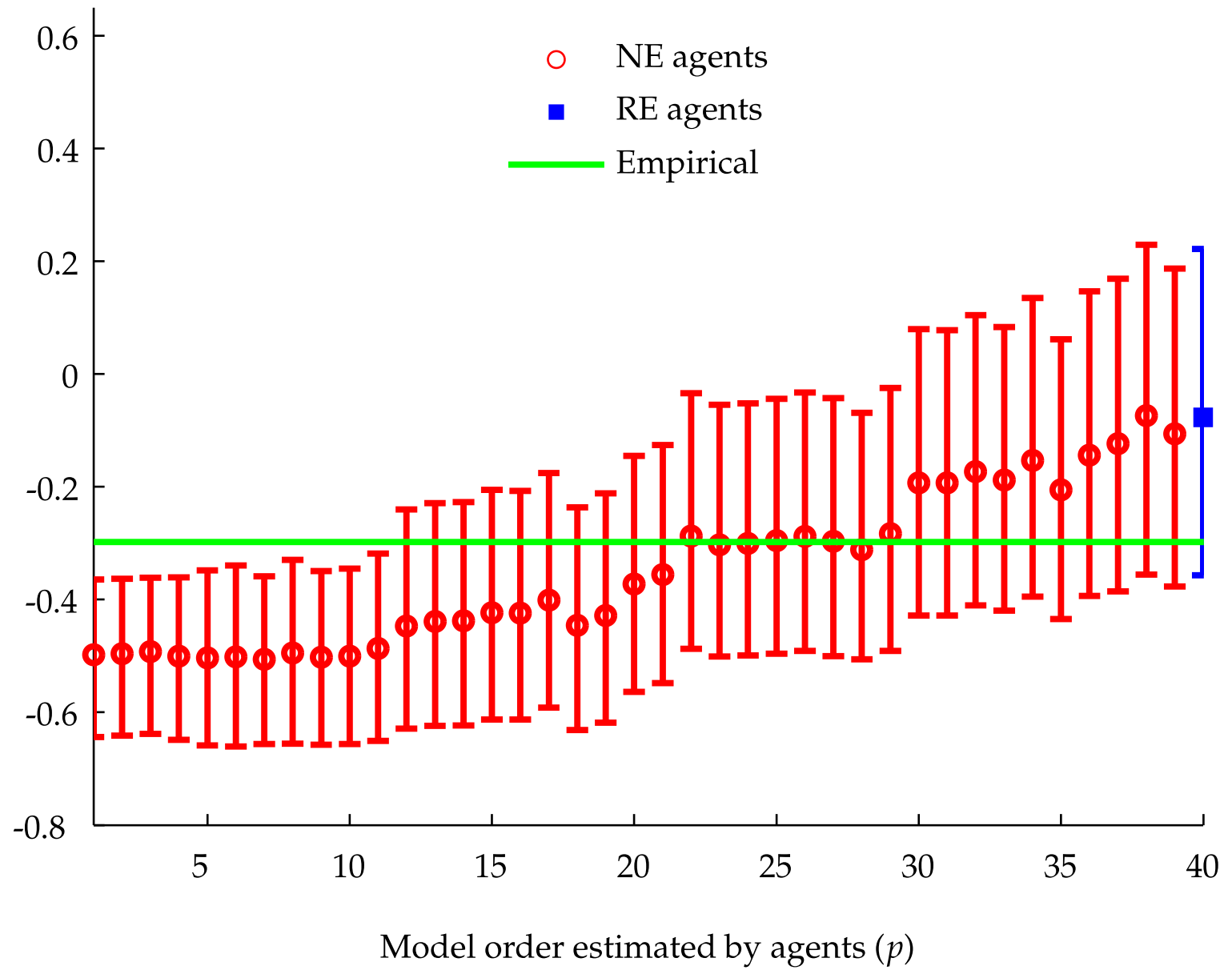

Notes: Same as for Figure 5. 
Figure 8: Correlation of the $\mathrm{P} / \mathrm{E}_{10}$ Ratio in Year $\tau$ with Consumption Growth from Year $\tau+2$ to $\tau+6$, for Different AR $(p)$ Models of Earnings Growth

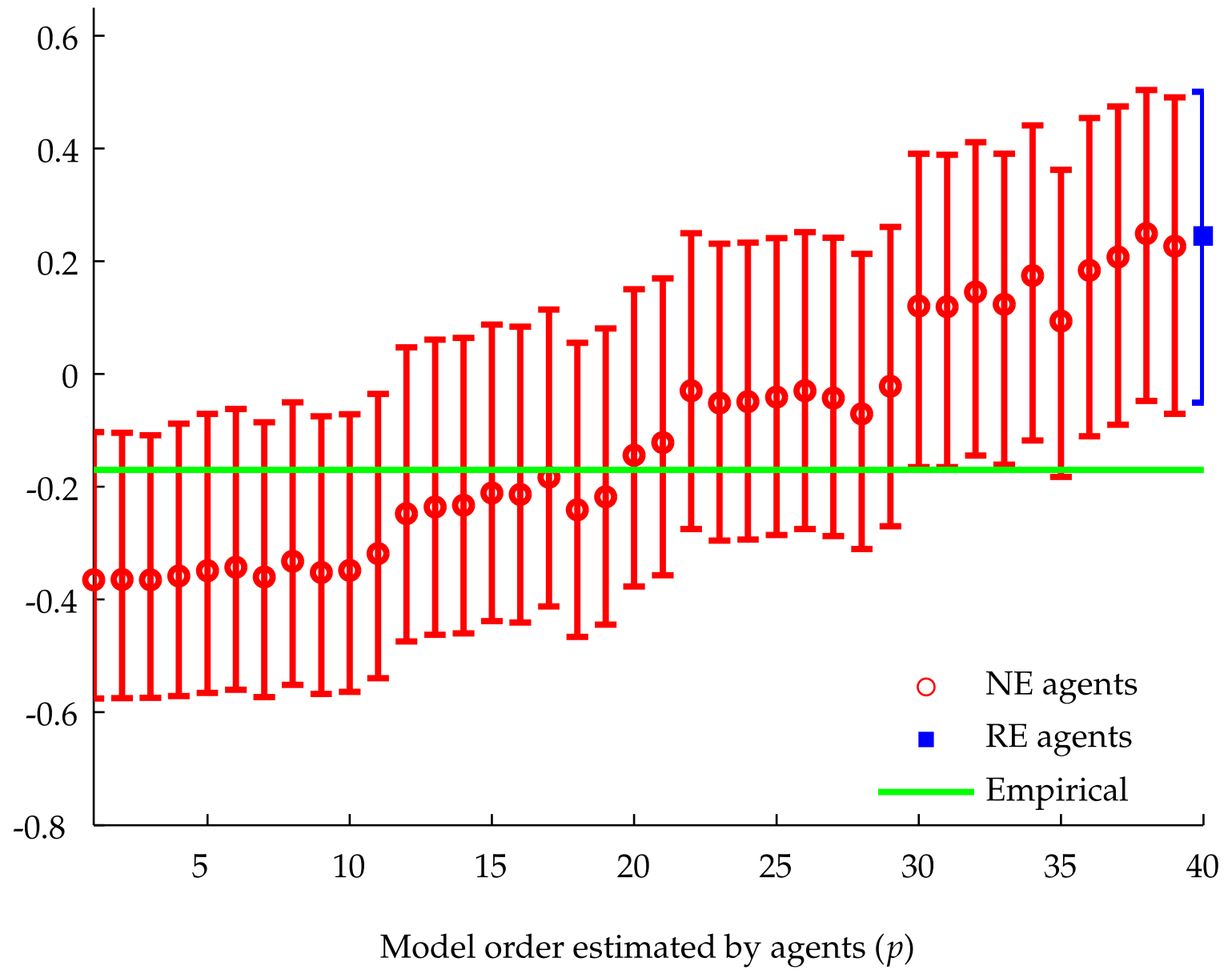

Notes: Same as for Figure 5. 
Figure 9: Correlation of Consumption Growth in Year $\tau$ with Consumption Growth from Year $\tau+2$ to $\tau+6$, for Different $\operatorname{AR}(p)$ Models of Earnings Growth

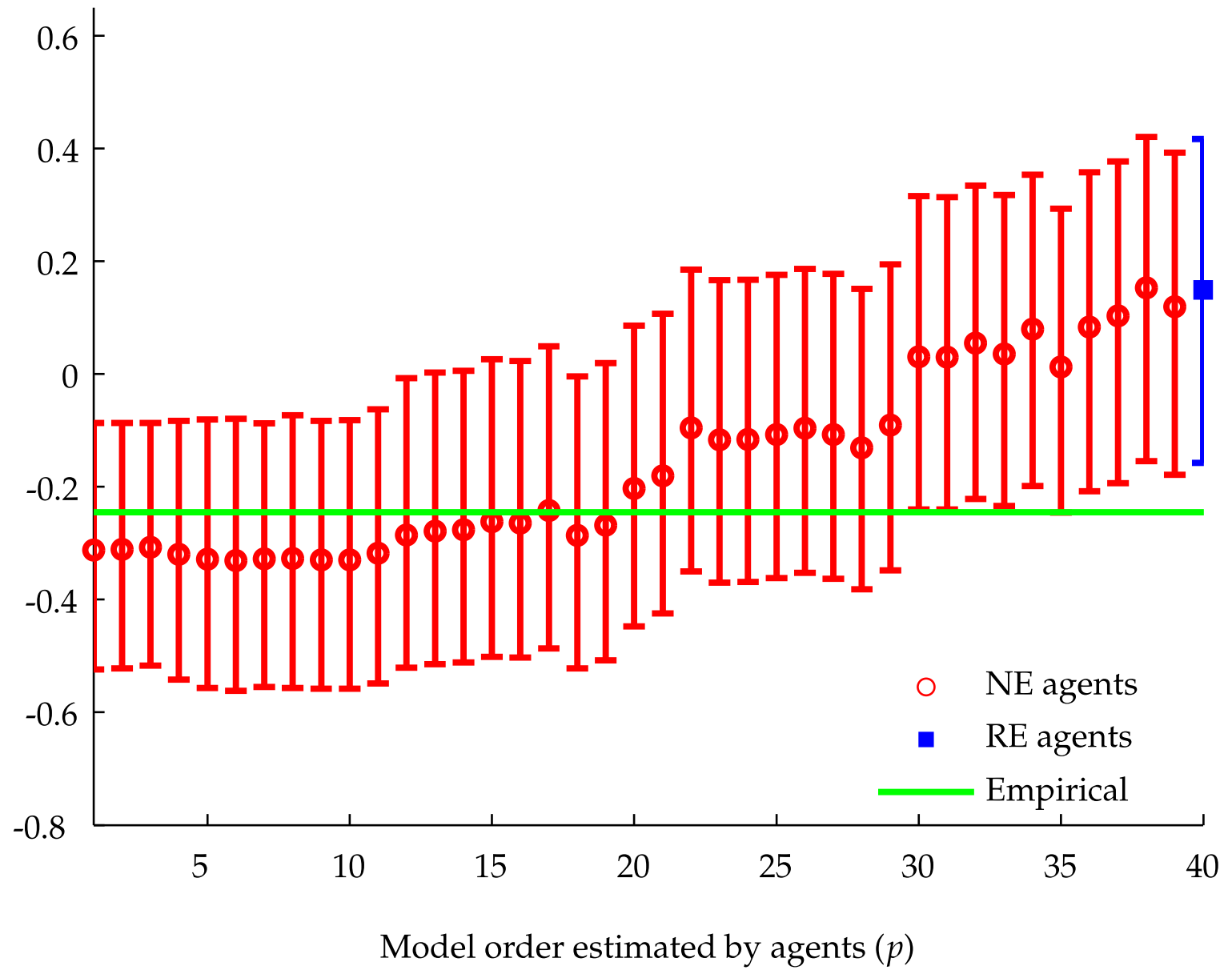

Notes: Same as for Figure 5. 
Figure 10: Equity Premium (= Mean Excess Return of Equity over the Riskfree Rate) for Different $\operatorname{AR}(p)$ Models of Earnings Growth

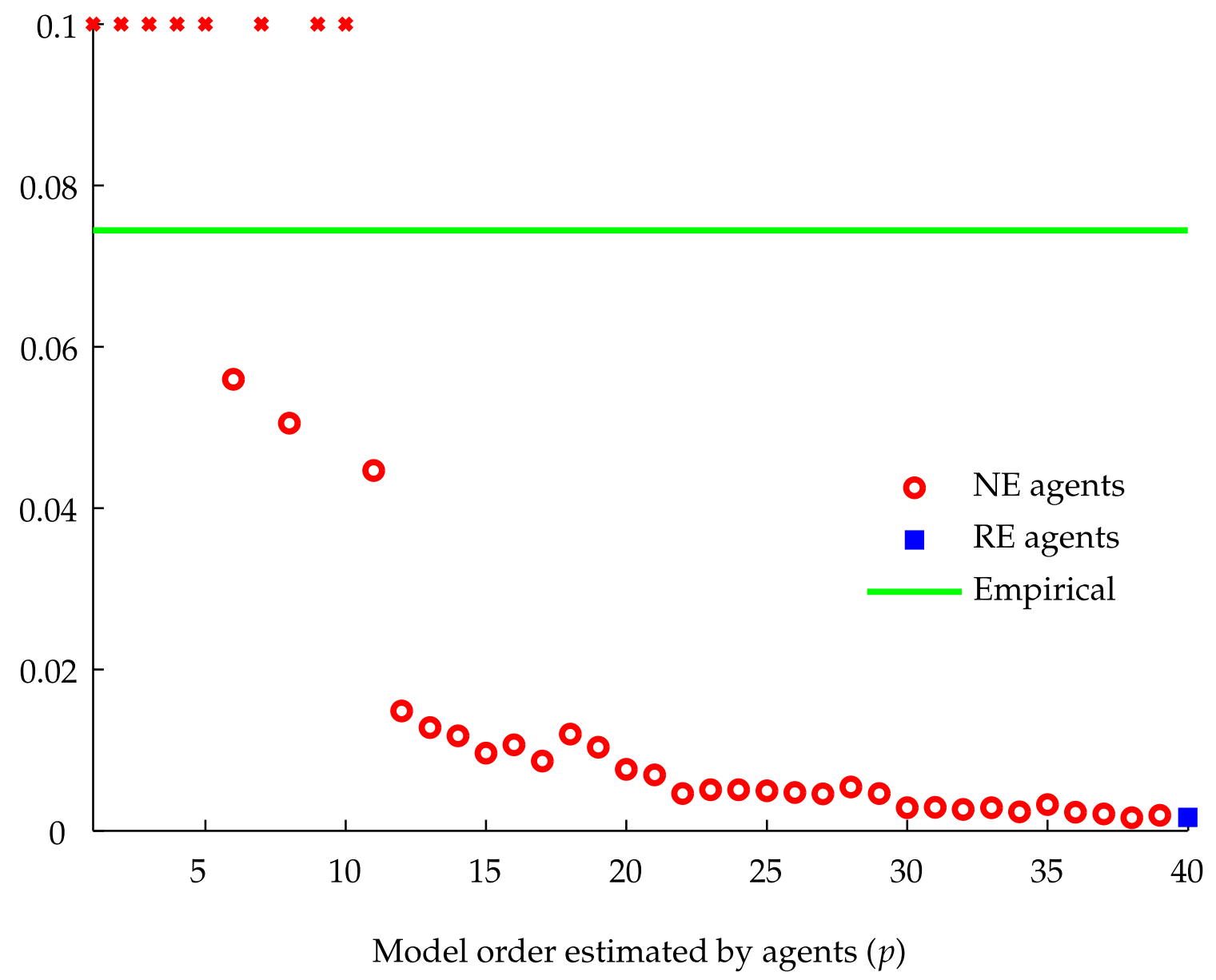

Note: " $x$ " denote equity premia above $10 \%$. "NE agents" use models with too few lags (AR(1) to AR(39)) while "RE agents" use the correct $(\mathrm{AR}(40))$ model for earnings growth. 
Figure 11: Standard Deviation of Excess Returns for Different $\operatorname{AR}(p)$ Models of Earnings Growth

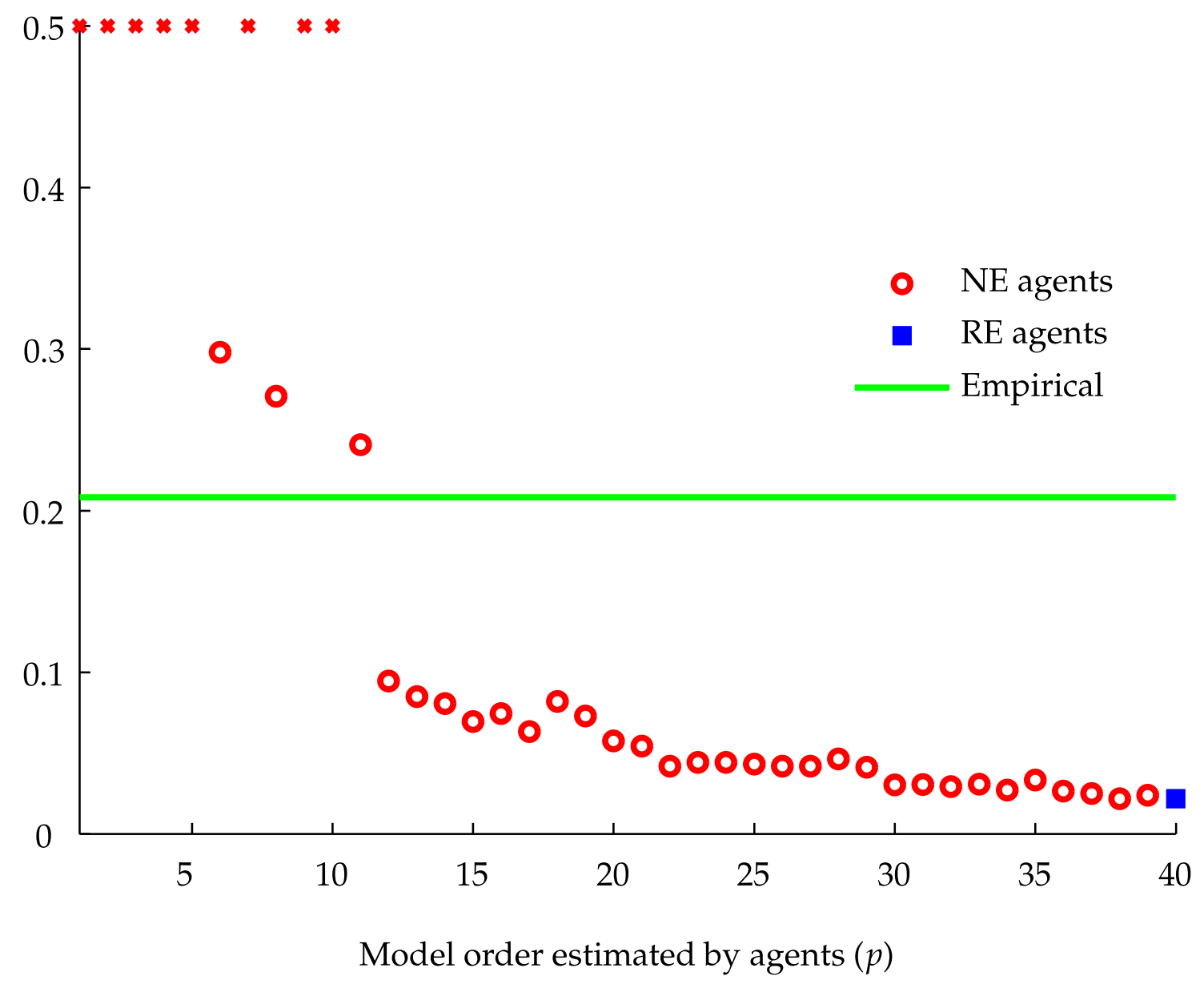

Note: " $\mathrm{x}$ " denote standard deviations above 50\%. "NE agents" use models with too few lags (AR(1) to AR(39)) while "RE agents" use the correct (AR(40)) model for earnings growth. 
Figure 12: Standard Deviation of Consumption Growth for Different AR( $p)$ Models of Earnings Growth

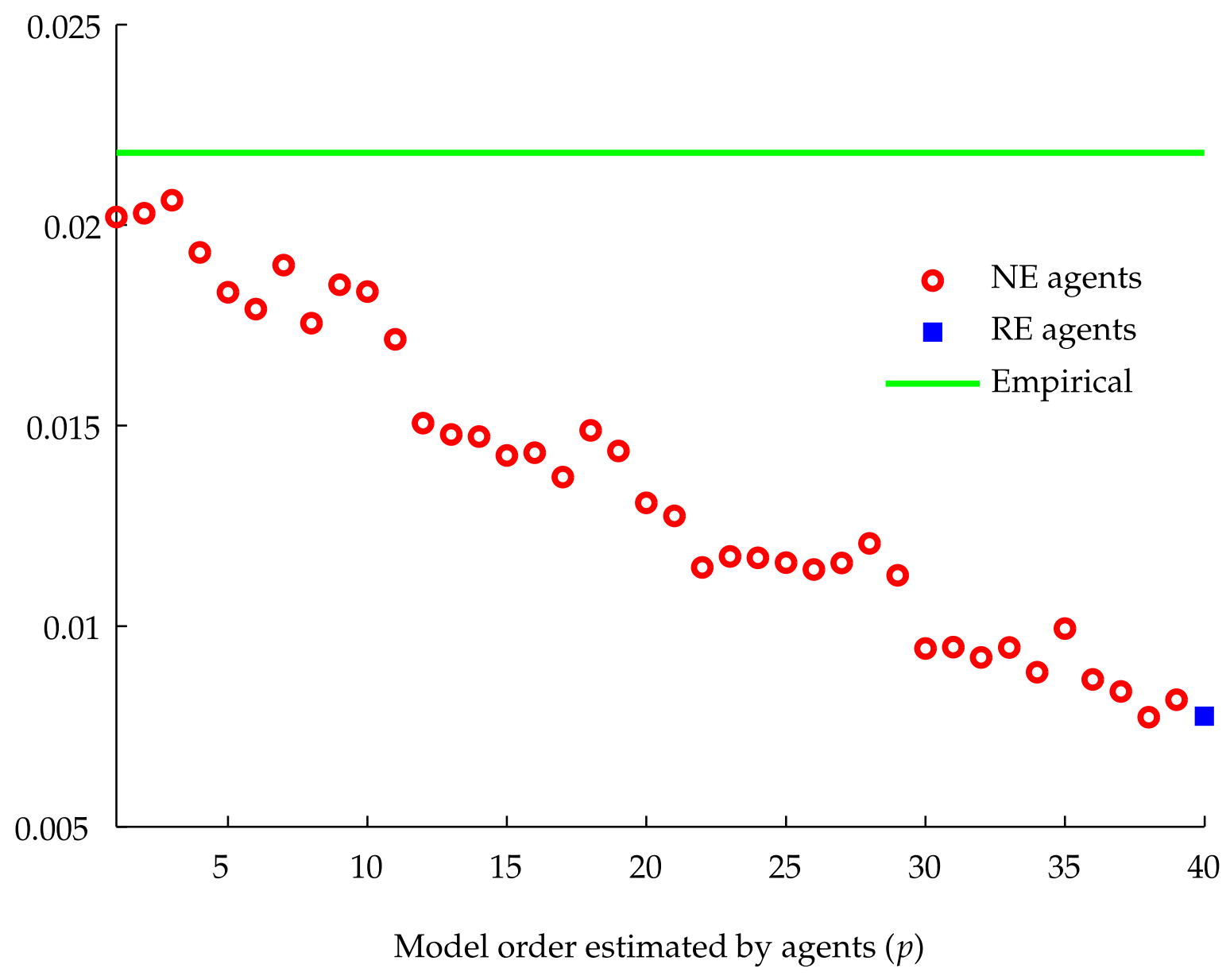


Figure 13: Equity Allocation of Rational Agents for Different $\operatorname{AR}(p)$ Models of Earnings Growth held by NE Agents: Average (Top Panel) and Lower Bound (Bottom Panel)

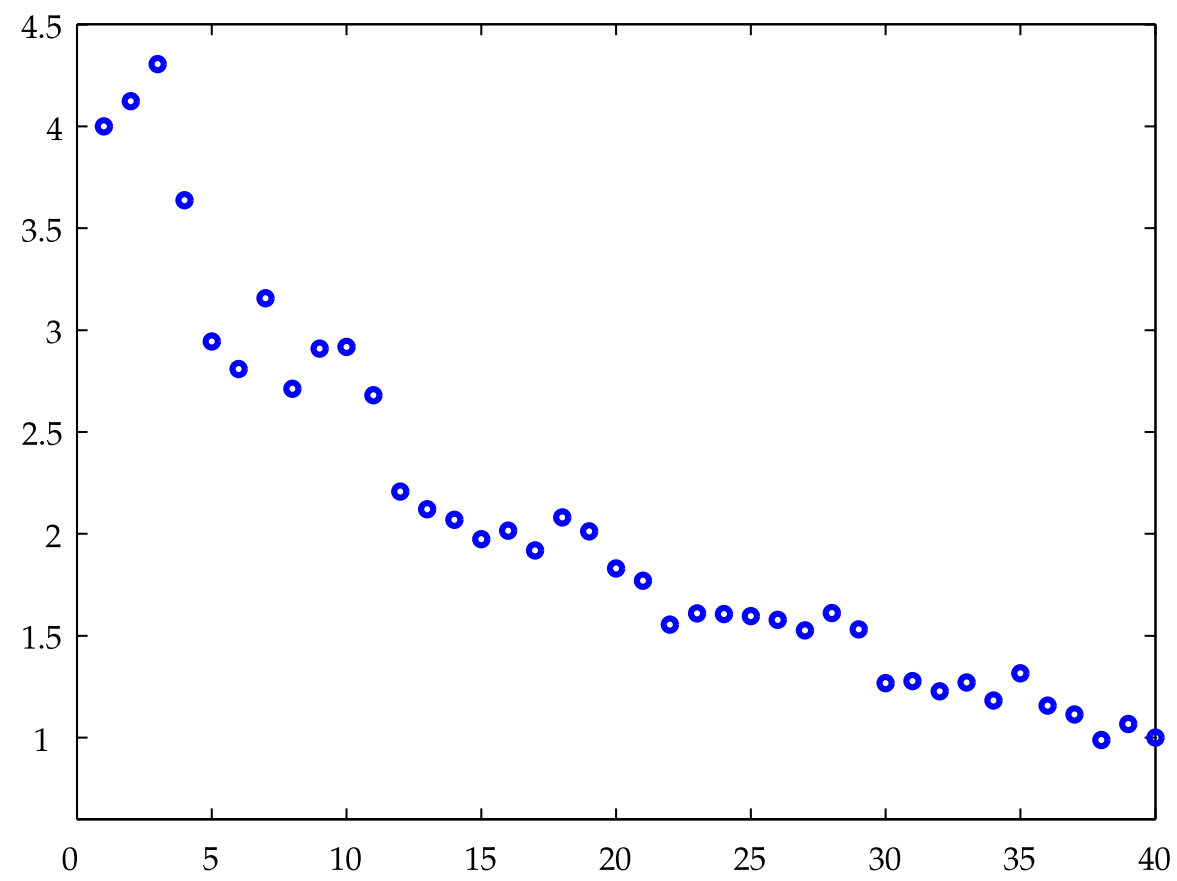

Model order estimated by agents $(p)$

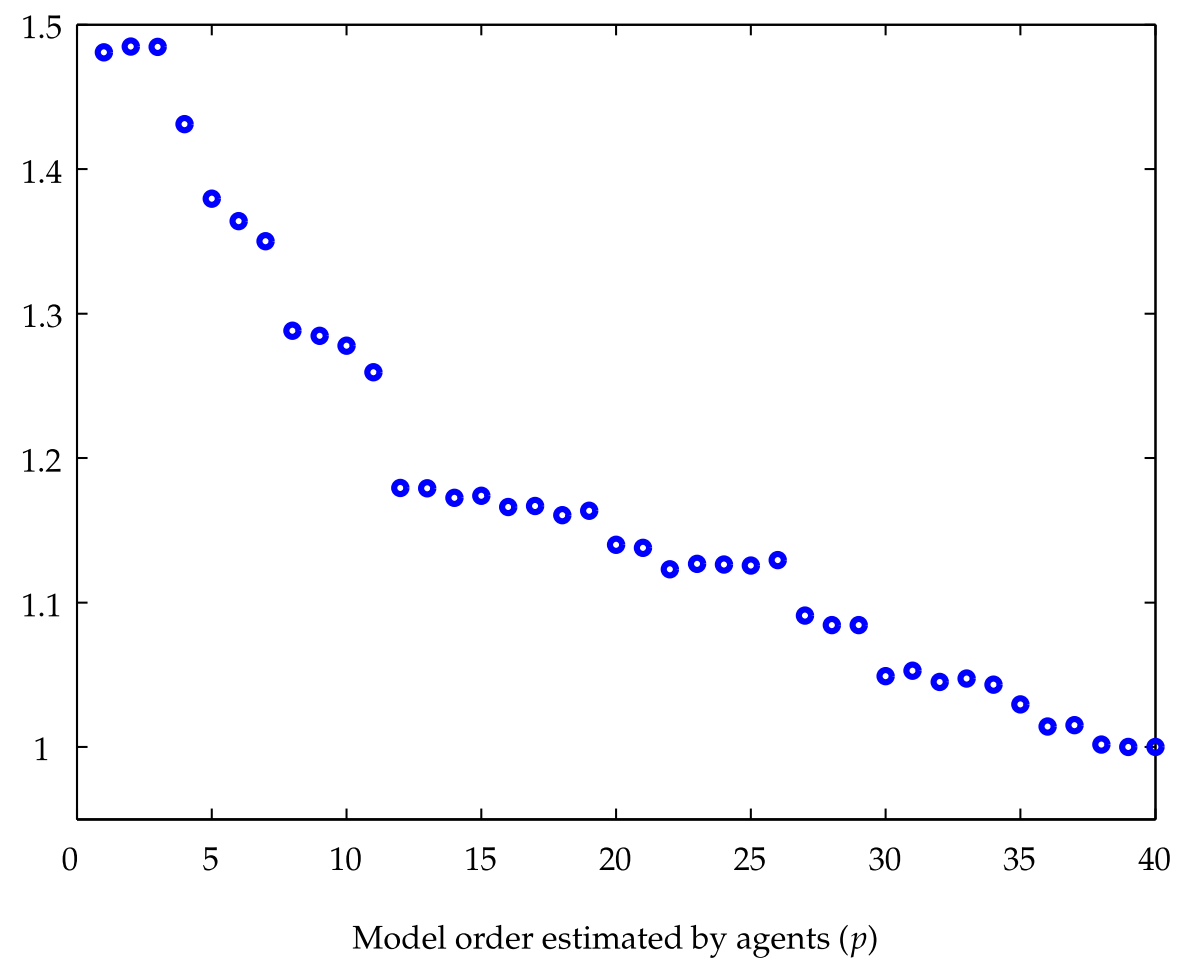

